\title{
Reinvestigation of Mycothiazole Reveals the Penta-2,4-dien-1-ol Residue Imparts Picomolar Potency and 8S Configuration
}

Tyler A. Johnson ${ }^{\dagger *^{*}}$ Joseph D. Morris, ${ }^{\dagger, \perp}$ David A. Coppage,,${ }^{\dagger}$ Colon V. Cook, ${ }^{\dagger}, \perp$ Lauren N. Persi, ${ }^{\dagger}$ Marcos A. Ogarrio, ${ }^{\dagger}$ Taylor C. Garcia, ${ }^{\dagger}$ Nicole L. McIntosh, ${ }^{\dagger}$ Erin P. McCauley, ${ }^{\dagger}$ Joseph Media, ${ }^{\S}$ Mani Maheshwari, ${ }^{\S}$ Frederick A. Valeriote, ${ }^{\S}$ Jiajiu Shaw, ${ }^{\|}$and Phillip Crews ${ }^{\ddagger *}$

†Department of Natural Sciences \& Mathematics, Dominican University of California, San Rafael, CA 94901, ${ }^{\sharp}$ Department of Chemistry \& Biochemistry, University of California, Santa Cruz, Santa Cruz, CA 95064, ${ }^{\S}$ Josephine Ford Cancer Center, Division of Hematology and Oncology, Department of Internal Medicine, Henry Ford Health System, Detroit, MI 48202, ${ }_{21}{ }^{\text {st }}$ Century Therapeutics, 440 Burroughs, Suite 447, Detroit, MI 48202.

\section{[Contents]}

General Experimental Procedures.

Page 3

Scheme S1. Summary semi-synthetic reactions using mycothiazole (1) to generate analogs 2 and 8-10. Page 6

Table S1. Solid Tumor Cell Line Selectivity Profile of Mycothiazole (1) in the Disk Diffusion Assay.

Table S2. ${ }^{13} \mathrm{C}$ and ${ }^{1} \mathrm{H}$ NMR Data of mycothiazole (1) in Benzene- $d 6$ and Chloroform- $d$.

Page 7

Table S3. ${ }^{13} \mathrm{C}$ and ${ }^{1} \mathrm{H}$ NMR Data of 8-O-acetylmycothiazole (3) in Benzene- $d 6$.

Page 8

Table S4. ${ }^{13} \mathrm{C},{ }^{1} \mathrm{H}, \mathrm{HMBC}$, and COSY NMR Data of 8-oxo-mycothiazole (3) in Benzene-d6.

Page 9

Table S5. ${ }^{13} \mathrm{C},{ }^{1} \mathrm{H}, 2 \mathrm{D}$ NMR Data of mycothiazole nitrosobenzene derivative 1 (MND1, 9a) in Benzene-d $d_{6}$. Page 11

Table S6. ${ }^{13} \mathrm{C},{ }^{1} \mathrm{H}, 2 \mathrm{D}$ NMR Data of mycothiazole nitrosobenzene derivative 1 (MND1, 9b) in Benzene- $d_{6}$. Page 12 Table S7. ${ }^{13} \mathrm{C},{ }^{1} \mathrm{H}, 2 \mathrm{D}$ NMR Data of mycothiazole nitrosobenzene derivative 2 (MND2, 10) in Benzene- $d_{6}$.

Figure S1. ${ }^{1} \mathrm{H}$ NMR spectrum of mycothiazole (1) in Benzene- $d_{6}$.

Figure S2. ${ }^{13} \mathrm{C}$ NMR spectrum of mycothiazole (1) in Benzene- $d_{6}$.

Page 13

Page 14

Figure S3. ${ }^{1} \mathrm{H}$ NMR spectrum of mycothiazole (1) in $\mathrm{CDCl}_{3}$.

Page 15

Figure S4. ${ }^{13} \mathrm{C}$ NMR spectrum of mycothiazole (1) in $\mathrm{CDCl}_{3}$.

Figure S5. ${ }^{1} \mathrm{H}$ NMR spectrum of mycothiazole (1) in Benzene- $d_{6}, 1,3$ and 6 weeks after purification.

Page 16

Page 17

Figure S6. ${ }^{1} \mathrm{H}$ NMR spectrum of mycothiazole (1) in $\mathrm{CDCl}_{3}$ at $400 \mathrm{MHz} \& 600 \mathrm{MHz} 6$ weeks after purification.

Figure S7. LCMS analysis of a) blank (methanol) injection and b) mycothiazole (1, standard control).

Page 18

Page 19

Figure S8. LCMS analysis of mycothiazole (1), amber vial, in methanol, dried using Air stream, $24 \mathrm{hrs.}$

Page 20

Page 21

Figure S9. LCMS analysis of mycothiazole (1), amber vial, in methanol, dried using $\mathbf{N}_{\mathbf{2}}$ stream, $24 \mathrm{hrs}$.

Page 22

Figure S10. LCMS analysis of mycothiazole (1), amber vial, dried using $\mathrm{N}_{2}$ stream, purged with Argon,

Page 23

exposure to refrigeration $\left(4^{\circ} \mathrm{C}\right), 24 \mathrm{hrs}$.

Figure S11. LCMS analysis of mycothiazole (1), clear vial, dried using $\mathrm{N}_{2}$ stream, exposed to direct light, 24 hrs. Page 24

Figure S12. ${ }^{1} \mathrm{H}$ NMR of mycothiazole (1) in Benzene- $d_{6}$. prior to and after taking ORD data,.

Page 25

Figure S13. ${ }^{1} \mathrm{H}$ NMR of semi-oxidized mycothiazole (1) in Benzene- $d_{6}$ prior to and after taking ORD data.

Figure S14. ${ }^{1} \mathrm{H}$ NMR spectrum of 8-O-acetyl-mycothiazole (3) in Benzene- $d_{6}$.

Figure S15. ${ }^{13} \mathrm{C}$ NMR spectrum of 8-O-acetyl-mycothiazole (3) in Benzene- $d_{6}$.

Page 26

Page 27

Figure S16. ${ }^{1} \mathrm{H}$ NMR spectrum of 8- $O$-acetyl-mycothiazole (3) in Benzene- $d_{6}$. 6 days \& 6 months after purifying. Page 29

Figure S17. ${ }^{1} \mathrm{H}$ NMR spectrum of 8-oxo-mycothiazole $(\mathbf{8})$ in Benzene- $d_{6 .}$.

Figure S18. ${ }^{13} \mathrm{C}$ NMR spectrum of 8-oxo-mycothiazole (8) in Benzene- $d_{6}$.

Figure S19. gCOSY spectrum of 8-oxo-mycothiazole (8) in Benzene- $d_{6}$.

Figure S20. HSQC spectrum of 8-oxo-mycothiazole $(\mathbf{8})$ in Benzene- $d_{6}$.

Figure S21. HMBC spectrum of 8-oxo-mycothiazole (8) in Benzene- $d_{6}$.

Figure S22. ${ }^{1} \mathrm{H}$ NMR spectrum of mycothiazole nitrosobenzene derivative 1 (MND1, 9a) in Benzene- $d_{6}$.

Figure S23. gCOSY spectrum of mycothiazole nitrosobenzene derivative 1 (MND1, 9a) in Benzene- $d_{6}$.

Figure S24. HSQC spectrum of mycothiazole nitrosobenzene derivative 1 (MND1, 9a) in Benzene- $d_{6}$.

Figure S25. HMBC spectrum of mycothiazole nitrosobenzene derivative 1 (MND1, 9a) in Benzene- $d_{6}$.

Figure S26. ${ }^{1} \mathrm{H}$ NMR spectrum of mycothiazole nitrosobenzene derivative 2 (MND2, 9b) in Benzene- $d_{6}$.

Page 30

Page 31

Page 32

Page 33

Page 34

Page 35

Page 36

Page 37

Page 38

Page 39 
Figure S27. gCOSY spectrum of mycothiazole nitrosobenzene derivative 2 (MND2, 9b) in Benzene- $d_{6}$.

Figure S28. HSQC spectrum of mycothiazole nitrosobenzene derivative 2 (MND2, 9b) in Benzene- $d_{6}$.

Figure S29. ${ }^{1} \mathrm{H}$ NMR spectrum of mycothiazole nitrosobenzene derivative 3 (MND3, 10) in Benzene- $d_{6}$.

Figure S30. COSY spectrum of mycothiazole nitrosobenzene derivative 3 (MND3, 10) in Benzene- $d_{6}$.

Figure S31. HSQC spectrum of mycothiazole nitrosobenzene derivative 3 (MND3, 10) in Benzene- $d_{6}$.

Figure S32. HAESIMS (LCMS) spectrum of 8-oxo mycothiazole (8).

Figure S33. HAESIMS (LCMS) spectrum of mycothiazole nitrosobenzene derivative 1 (MND1, 9a).

Figure S34. HAESIMS (LCMS) spectrum of mycothiazole nitrosobenzene derivative 1 (MND2, 9b).

Figure S35. HAESIMS (LCMS) spectrum of mycothiazole nitrosobenzene derivative 2 (MND3, 10).

Figure S36. ${ }^{1} \mathrm{H}$ NMR spectrum of myxothiazole-4,19-diol (7).
Page 40

Page 41

Page 42

Page 43

Page 44

Page 45

Page 46

Page 47

Page 48

Page 49 


\section{Experimental Section}

General Experimental Procedures. Optical rotation was determined on a JASCO P-2000 polarimeter. NMR experiments were run on several spectrometers which consisted of: a) Varian $400 \mathrm{MHz}$ for ${ }^{1} \mathrm{H}$, $100 \mathrm{MHz}$ for ${ }^{13} \mathrm{C}$ (fitted with a $5 \mathrm{~mm}$ triple-resonance probe), b) a Bruker Avance III HD $500 \mathrm{MHz}$ for ${ }^{1} \mathrm{H}$ and 125 $\mathrm{MHz}$ for ${ }^{13} \mathrm{C}$ equipped with a $5 \mathrm{~mm}$ BBO Smart Probe. c) Varian (INOVA) $600 \mathrm{MHz}$ for ${ }^{1} \mathrm{H}$ and $150 \mathrm{MHz}$ for ${ }^{13} \mathrm{C}$ outfitted with a $5 \mathrm{~mm}$ triple-resonance $\left({ }^{1} \mathrm{H}^{13} \mathrm{C}^{15} \mathrm{~N}\right)$ cryoprobe (AgilentTechnologies) and d) Bruker (AV) 700 $\mathrm{MHz}$ for ${ }^{1} \mathrm{H}$ and $175 \mathrm{MHz}$ for ${ }^{13} \mathrm{C}$, outfitted with a $5 \mathrm{~mm}$ triple-resonance probe $\left({ }^{1} \mathrm{H}^{13} \mathrm{C}^{15} \mathrm{~N}\right)$ cryoprobe. LCMS and High accuracy mass spectrometer measurements were performed on a VelosPro Orbitrap mass spectrometer (Thermo Scientific) coupled to a PhotoDiode Array detector using the following parameters: ion transfer tube temperature, $380{ }^{\circ} \mathrm{C}$; vaporizer temperature, $300{ }^{\circ} \mathrm{C}$; sheath gas pleasure, 60 psi; auxiliary gas flow, $20 \mathrm{abu}$; spray voltage, 3.0kV; S-lens RF level, 68.3\%. LCMS analysis for samples used for spectra described in Figure S7-S11 were obtained using a sample of $1([1 \mathrm{mg} / 1 \mathrm{~mL}])$ in $100 \%$ dichloromethane $\left(\mathrm{CH}_{2} \mathrm{Cl}_{2}\right)$. Ultra-High Performance Liquid Chromatography was performed using a Phenomenex Luna® Omega C18 (50 X $2.1 \mathrm{~mm}$, $1.6 \mu \mathrm{m})$ column with a flow rate of $500 \mu \mathrm{l} / \mathrm{mL}$. HPLC purification was performed on a Luna $5 \mu \mathrm{m}, \mathrm{C} 18(2) 100$ $\AA 10 \times 250 \mathrm{~mm}$ column (Phenomenex, Inc.) in conjunction with a $4.0 \times 3.0 \mathrm{~mm} \mathrm{C18}$ (Octadecyl) guard column and cartridge (holder part number: KJ0-4282, cartridge part number: AJ0-4287, Phenomenex, Inc., Torrance, CA, USA). Compound detection was measured by means of a single wavelength ( $\lambda$ max $=230 \mathrm{nM})$ using an Applied Biosystems 759a UV detector at Dominican University of California (DUC). HPLC purification was also performed on a Gemini-NX $5 \mu, \mathrm{C} 18,110 \AA 50$ x 21.2mm (preparative) and Phenomenex Luna $5 \mu, \mathrm{C} 18(2)$ $250 \times 4.60 \mathrm{~mm}$ column. Compound detection was measured by means of a single wavelength $(\lambda \max =254 \mathrm{nM}) \mathrm{using}$ an Pharmacia LKB optical Unit UV-1 at the University of California, Santa Cruz (UCSC). All chemicals were purchased from Sigma Aldrich.

Biological Material, Collection and Identification. Specimens of the sponge C. mycofijiensis were collected using scuba as reported previously from Vanuatu. ${ }^{4,6}$ Taxonomic identification was based on comparison of biological features to other samples in the UCSC repository. Voucher specimens and underwater photos are available upon request.

Extraction and Isolation. Samples of C. mycofijiensis were processed according to previous reports. ${ }^{6}$ Repository hexanes extracts (coded FH) from the UCSC repository, not traditionally processed (due to their high fat content), were used in the repeated scale up HPLC isolation of mycothiazole (1) for further biological evaluation and or semi synthesis experiments. Semi-preparative HPLC using a reversed-phase gradient (30:70 $\mathrm{CH}_{3} \mathrm{CN} / \mathrm{H}_{2} \mathrm{O}$ up to $80: 20$ over $50 \mathrm{~min}$, ramping up to $100 \% \mathrm{CH}_{3} \mathrm{CN}$ (51 min.) until $60 \mathrm{~min}$, then down to 30:70 re-equilibration at $60 \mathrm{~min}$.) gave four major HPLC fractions that began to elute at approximately 45 minutes. For 
each HPLC sample of the FH extract injected ([15 mg/100 $\mu 1, \mathrm{MeOH}])$, approximately $0.8 \mathrm{mg}$ of pure mycothiazole (H3) was liberated alongside HPLC fractions H1 (0.1 mg), H2, Latrunculin A, (0.2 mg) and H4 $(0.1 \mathrm{mg})$. Pure compounds were evaporated using a Nitrogen $\left(\mathrm{N}_{2}\right)$ stream, stored in amber vial, purged with Argon and sealed in a dark desiccator under vacuum. A total of thirty one [15 mg/100 $\mu \mathrm{l}] \mathrm{FH}$ extract injections were processed by HPLC for the initial scale up isolation of $\mathbf{1}$. This provided $26 \mathrm{mg}$ of pure $\mathbf{1}$ that served as starting material for semi-synthesis experiments $(\sim 8.0 \mathrm{mg} / \mathrm{ea})$ to generate 8 - $O$-acetylmycothiazole $(\mathbf{2})$ and 2$) 8$ Oxo-mycothiazole, (3). The FH extract was further processed at UCSC using preparative HPLC using reversedphase stepwise gradient $\left(0: 100 \mathrm{CH}_{3} \mathrm{CN} / \mathrm{H}_{2} \mathrm{O}\right.$ for $0.5 \mathrm{~min}$; 0:100 to 40:60 over the course of 0.6 min followed by a hold for $0.5 \mathrm{~min}$; 40:70 to 70:30 over the course of $1 \mathrm{~min}$ followed by a hold for 0.4min; 70:30 to 100:0 over the course of $0.5 \mathrm{~min}$ followed by a hold for $6 \mathrm{~min}$ ) yielded 1 main fraction that eluted between 5.0 and 6.5 minutes. The collected fraction was dried under air and exhaustively extracted with Hexanes yielding predominately 1 with minor impurities. This provided the starting material for the semi-synthesis of analogs MND1 (9a), MND2 (9b), and MND3 (10). Freshly purified 1 (10.0 mg) at DUC was also used to: a) evaluate solid tumor selectivity (shown in Table S1) and $\mathrm{IC}_{50}$ determination (2.1 mg) against pancreatic (PANC-1), liver (HepG2) and colon (HCT116) cancer cell lines bioassay evaluation (Table 1) and b) reevaluate 1 for optical rotatory dispersion (ORD) analysis (1.9 mg) and provide material $(6.0 \mathrm{mg})$ for decomposition experiments (a-e) shown in Table 3.

Disk Diffusion Soft Agar Colony Formation Assay. An in vitro cell-based assay was employed to identify solid tumor selectivity for pure compounds. The differential cytotoxicity is expressed by calculating the zone differential between any solid tumor cells (e.g. human colon HCT-116, human lung H125) and either leukemia cells (human CEM) or normal cells (CFU-GM). Differential results are designated as (zone units of solid tumor: leukemia tumor, SL), or (zone units of solid tumor: normal cells, SN). If the zone differential is 250 zone units or greater, the activity is considered to demonstrate solid tumor selectivity, and such results are bolded. ${ }^{20}$

IC50 Determinations. Pancreatic (PANC-1) and liver (HepG2) and colon (HCT-116) tumor cells are plated at 5104 cells in T25 tissue culture flasks (Falcon Plastics, New Jersey) with 5 mL of media RPMI 1640 (Cellgro, Virginia) supplementedwith 15\% BCS (Hyclone, Utah), 5\% pen. strep., and 5\% glutamine (Cellgro). Three days later (cells in logarithmic growth phase; 5105cells/flask), test compound is added to the flasks to achieveconcentrations ranging from 10 to $10-4 \mathrm{ug} / \mathrm{mL}$. At day 3, the flasksare washed, trypsinized, and spun down, and the cells were countedfor both viable and dead cells using 0.08\% trypan blue (Gibco,Maryland). Viable cell number as a function of concentration isplotted and the IC50 values are determined by interpolation. 


\section{Experimental Conditions}

Mycothiazole (1): white oil; ${ }^{1} \mathrm{H}$ and ${ }^{13} \mathrm{C}$ NMR data $\left(\mathrm{C}_{6} \mathrm{D}_{6}\right)$ see Table $\mathrm{S} 2$ and Figures S1-S2; LRESITOFMS $\mathrm{m} / \mathrm{z}$ $\left(405.2[\mathrm{M}+\mathrm{H}]^{+}\right),[\alpha]^{25}{ }_{\mathrm{D}}=+25.78^{\circ}\left(c 1.11, \mathrm{CHCl}_{3}\right),[\alpha]^{23}{ }_{\mathrm{D}}=-56.76^{\circ}(c 0.55, \mathrm{MeOH})$.

8-O-acety-mycothiazole (2): Compound $\mathbf{2}$ was obtained by semi-synthesis. A sample of $\mathbf{1}$ (7.3 mg, isolated from C. mycofifiensis) was added to dry pyridine $(1000 \mu \mathrm{L})$ and acetic anhydride $(1000 \mu \mathrm{L})$. The mixture was stirred for 24 hours and quenched using water $(2 \mathrm{~mL})$ and $\mathrm{CH}_{2} \mathrm{Cl}_{2}(2 \mathrm{~mL})$. The organic layer was dried under $\mathrm{N}_{2}$ stream and purified using RP-HPLC (Phenomenex Luna $5 \mu, \mathrm{C}_{18}(2), 250 \times 10.00 \mathrm{~mm}$, isocratic $70 \% \mathrm{CH}_{3} \mathrm{CN}$ in $\left.\mathrm{H}_{2} \mathrm{O}, 2.0 \mathrm{~mL} / \mathrm{min}\right)$ to generate $2(1.6 \mathrm{mg})$. white oil; ${ }^{1} \mathrm{H}$ and ${ }^{13} \mathrm{C}$ NMR data $\left(\mathrm{C}_{6} \mathrm{D}_{6}\right)$ see Table $\mathrm{S} 3$ and Figures S14$\mathrm{S} 15$; LRESITOFMS $\mathrm{m} / \mathrm{z}\left(469.2[\mathrm{M}+\mathrm{Na}]^{+}\right)$and was consistent with previous reports. ${ }^{4}$

Mycothiazole-4,19-diol (7): white oil; ${ }^{1} \mathrm{H}$ NMR data (d-DMSO) Figure S36. LRESIMS $m / z\left(439.2[\mathrm{M}+\mathrm{H}]^{+}\right)$. The bioassay data reported herein for $7\left(\mathrm{IC}_{50}=>1.0 \mu \mathrm{M}, \mathrm{HCT} 116\right)$ is from a repository sample of 7 that was prepared and assayed previously alongside data from another report, but was not included in the publication. ${ }^{4}$ 8-Oxo-mycothiazole (8): Compound 3 was obtained by semi-synthesis. A sample of 1 (7.4 mg) and DessMartin periodinane $(39 \mathrm{mg}$ ) were added to $5 \mathrm{~mL}$ of dichloromethane. The mixture was stirred for 20 hours and dried under an $\mathrm{N}_{2}$ stream. The crude product was immediately purified using RP-HPLC (Phenomenex Luna $5 \mu$, $\mathrm{C}_{18}$ (2), $250 \times 10.00 \mathrm{~mm}, 30: 70 \mathrm{CH}_{3} \mathrm{CN} / \mathrm{H}_{2} \mathrm{O}$ up to $80: 20$ over $50 \mathrm{~min}$ ) to generate $3(3.2 \mathrm{mg}$ ) at DUC. white oil; ${ }^{1} \mathrm{H}$ and $13 \mathrm{C}$ NMR data $\left(\mathrm{C}_{6} \mathrm{D}_{6}\right)$ see Table S4 and Figures S17-S21. HAESIMS $m / z 403.2047[\mathrm{M}+\mathrm{H}]^{+}$ (calcd for $\mathrm{C}_{22} \mathrm{H}_{31} \mathrm{~N}_{2} \mathrm{O}_{3} \mathrm{~S}, 403.2050$ ).

Mycothiazole nitrosobenzene derivative 1 (MND1, 9a): Compounds 9a, 9b and 10 were generated together through a one pot semi synthesis. A sample of $\mathbf{1}(62.2 \mathrm{mg}$, isolated from C. mycofijiensis) was added to benzene (20 $\mathrm{ml})$ and 5 molar equivalence of nitrosobenzene $(8.2 \mathrm{mg})$. The mixture was allowed to react at room temperature with mild stirring for 24 hours, then dried and partitioned between $80 \% \mathrm{MeOH}_{\mathrm{aq}}$ and hexanes. Hexane fraction was dried under vacuum and purified using RP-HPLC (Phenomenex Luna $5 \mu, \mathrm{C} 18$ (2) $250 \times 4.60 \mathrm{~mm}$, isocratic $70 \% \mathrm{CH}_{3} \mathrm{CN}$ in $\left.\mathrm{H}_{2} \mathrm{O}, 1.0 \mathrm{~mL} / \mathrm{min}\right)$ to generate MND1 (9a, $\left.7.4 \mathrm{mg}\right)$, MND2 (9b, $3.4 \mathrm{mg}$ ), and MND3 (10, $\left.3.4 \mathrm{mg}\right)$.

white oil; ${ }^{1} \mathrm{H}$ and ${ }^{13} \mathrm{C}$ NMR white oil; ${ }^{1} \mathrm{H}$ and $13 \mathrm{C}$ NMR data $\left(\mathrm{C}_{6} \mathrm{D}_{6}\right)$ see Table S5 and Figures S22-S25. HAESIMS $m / z\left(512.2545[\mathrm{M}+\mathrm{H}]^{+}\right)\left(\right.$calcd for $\left.\mathrm{C}_{28} \mathrm{H}_{38} \mathrm{~N}_{3} \mathrm{O}_{4} \mathrm{~S}, 512.2578\right) ;[\alpha]^{25}=-96.6(c 0.9 ; \mathrm{CHCl} 3)$. Mycothiazole nitrosobenzene derivative 2 (MND2, 9b): white oil; ${ }^{1} \mathrm{H}$ and ${ }^{13} \mathrm{C}$ NMR white oil; ${ }^{1} \mathrm{H}$ and $13 \mathrm{C}$ NMR data $\left(\mathrm{C}_{6} \mathrm{D}_{6}\right)$ see Table $\mathrm{S} 6$ and Figures S26-S28. HAESIMS $m / z\left(512.2580[\mathrm{M}+\mathrm{H}]^{+}\right)($calcd for $\left.\mathrm{C}_{28} \mathrm{H}_{38} \mathrm{~N}_{3} \mathrm{O}_{4} \mathrm{~S}, 512.2578\right) ;[\alpha]^{25}=+119.6$ (c 0.9; $\mathrm{CHCl} 3$ )

Mycothiazole nitrosobenzene derivative 3 (MND3, 10): white oil; ${ }^{1} \mathrm{H}$ and ${ }^{13} \mathrm{C}$ NMR white oil; ${ }^{1} \mathrm{H}$ and $13 \mathrm{C}$ NMR data $\left(\mathrm{C}_{6} \mathrm{D}_{6}\right)$ see Table $\mathrm{S} 7$ and Figures S29-S31. HAESIMS $m / z\left(512.2587[\mathrm{M}+\mathrm{H}]^{+}\right)($calcd for $\left.\mathrm{C}_{28} \mathrm{H}_{38} \mathrm{~N}_{3} \mathrm{O}_{4} \mathrm{~S}, 512.2578\right) ;[\alpha]^{25}=+10.8(c 0.25 ; \mathrm{CHCl} 3)$. 


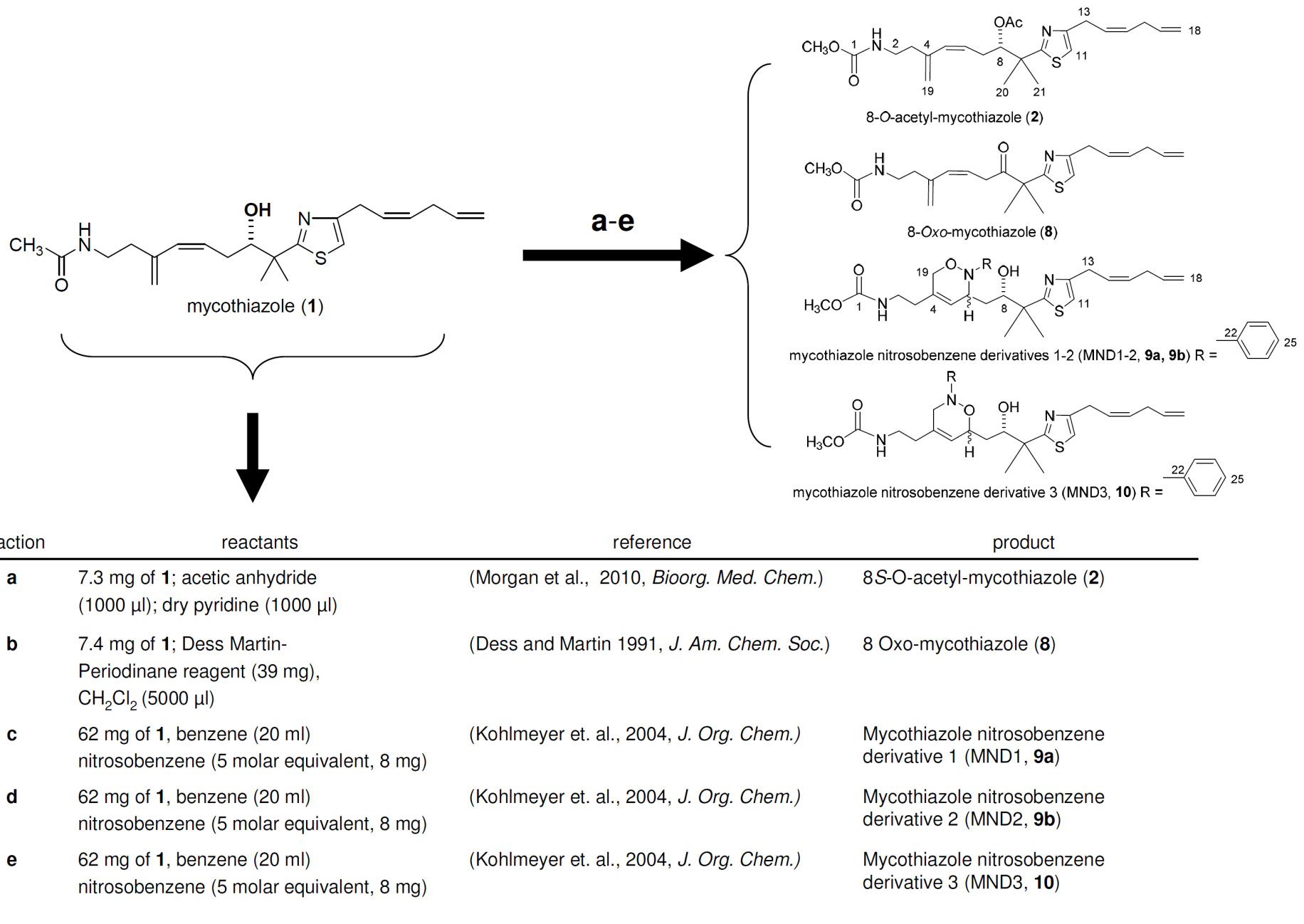

Scheme S1. Summary of semi-synthetic reactions (a-e) using mycothiazole (1) to generate analogs 2 and 8-10. 
Table S1. Solid Tumor Selectivity Profile of Mycothiazole (1) Against Cell Lines in the HFCC Disk Diffusion Soft Agar Assay.

\begin{tabular}{|c|c|c|c|c|c|c|c|}
\hline entry & a) tumor cell line ${ }^{a}$ & $\begin{array}{l}\text { mea. zone } \\
\text { of cell kill }\end{array}$ & $\begin{array}{l}\text { b) normal } \\
\text { cell line }{ }^{b}\end{array}$ & $\begin{array}{l}\text { mea. zone } \\
\text { of cell kill }\end{array}$ & $\begin{array}{l}\text { zone of cell kill } \\
\text { calc. selectivity } \\
\text { difference }^{c}\end{array}$ & $\begin{array}{l}\text { index } \\
\text { value }\end{array}$ & $\begin{array}{l}\text { selective for } \\
\text { solid tumor } \\
\text { cell line? }\end{array}$ \\
\hline 1 & pancreatic (PANC-1) & $30 \mathrm{~mm}$ & $\begin{array}{l}\text { bone marrow } \\
\text { (CFU-GM) }\end{array}$ & $6.5 \mathrm{~mm}$ & $30-6.5=23.5$ & 23.5 & YES \\
\hline 2 & colon (HCT 116) & $30 \mathrm{~mm}$ & $\begin{array}{l}\text { bone marrow } \\
\text { (CFU-GM) }\end{array}$ & $6.5 \mathrm{~mm}$ & $30-6.5=23.5$ & 23.5 & YES \\
\hline 3 & lung (H-125) & $30 \mathrm{~mm}$ & $\begin{array}{l}\text { bone marrow } \\
\text { (CFU-GM) }\end{array}$ & $6.5 \mathrm{~mm}$ & $30-6.5=23.5$ & 23.5 & YES \\
\hline 4 & brain (U251) & $30 \mathrm{~mm}$ & $\begin{array}{l}\text { bone marrow } \\
\text { (CFU-GM) }\end{array}$ & $6.5 \mathrm{~mm}$ & $30-6.5=23.5$ & 23.5 & YES \\
\hline 5 & breast (MDA-MB-231) & $30 \mathrm{~mm}$ & $\begin{array}{l}\text { bone marrow } \\
\text { (CFU-GM) }\end{array}$ & $6.5 \mathrm{~mm}$ & $30-6.5=23.5$ & 23.5 & YES \\
\hline 6 & liver (HepG2) & $30 \mathrm{~mm}$ & $\begin{array}{l}\text { bone marrow } \\
\text { (CFU-GM) }\end{array}$ & $6.5 \mathrm{~mm}$ & $30-6.5=23.5$ & 23.5 & YES \\
\hline 7 & ovarian (OVC-5) & $15 \mathrm{~mm}$ & $\begin{array}{l}\text { bone marrow } \\
\text { (CFU-GM) }\end{array}$ & $6.5 \mathrm{~mm}$ & $15-6.5=8.5$ & 8.5 & YES \\
\hline 8 & breast (MCF-7) & $13.5 \mathrm{~mm}$ & $\begin{array}{l}\text { bone marrow } \\
\text { (CFU-GM) }\end{array}$ & $6.5 \mathrm{~mm}$ & $13.5-6.5=7$ & 7 & No \\
\hline 9 & prostate $(\mathrm{LNCaP})$ & $7.5 \mathrm{~mm}$ & $\begin{array}{l}\text { bone marrow } \\
\text { (CFU-GM) }\end{array}$ & $6.5 \mathrm{~mm}$ & $7.5-6.5=1$ & 1 & No \\
\hline
\end{tabular}

${ }^{a}$ Human tumor cell lines evaluated include: pancreatic (PANC-1), colon (human colon tumor, HCT 116), lung (H125), brain (U251, glioblastoma), breast (MDA-MB-235), liver (HepG2), , ovarian (OVC-5), breast (MCF-7), prostate (lymph node cancer prostate, LNCaP). ${ }^{b}$ Non tumorigenic cells lines include: normal bone marrow (colony-forming unit-granulocyte macrophage; CFU-GM). ${ }^{c} \mathrm{~A}$ zone of cell kill calculated selectivity difference index value (in bold) of $\geq 8 \mathrm{~mm}$ is indicative of a compound with selective cytotoxicity for that tumor cell line versus a normal bone marrow (CFU-GM) cell lines.

\section{$\begin{array}{ll}\text { a) Human tumor cell lines: } & \text { b) Normal cell lines: }\end{array}$}

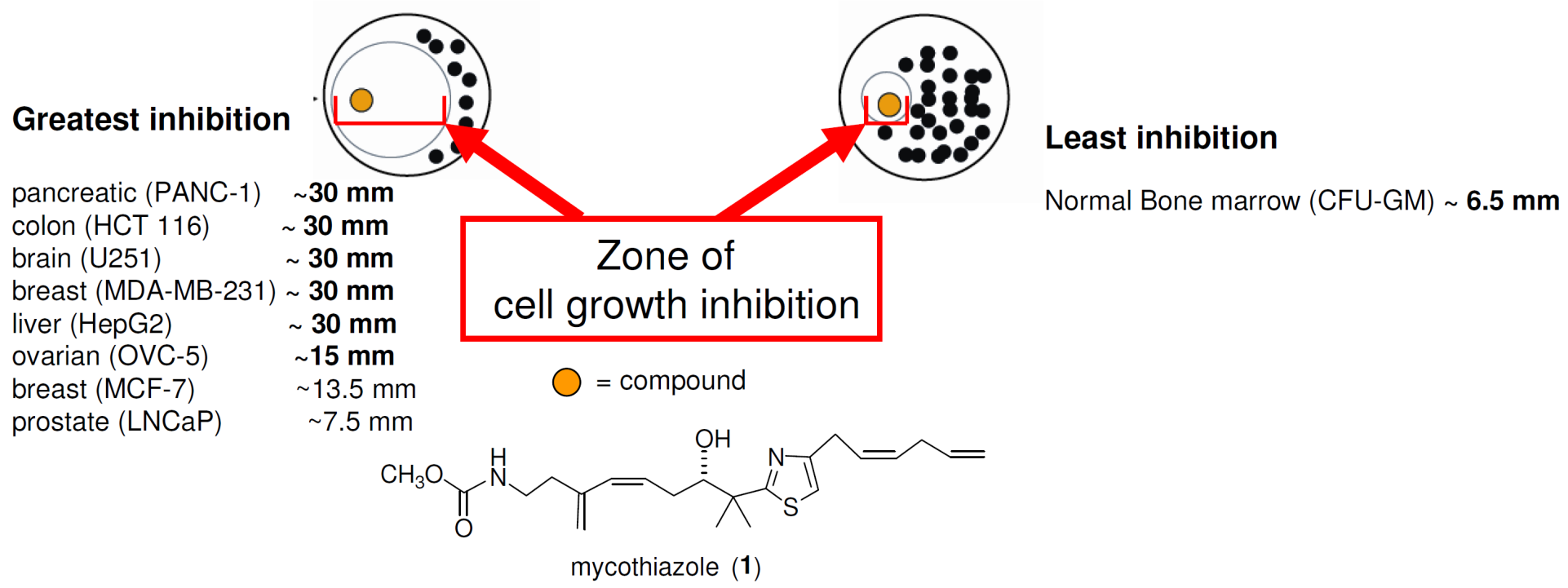


Table S2. ${ }^{13} \mathrm{C}$ and ${ }^{1} \mathrm{H}$ NMR of Mycothiazole (1) in Benzene- $d 6$ and Chloroform- $d$.

\begin{tabular}{|c|c|c|c|c|c|c|c|}
\hline No. & Type & $\delta_{\mathrm{C}}{ }^{a}$ & $\delta_{\mathrm{H}}^{a}$ & mult. & $J(\mathrm{~Hz})$ & $\delta_{\mathrm{C}}^{b,}$ & $\delta_{\mathrm{H}}^{b}$ \\
\hline 1 & $\mathrm{C}$ & 156.7 & & & & 157.3 & \\
\hline 2 & $\mathrm{CH}_{2}$ & 39.5 & 3.26 & dddd & $13.9,7.2,6.6,6.0$ & 39.5 & 3.48 \\
\hline 2 ' & & & 3.07 & dddd & $13.9,8.5,5.8,4.8$ & & 3.11 \\
\hline 3 & $\mathrm{CH}_{2}$ & 37.5 & 2.28 & dddd & $14.0,8.4,5.8,0.8$ & 37.3 & 2.30 \\
\hline 3 & & & & dddd & $13.9,6.6,4.7,0.8$ & & 2.02 \\
\hline 4 & $\mathrm{C}$ & 142.9 & & & & 142.6 & \\
\hline 5 & $\mathrm{CH}$ & 130.9 & 5.74 & $\mathrm{~d}$ & 11.6 & 131.0 & 5.78 \\
\hline 6 & $\mathrm{CH}$ & 130.6 & 5.58 & ddd & $11.6,9.0,3.6$ & 130.7 & 5.67 \\
\hline 7 & $\mathrm{CH}_{2}$ & 30.7 & & dddd & $14.2,10.5,9.0,0.7$ & 30.7 & 2.56 \\
\hline $7^{\prime}$ & & & & dddd & $14.2,3.6,2.4,1.7$ & & 2.50 \\
\hline 8 & $\mathrm{CH}$ & 77.9 & 3.75 & dd & $10.5,2.3$ & 78.3 & 3.79 \\
\hline 9 & $\mathrm{C}$ & 44.7 & & & & 44.7 & \\
\hline 10 & $\mathrm{C}$ & 179.4 & & & & 179.6 & \\
\hline 11 & $\mathrm{CH}$ & 111.6 & 6.26 & s & & 111.9 & 6.31 \\
\hline 12 & $\mathrm{C}$ & 155.0 & & & & 155.1 & \\
\hline 13 & $\mathrm{CH}_{2}$ & 29.3 & 3.28 & $\mathrm{~d}$ & 7.1 & 29.5 & 3.33 \\
\hline 14 & $\mathrm{CH}$ & 126.8 & 5.62 & $\mathrm{dtt}$ & $10.8,7.6,1.2$ & 126.9 & 5.62 \\
\hline 15 & $\mathrm{CH}$ & 128.6 & 5.45 & $\mathrm{dtt}$ & $10.8,7.4,1.4$ & 129.0 & 5.53 \\
\hline 16 & $\mathrm{CH}_{2}$ & 31.3 & 2.65 & ddd & $8.0,6.7,1.2$ & 31.6 & 2.69 \\
\hline 17 & $\mathrm{CH}$ & 136.3 & 5.68 & $\mathrm{ddt}$ & $17.2,10.5,6.8$ & 136.5 & \\
\hline \multirow[t]{2}{*}{18} & $\mathrm{CH}_{2}$ & 114.7 & 4.98 & $\mathrm{dq}$ & $17.1,1.6$ & 115.2 & 5.02 \\
\hline & & & 4.94 & $\mathrm{dq}$ & $10.0,1.6$ & & 4.97 \\
\hline \multirow[t]{2}{*}{19} & $\mathrm{CH}_{2}$ & 115.4 & 4.92 & bs & & 116.0 & 4.95 \\
\hline & & & 4.85 & bs & & & 4.89 \\
\hline 20 & $\mathrm{CH}_{3}$ & 25.8 & 1.30 & s & & 26.8 & 1.34 \\
\hline \multirow[t]{4}{*}{21} & $\mathrm{CH}_{3}$ & 115.4 & 1.22 & $\mathrm{~s}$ & & 23.9 & 1.28 \\
\hline & $\mathrm{OCH}_{3}$ & 51.4 & 3.44 & $\mathrm{~s}$ & & 52.3 & 3.48 \\
\hline & $\mathrm{NH}$ & & 4.73 & bs & & & 5.36 \\
\hline & $\mathrm{OH}$ & & 5.39 & bs & & & \\
\hline
\end{tabular}

${ }^{a}$ Measured at $400 \mathrm{MHz}\left({ }^{1} \mathrm{H}\right)$ and $100 \mathrm{MHz}\left({ }^{13} \mathrm{C}\right)$ in benzene- $d 6$.

${ }^{b}$ Measured at $400 \mathrm{MHz}\left({ }^{1} \mathrm{H}\right)$ and $100 \mathrm{MHz}\left({ }^{13} \mathrm{C}\right)$ in chloroform- $d$. 
Table S3. ${ }^{13} \mathrm{C}$ and ${ }^{1} \mathrm{H}$ NMR Data of 8-O-acetylmycothiazole (2) in Benzene- $d 6$.

\begin{tabular}{|c|c|c|c|c|c|}
\hline No. & Type & $\delta_{\mathrm{C}}$ & $\delta_{\mathrm{H}}$ & mult. & $J(\mathrm{~Hz})$ \\
\hline 1 & $\mathrm{C}$ & 155.6 & & & \\
\hline 2 & $\mathrm{CH}_{2}$ & 39.3 & 3.08 & dddd & $13.9,7.2,6.5,6.0$ \\
\hline 2' & & & 2.97 & dddd & $13.8,8.4,6.5,4.8$ \\
\hline 3 & $\mathrm{CH}_{2}$ & 37.1 & 1.96 & $\mathrm{~m}$ & \\
\hline 4 & $\mathrm{C}$ & 142.1 & & & \\
\hline 5 & $\mathrm{CH}$ & 131.2 & 5.73 & $\mathrm{~d}$ & 11.5 \\
\hline 6 & $\mathrm{CH}$ & 128.5 & 5.41 & ddd & $11.5,8.4,6.0$ \\
\hline 7 & $\mathrm{CH}_{2}$ & 29.6 & 2.53 & dddd & $15.0,10.1,8.4,1.4$ \\
\hline 7 & & & 2.57 & dddd & $15.1,6.0,3.0,1.2$ \\
\hline 8 & $\mathrm{CH}$ & 78.6 & 5.60 & $\mathrm{dd}$ & $10.1,3.2$ \\
\hline 9 & $\mathrm{C}$ & 44.5 & & & \\
\hline 10 & $\mathrm{C}$ & 175.6 & & & \\
\hline 11 & $\mathrm{CH}$ & 112.4 & 6.40 & $\mathrm{~s}$ & \\
\hline 12 & $\mathrm{C}$ & 155.3 & & & \\
\hline 13 & $\mathrm{CH}_{2}$ & 29.6 & 3.49 & $\mathrm{~d}$ & 7.4 \\
\hline 14 & $\mathrm{CH}$ & 127.3 & & $\mathrm{dtt}$ & $10.2,7.4,1.4$ \\
\hline 15 & $\mathrm{CH}$ & 128.8 & 5.50 & $\mathrm{dtt}$ & $10.2,7.7,1.6$ \\
\hline 16 & $\mathrm{CH}_{2}$ & 31.4 & 2.70 & ddd & $7.7,5.5,1.8$ \\
\hline 17 & $\mathrm{CH}$ & 126.4 & & ddt & $17.2,10.2,5.8$ \\
\hline \multirow[t]{2}{*}{18} & $\mathrm{CH}_{2}$ & 114.7 & 5.00 & $\mathrm{dq}$ & $17.2,1.6$ \\
\hline & & & 4.94 & $\mathrm{dq}$ & $10.2,1.6$ \\
\hline \multirow[t]{2}{*}{19} & $\mathrm{CH}_{2}$ & 115.5 & 4.79 & bs & \\
\hline & & & 4.78 & bs & \\
\hline 20 & $\mathrm{CH}_{3}$ & 25.8 & 1.37 & s & \\
\hline \multirow[t]{3}{*}{21} & $\mathrm{CH}_{3}$ & 23.6 & 1.36 & $\mathrm{~s}$ & \\
\hline & $\mathrm{OCH}_{3}$ & 51.2 & 3.42 & s & \\
\hline & $\mathrm{NH}$ & & 4.35 & bs & \\
\hline OAc & $\mathrm{C}$ & 169.3 & & & \\
\hline $\mathrm{OAc}$ & $\mathrm{CH}_{3}$ & 20.1 & 1.72 & $\mathrm{~s}$ & \\
\hline
\end{tabular}


Table S4. ${ }^{13} \mathrm{C},{ }^{1} \mathrm{H}, \mathrm{HMBC}$ and COSY NMR Data of 8-Oxo-mycothiazole (8) in Benzene-d6.

\begin{tabular}{|c|c|c|c|c|c|c|c|}
\hline No. & Type $^{a}$ & $\delta_{\mathrm{C}}{ }^{b}$ & $\delta_{\mathrm{H}}^{c}$ & mult. & $J(\mathrm{~Hz})$ & $\mathrm{gHMBC}^{c}$ & $\mathrm{gCOSY}^{c}$ \\
\hline 1 & $\mathrm{C}$ & $157.1^{*}$ & & & & & \\
\hline 2 & $\mathrm{CH}_{2}$ & 40.6 & 3.00 & $q$ & 6.6 & $1,3,4$ & $3, \mathrm{NH}$ \\
\hline 3 & $\mathrm{CH}_{2}$ & $38.2 *$ & 1.93 & $\mathrm{t}$ & 6.7 & $2,4,5,19$ & 2,19 \\
\hline 4 & $\mathrm{C}$ & 143.4 & & & & & \\
\hline 5 & $\mathrm{CH}$ & 133.1 & 5.69 & d & 11.0 & 4,7 & 6 \\
\hline 6 & $\mathrm{CH}$ & 125.8 & 5.65 & $\mathrm{dd}$ & $11.1,2.3$ & 4,7 & 7 \\
\hline 7 & $\mathrm{CH}_{2}$ & $38.2 *$ & 3.34 & $\mathrm{t}$ & 2.3 & $5,6,8$ & 6 \\
\hline 8 & $\mathrm{C}$ & 207.6 & & & & & \\
\hline 9 & $\mathrm{C}$ & 54.7 & & & & & \\
\hline 10 & $\mathrm{C}$ & 174.6 & & & & & \\
\hline 11 & $\mathrm{CH}$ & 114.4 & 6.32 & s & & $10,12,13$ & \\
\hline 12 & $\mathrm{C}$ & $157.1 *$ & & & & & \\
\hline 13 & $\mathrm{CH}_{2}$ & 30.7 & 3.43 & $\mathrm{~d}$ & 7.2 & $11,12,14,15$ & 14 \\
\hline 14 & $\mathrm{CH}$ & 128.7 & 5.67 & $\mathrm{dtt}$ & $10.6,7.2,1.6$ & 15,16 & 13,15 \\
\hline 15 & $\mathrm{CH}$ & 129.0 & 5.49 & $\mathrm{dtt}$ & $10.6,7.4,1.5$ & 16 & 14,16 \\
\hline 16 & $\mathrm{CH}_{2}$ & 32.6 & 2.69 & ddd & $7.7,6.4,1.6$ & $14,15,17,18$ & 15,17 \\
\hline 17 & $\mathrm{CH}$ & 137.5 & 5.72 & ddt & $17.0,10.1,6.2$ & 16,18 & 16,18 \\
\hline \multirow[t]{2}{*}{18} & $\mathrm{CH}_{2}$ & 115.9 & 4.99 & $\mathrm{dq}$ & $17.2,1.7$ & 16 & 17 \\
\hline & & & 4.93 & $\mathrm{dq}$ & $10.1,1.6$ & & \\
\hline \multirow[t]{2}{*}{19} & $\mathrm{CH}_{2}$ & 116.5 & 4.76 & bs & & $3,4,5$ & 3 \\
\hline & & & 4.71 & bs & & & \\
\hline 20 & $\mathrm{CH}_{3}$ & $26.2 *$ & $1.47 *$ & $\mathrm{~s}$ & & $8,9,10,21$ & \\
\hline \multirow[t]{3}{*}{21} & $\mathrm{CH}_{3}$ & $26.2 *$ & 1.47 & $\mathrm{~s}$ & & $8,9,10,20$ & \\
\hline & $\mathrm{OCH}_{3}$ & 52.4 & 3.42 & s & & 1 & \\
\hline & $\mathrm{NH}$ & & 4.45 & bs & & & 2 \\
\hline
\end{tabular}

${ }^{a}$ Carbon type determined by HSQC and HMBC experiments (see Figures S20 and S21 in Supporting Information). ${ }^{b}$ Measured at $175 \mathrm{MHz} .{ }^{c}$ Measured at $400 \mathrm{MHz} .{ }^{*}$ Interchangeable assignments. 
Table S5. ${ }^{13} \mathrm{C},{ }^{1} \mathrm{H}, \mathrm{HMBC}$ and COSY NMR data for MND1 (9a) in Benzene- $d_{6}$.

\begin{tabular}{|c|c|c|c|c|c|c|c|}
\hline No. & Type $^{a}$ & $\delta_{\mathrm{C}}^{b}$ & $\delta_{\mathrm{H}}^{c}$ & mult. & $J(\mathrm{~Hz})$ & $\mathrm{gHMBC}^{c}$ & $\mathrm{gCOSY}^{c}$ \\
\hline 1 & $\mathrm{C}$ & 156.7 & & & & & \\
\hline 2 & $\mathrm{CH}_{2}$ & 38.6 & 2.88 & tq & $13.5,6.7$ & & 3 \\
\hline 3 & $\mathrm{CH}_{2}$ & 32.6 & 1.58 & $\mathrm{t}$ & 6.9 & $2,4,5$ & 2,19 \\
\hline 4 & $\mathrm{C}$ & 132.7 & & & & & \\
\hline 5 & $\mathrm{CH}$ & 123.3 & 5.50 & $\mathrm{~m}$ & & & 6,19 \\
\hline 6 & $\mathrm{CH}$ & 55.1 & 4.45 & $\mathrm{~d}$ & 4.0 & & 5,7 \\
\hline \multirow[t]{2}{*}{7} & $\mathrm{CH}_{2}$ & 34.7 & 2.11 & $\mathrm{dd}$ & $13.4,8.0$ & 6 & $6,7,8$ \\
\hline & & & 1.62 & $\mathrm{dd}$ & $14.2,3.7$ & & $6,7,8$ \\
\hline 8 & $\mathrm{CH}$ & 75.5 & 4.06 & ddd & $10.6,4.9,1.8$ & & $7, \mathrm{OH}$ \\
\hline 9 & $\mathrm{C}$ & 44.98 & & & & & \\
\hline 10 & $\mathrm{C}$ & 179.7 & & & & & \\
\hline 11 & $\mathrm{CH}$ & 111.6 & 6.30 & $\mathrm{t}$ & 1.25 & 10,12 & 13 \\
\hline 12 & $\mathrm{C}$ & 155.3 & & & & & \\
\hline 13 & $\mathrm{CH}_{2}$ & 29.5 & 3.37 & $\mathrm{~d}$ & 7.1 & $11,12,14$ & $11,14,15$ \\
\hline 14 & $\mathrm{C}$ & 127.0 & 5.65 & $\mathrm{~m}$ & & & 13,15 \\
\hline 15 & $\mathrm{C}$ & 128.6 & 5.50 & $\mathrm{~m}$ & & 14 & $13,14,16$ \\
\hline 16 & $\mathrm{CH}_{2}$ & 31.5 & 2.70 & $\mathrm{t}$ & 6.3 & $15,17,18$ & $15,17,18$ \\
\hline 17 & $\mathrm{C}$ & 136.3 & 5.72 & ddt & $16.5,10.1,6.2$ & & 16,18 \\
\hline \multirow[t]{2}{*}{18} & $\mathrm{CH}_{2}$ & 114.8 & 5.02 & $\mathrm{dq}$ & $17.1,1.9$ & & 16,17 \\
\hline & & & 4.97 & $\mathrm{dq}$ & $10.1,1.7$ & 16 & \\
\hline \multirow[t]{2}{*}{19} & $\mathrm{CH}_{2}$ & 65.9 & 4.13 & $\mathrm{~d}$ & 15.4 & & 5,19 \\
\hline & & & 3.66 & $\mathrm{~d}$ & 15.5 & 4,5 & \\
\hline 20 & $\mathrm{CH}_{3}$ & 26.4 & 1.32 & $\mathrm{~s}$ & & $8,9,10,21$ & \\
\hline 21 & $\mathrm{CH}_{3}$ & 24.2 & 1.32 & $\mathrm{~s}$ & & $8,9,10,20$ & \\
\hline 22 & $\mathrm{C}$ & 148.6 & & & & & \\
\hline 23 & $\mathrm{CH}$ & 116.6 & 7.19 & $\mathrm{~d}$ & 3.4 & 22 & 25 \\
\hline 24 & $\mathrm{CH}$ & $\mathrm{a}$ & $\mathrm{a}$ & $\mathrm{m}$ & & & \\
\hline \multirow[t]{4}{*}{25} & $\mathrm{CH}$ & 121.5 & 6.83 & $\mathrm{tt}$ & $6.9,1.6$ & 23 & 23 \\
\hline & $\mathrm{OCH}_{3}$ & 51.36 & 3.46 & $\mathrm{~s}$ & & 1 & \\
\hline & $\mathrm{NH}$ & & 4.31 & bs & & & 2 \\
\hline & $\mathrm{OH}$ & & 4.84 & $\mathrm{~d}$ & 5.0 & & 8 \\
\hline
\end{tabular}

${ }^{a}$ Carbon type and chemical shift determined by HSQC and HMBC experiments (see Figures S24 and S25

in Supporting Information). ${ }^{b}$ Measured at $125 \mathrm{MHz} .{ }^{c}$ Measured at $500 \mathrm{MHz} . \mathrm{a}=$ Under solvent peak. nd = No data. 
Table S6. ${ }^{13} \mathrm{C},{ }^{1} \mathrm{H}$, and COSY NMR data for MND2 (9b) in Benzene- $d_{6}$.

\begin{tabular}{|c|c|c|c|c|c|c|}
\hline No. & Type $^{a}$ & $\delta_{C}{ }^{b}$ & $\delta_{\mathrm{H}}{ }^{c}$ & mult. & $J(\mathrm{~Hz})$ & $\mathrm{gCOSY}^{c}$ \\
\hline 1 & $\mathrm{C}$ & nd & & & & \\
\hline 2 & $\mathrm{CH}_{2}$ & 38.9 & 2.92 & ddt & $21.2,14.3,7.1$ & $3, \mathrm{NH}$ \\
\hline 3 & $\mathrm{CH}_{2}$ & 32.7 & 1.68 & $\mathrm{t}$ & 7.1 & 2,5 \\
\hline 4 & $\mathrm{C}$ & nd & & & & \\
\hline 5 & $\mathrm{CH}$ & 123.4 & 5.87 & $\mathrm{~d}$ & 3.3 & $3,6,19$ \\
\hline 6 & $\mathrm{CH}$ & 55.0 & 4.6 & $\mathrm{~d}$ & 3.8 & 5,7 \\
\hline 7 & $\mathrm{CH}_{2}$ & 32.3 & 1.92 & $\mathrm{~m}$ & & 6,8 \\
\hline 8 & $\mathrm{CH}$ & 75.5 & 4.05 & $\mathrm{~d}$ & 8.7 & $7, \mathrm{OH}$ \\
\hline 9 & $\mathrm{C}$ & nd & & & & \\
\hline 10 & $\mathrm{C}$ & nd & & & & \\
\hline 11 & $\mathrm{CH}$ & 111.6 & 6.25 & $\mathrm{~s}$ & & 13 \\
\hline 12 & $\mathrm{C}$ & nd & & & & \\
\hline 13 & $\mathrm{CH}_{2}$ & 29.4 & 3.35 & $\mathrm{~d}$ & 7.4 & $11,14,15$ \\
\hline 14 & $\mathrm{C}$ & 127.0 & 5.63 & $\mathrm{dt}$ & $9.5,7.2$ & 13,15 \\
\hline 15 & $\mathrm{C}$ & 128.7 & 5.51 & $\mathrm{~m}$ & & $13,14,16$ \\
\hline 16 & $\mathrm{CH}_{2}$ & 31.5 & 2.71 & $\mathrm{t}$ & 7.0 & $15,17,18$ \\
\hline 17 & $\mathrm{C}$ & 136.2 & 5.73 & ddt & $16.6,10.2,6.2$ & 16,18 \\
\hline \multirow[t]{2}{*}{18} & $\mathrm{CH}_{2}$ & 114.9 & 5.03 & $\mathrm{dq}$ & $17.0,1.7$ & 16,17 \\
\hline & & & 4.98 & $\mathrm{dq}$ & $10.1,1.6$ & \\
\hline \multirow[t]{2}{*}{19} & $\mathrm{CH}_{2}$ & 69 & 4.25 & $\mathrm{~d}$ & 15.3 & 5,19 \\
\hline & & & 3.83 & $\mathrm{~d}$ & 15.2 & \\
\hline 20 & $\mathrm{CH}_{3}$ & 26.2 & 1.27 & $\mathrm{~s}$ & & \\
\hline 21 & $\mathrm{CH}_{3}$ & 23.7 & 1.19 & $\mathrm{~s}$ & & \\
\hline 22 & $\mathrm{C}$ & nd & & & & \\
\hline 23 & $\mathrm{CH}$ & 115.6 & 7.20 & $\mathrm{~s}$ & & 25 \\
\hline 24 & $\mathrm{CH}$ & $\mathrm{a}$ & $\mathrm{a}$ & & & \\
\hline \multirow[t]{4}{*}{25} & $\mathrm{CH}$ & 121.3 & 6.83 & $\mathrm{tt}$ & $6.5,1.9$ & 23 \\
\hline & $\mathrm{OCH}_{3}$ & 51.4 & 3.45 & $\mathrm{~s}$ & & \\
\hline & NH & & 4.28 & bs & & 2 \\
\hline & $\mathrm{OH}$ & & 5.19 & bs & & 8 \\
\hline
\end{tabular}

${ }^{a}$ Carbon type and chemical shift determined by HSQC experiments (see Figure S28 in Supporting Information).

${ }^{b}$ Measured at $125 \mathrm{MHz} .{ }^{c}$ Measured at $500 \mathrm{MHz}$. a=Under solvent peek. Nd =No data 
Table S7. ${ }^{13} \mathrm{C},{ }^{1} \mathrm{H}$, and COSY NMR data for MND3 (10) in Benzene- $d_{6}$.

\begin{tabular}{|c|c|c|c|c|c|c|}
\hline No. & Type $^{a}$ & $\delta_{\mathrm{C}}^{b}$ & $\delta_{\mathrm{H}}^{c}$ & Mult. & $J(\mathrm{~Hz})$ & $\mathrm{gCOSY}^{\mathrm{c}}$ \\
\hline 1 & $\mathrm{C}$ & nd & & & & \\
\hline 2 & $\mathrm{CH}_{2}$ & 38.8 & 3.08 & $\mathrm{~m}$ & & $3, \mathrm{NH}$ \\
\hline 3 & $\mathrm{CH}_{2}$ & 34.2 & 1.84 & $\mathrm{~m}$ & & \\
\hline 4 & $\mathrm{C}$ & nd & & & & \\
\hline 5 & $\mathrm{CH}$ & 125.2 & 5.62 & $\mathrm{~m}$ & & 6 \\
\hline 6 & $\mathrm{CH}$ & 76.06 & 4.93 & bs & & $5,7,19$ \\
\hline \multirow[t]{2}{*}{7} & $\mathrm{CH}_{2}$ & 36.4 & 1.96 & $d$ & 8.86 & 6,8 \\
\hline & & & 1.84 & $\mathrm{~m}$ & & \\
\hline 8 & $\mathrm{CH}$ & 75.5 & 4.10 & $\mathrm{~m}$ & & 7, $\mathrm{OH}$ \\
\hline 9 & $\mathrm{C}$ & nd & & & & \\
\hline 10 & $\mathrm{C}$ & nd & & & & \\
\hline 11 & $\mathrm{CH}$ & 111.5 & 6.33 & S & & 13 \\
\hline 12 & $\mathrm{C}$ & nd & & & & \\
\hline 13 & $\mathrm{CH}_{2}$ & 29.5 & 3.39 & bs & & 11,14 \\
\hline 14 & $\mathrm{C}$ & 126.8 & 5.66 & $\mathrm{~m}$ & & 13 \\
\hline 15 & $\mathrm{C}$ & 128.7 & 5.50 & $\mathrm{~m}$ & & 16 \\
\hline 16 & $\mathrm{CH}_{2}$ & 31.4 & 2.69 & $\mathrm{t}$ & 6.78 & $\begin{array}{l}15,17 \\
18\end{array}$ \\
\hline 17 & $\mathrm{C}$ & nd & 5.72 & ddt & $16.6,10.4,6.3$ & 16,18 \\
\hline \multirow[t]{2}{*}{18} & $\mathrm{CH}_{2}$ & 114.9 & 5.02 & $\mathrm{dq}$ & $17.23,1.7$ & 16,17 \\
\hline & & & 5.97 & $\mathrm{dq}$ & $10.25,1.7$ & \\
\hline 19 & $\mathrm{CH}_{2}$ & 54.2 & 3.38 & bs & & 5,6 \\
\hline 20 & $\mathrm{CH}_{3}$ & 26.1 & 1.38 & $\mathrm{~S}$ & & \\
\hline 21 & $\mathrm{CH}_{3}$ & 24.3 & 1.35 & $\mathrm{~S}$ & & \\
\hline 22 & $\mathrm{C}$ & nd & & & & \\
\hline 23 & $\mathrm{CH}$ & 116.0 & 7.15 & & & 25 \\
\hline 24 & $\mathrm{CH}$ & a & $\mathrm{a}$ & & & \\
\hline \multirow[t]{4}{*}{25} & $\mathrm{CH}$ & 122.06 & 6.9 & $\mathrm{t}$ & 7.03 & 23 \\
\hline & $\mathrm{OCH}_{3}$ & 51.3 & 3.48 & $\mathrm{~s}$ & & \\
\hline & $\mathrm{NH}$ & & 4.71 & bs & & \\
\hline & $\mathrm{OH}$ & & 4.63 & bs & & \\
\hline
\end{tabular}

${ }^{a}$ Carbon type and chemical shift determined by HSQC experiments (see Figure S31 in Supporting Information).

${ }^{b}$ Measured at $125 \mathrm{MHz} .{ }^{c}$ Measured at $500 \mathrm{MHz}$. a=Under solvent peek. Nd =No data 
Figure S1. ${ }^{1} \mathrm{H}$ NMR spectrum of mycothiazole (1) in Benzene- $d_{6}$ at $400 \mathrm{MHz}$.

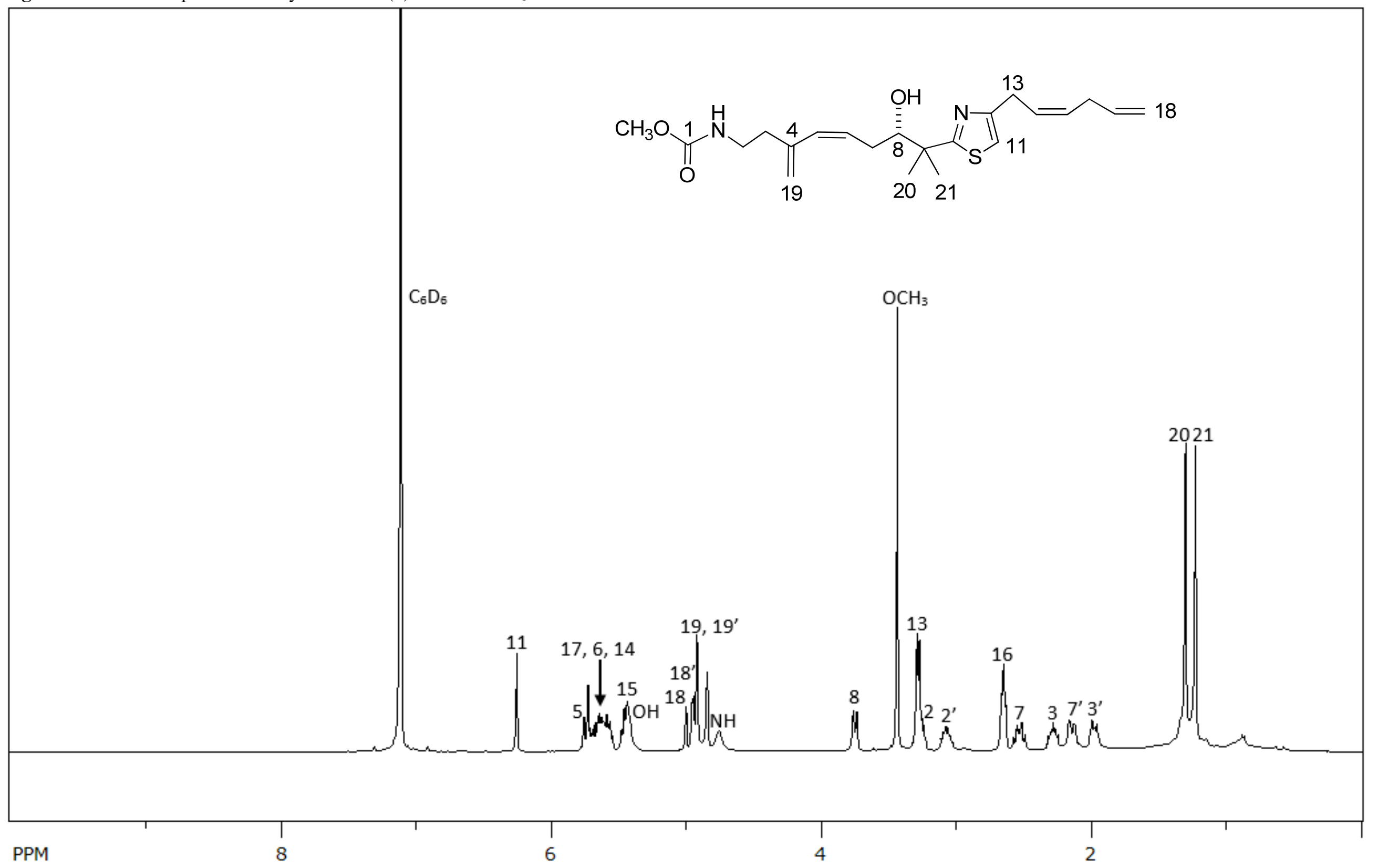


Figure S2. ${ }^{13} \mathrm{C}$ NMR spectrum of mycothiazole (1) in Benzene- $d_{6}$ at $100 \mathrm{MHz}$.

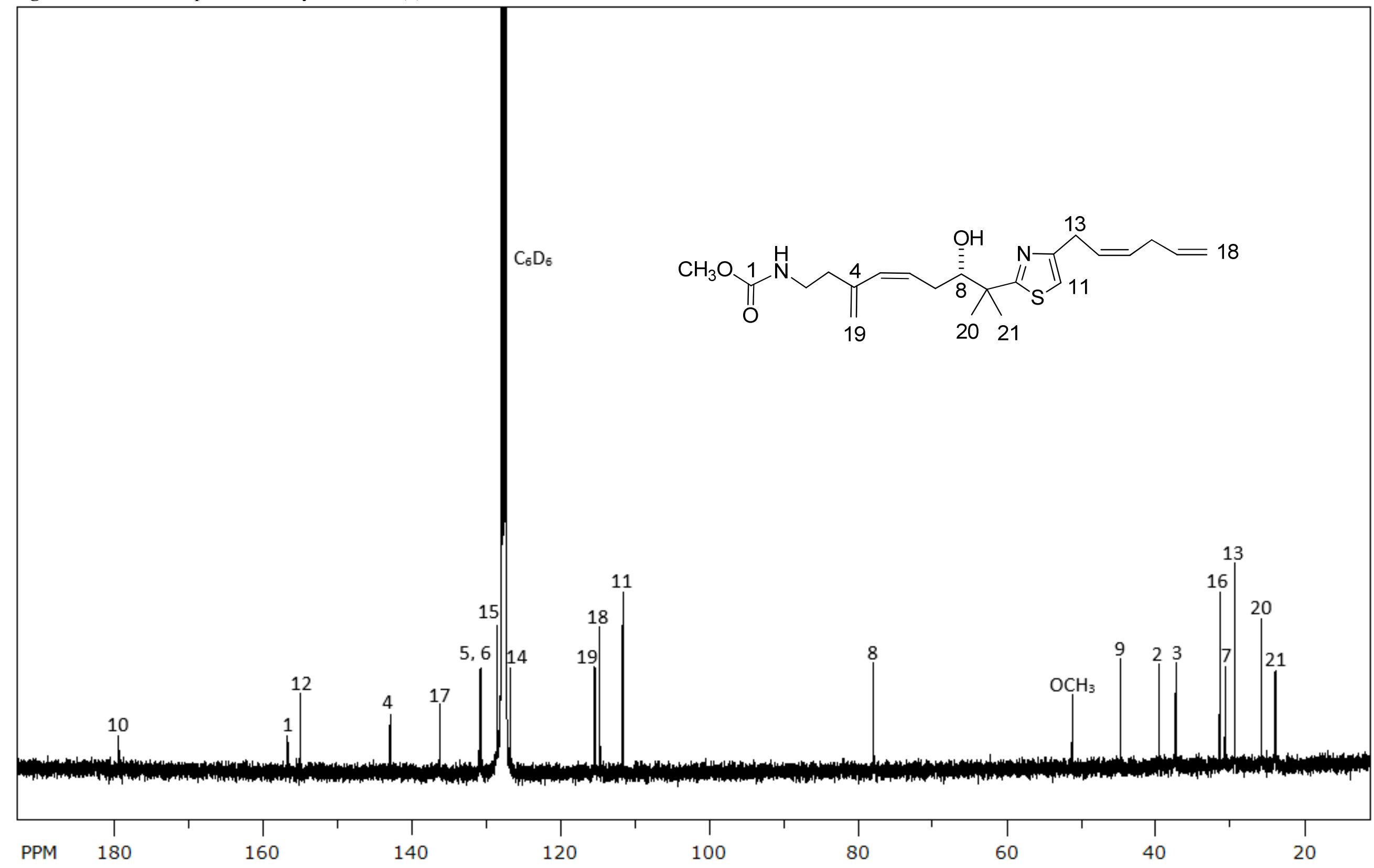


Figure S3. ${ }^{1} \mathrm{H}$ NMR spectrum of mycothiazole (1) in $\mathrm{CDCl}_{3}$ at $400 \mathrm{MHz}$.

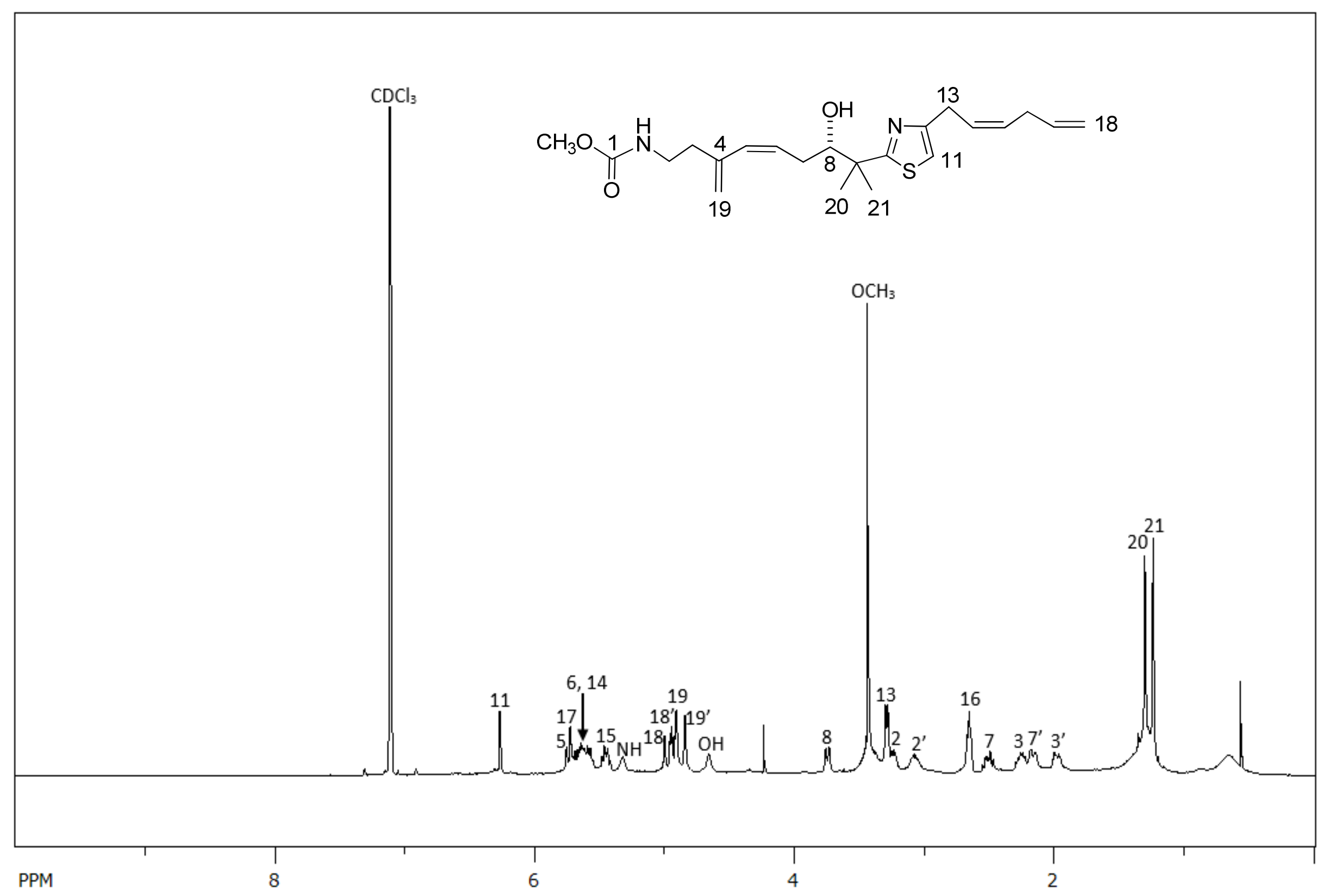


Figure S4. ${ }^{13} \mathrm{C}$ NMR spectrum of mycothiazole (1) in $\mathrm{CDCl}_{3}$ at $100 \mathrm{MHz}$.

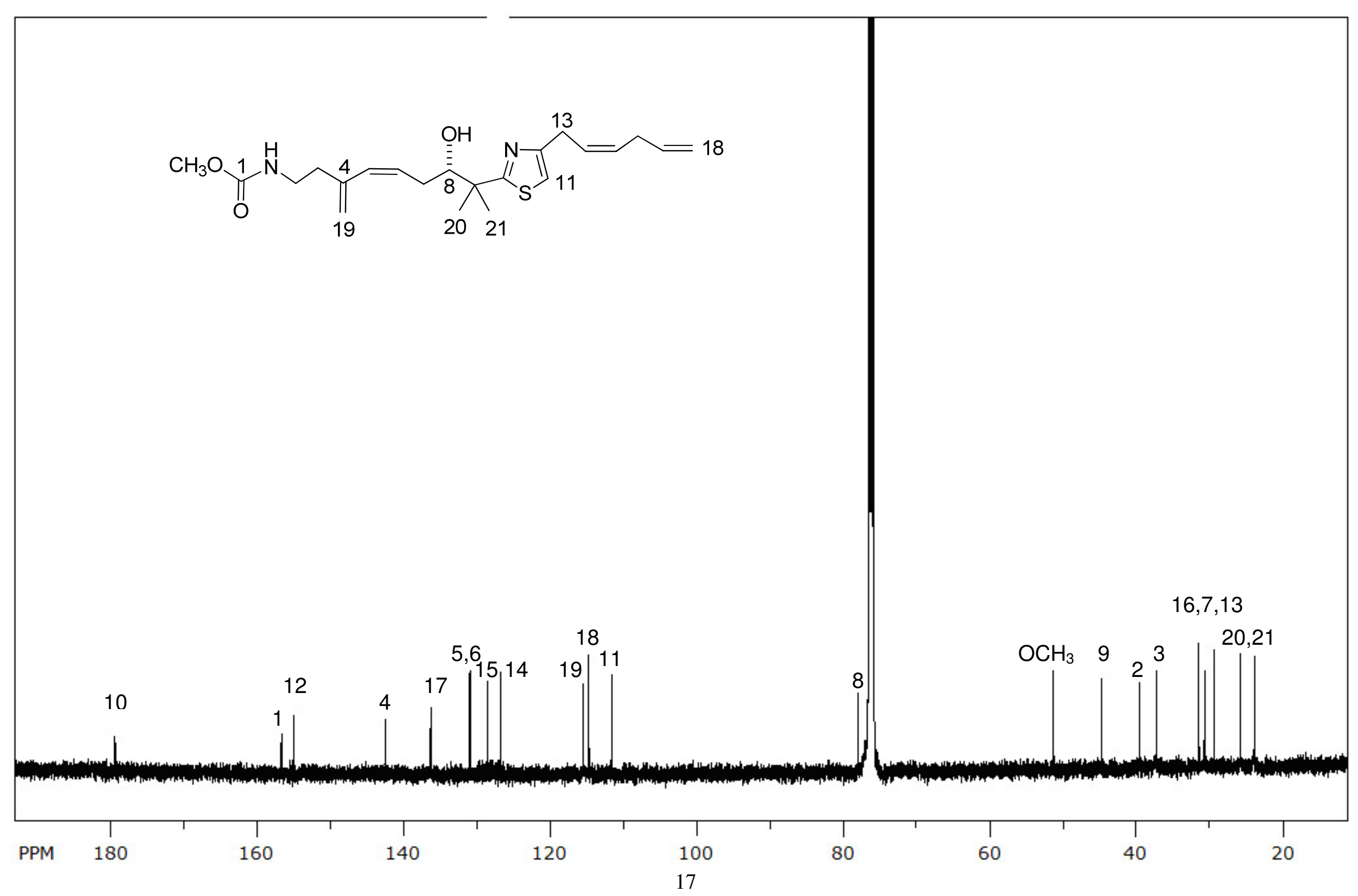


Figure S5. ${ }^{1} \mathrm{H}$ NMR spectrum of mycothiazole (1) in Benzene- $d_{6}$ at $400 \mathrm{MHz}$ :

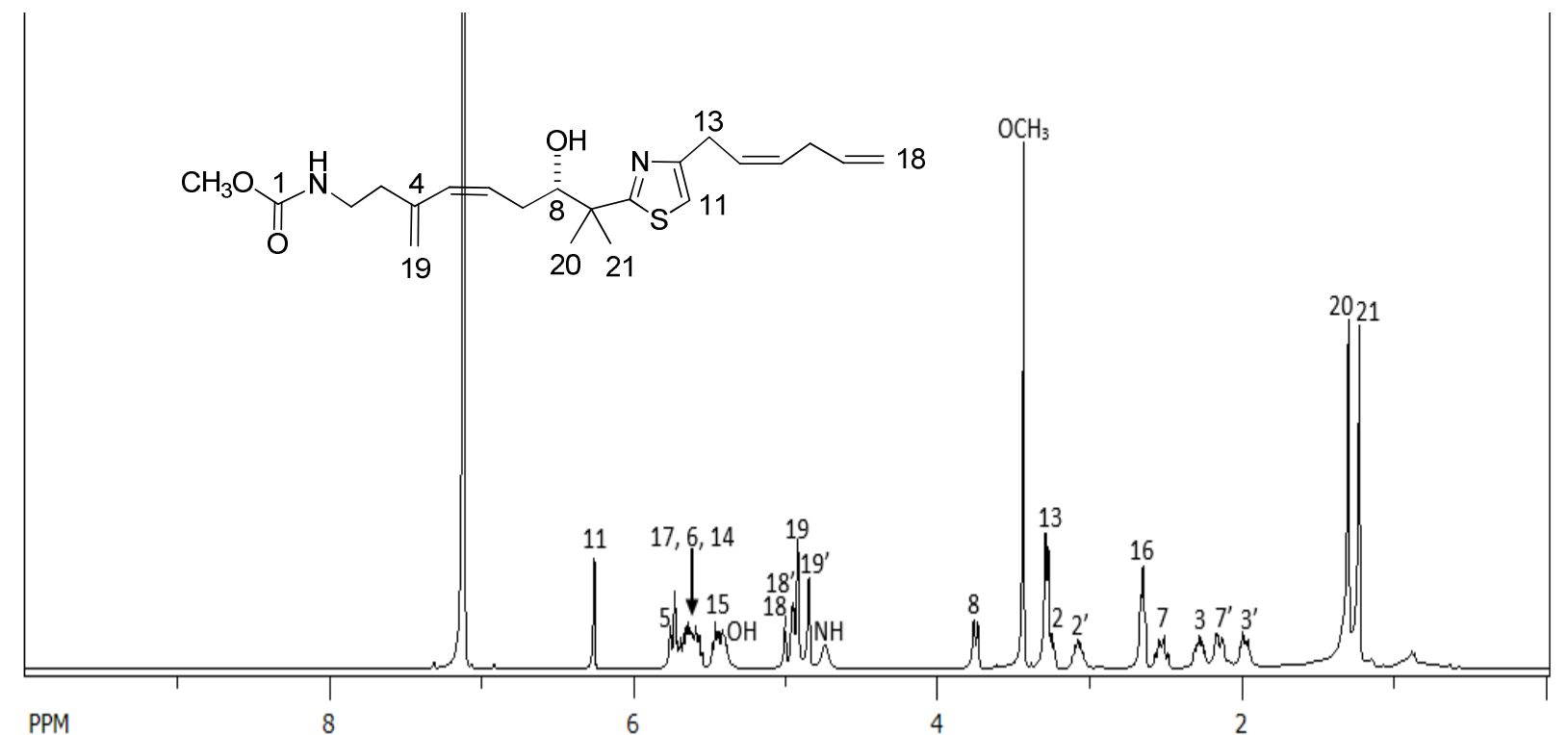

a) week 1 after purification of $\mathbf{1}$.

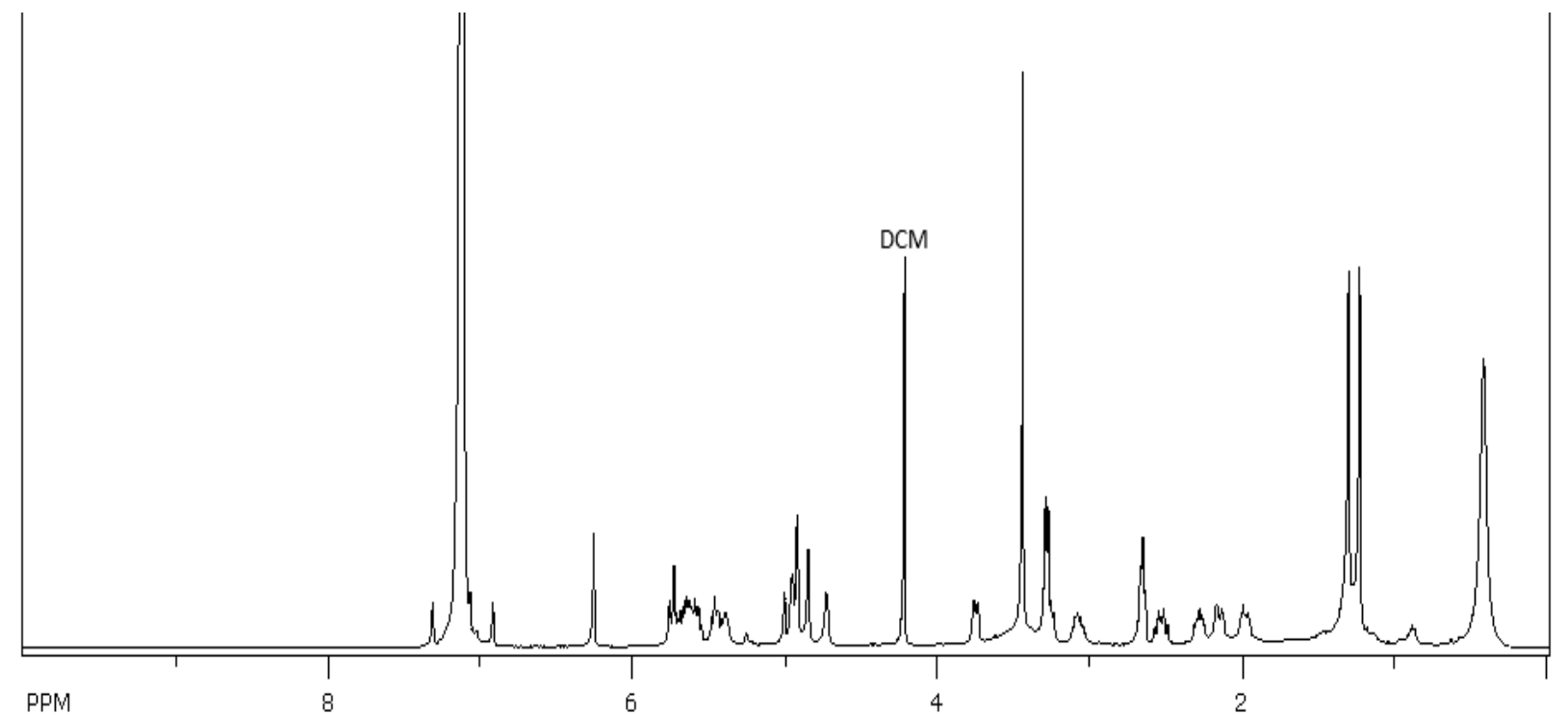

b) week 3 after purification of $\mathbf{1}$.

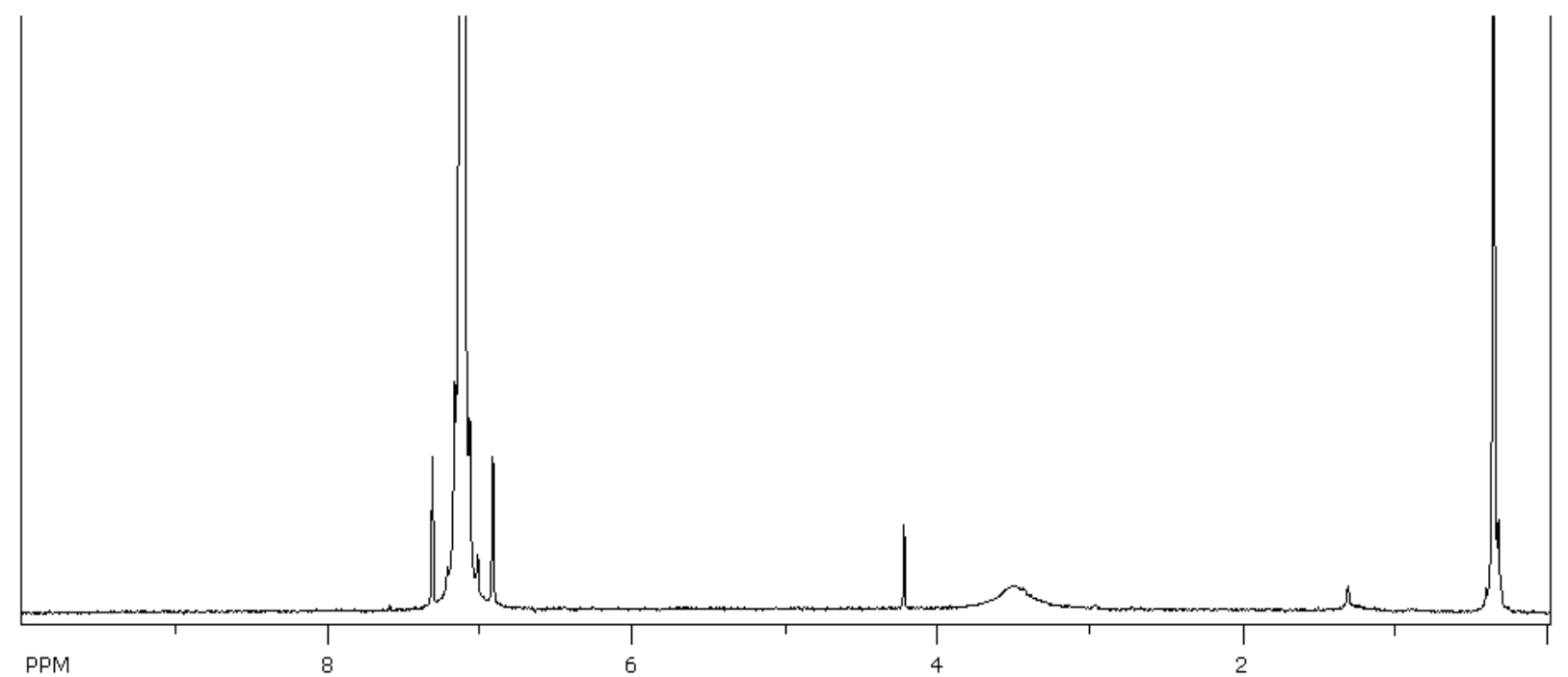

c) $>6$ weeks after purification of $\mathbf{1}$. 
Figure S6. ${ }^{1} \mathrm{H}$ NMR spectrum of mycothiazole (1): $\mid=$ Impurity peaks

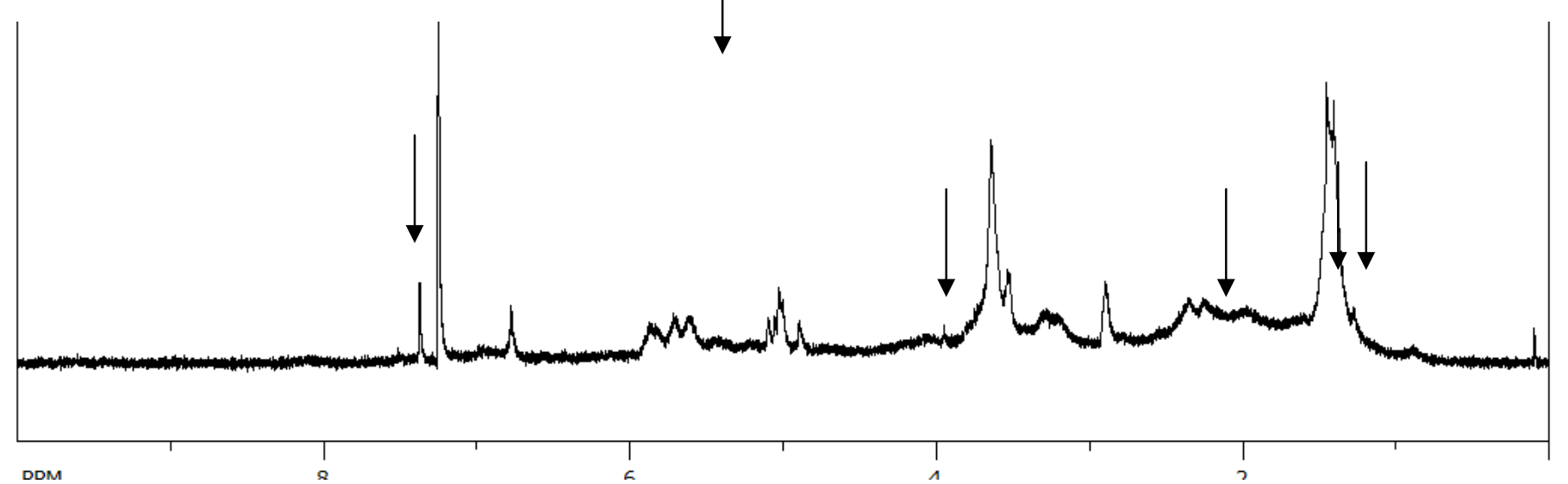

a) $>6$ weeks after purification of $\mathbf{1}$ in $\mathrm{CDCl}_{3}$ at $400 \mathrm{MHz}$

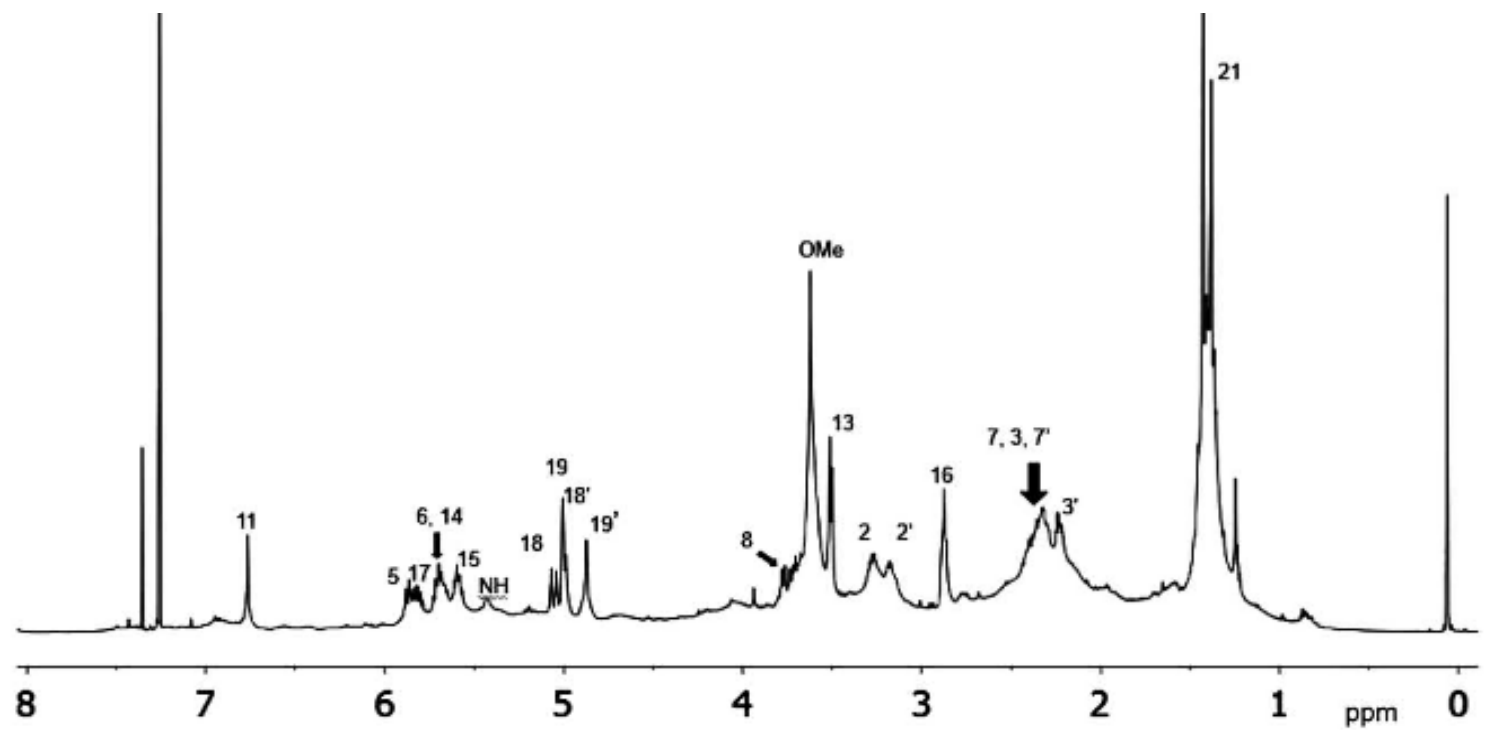

b) $>6$ weeks after purification of $\mathbf{1}$ in $\mathrm{CDCl}_{3}$ at $600 \mathrm{MHz}$.

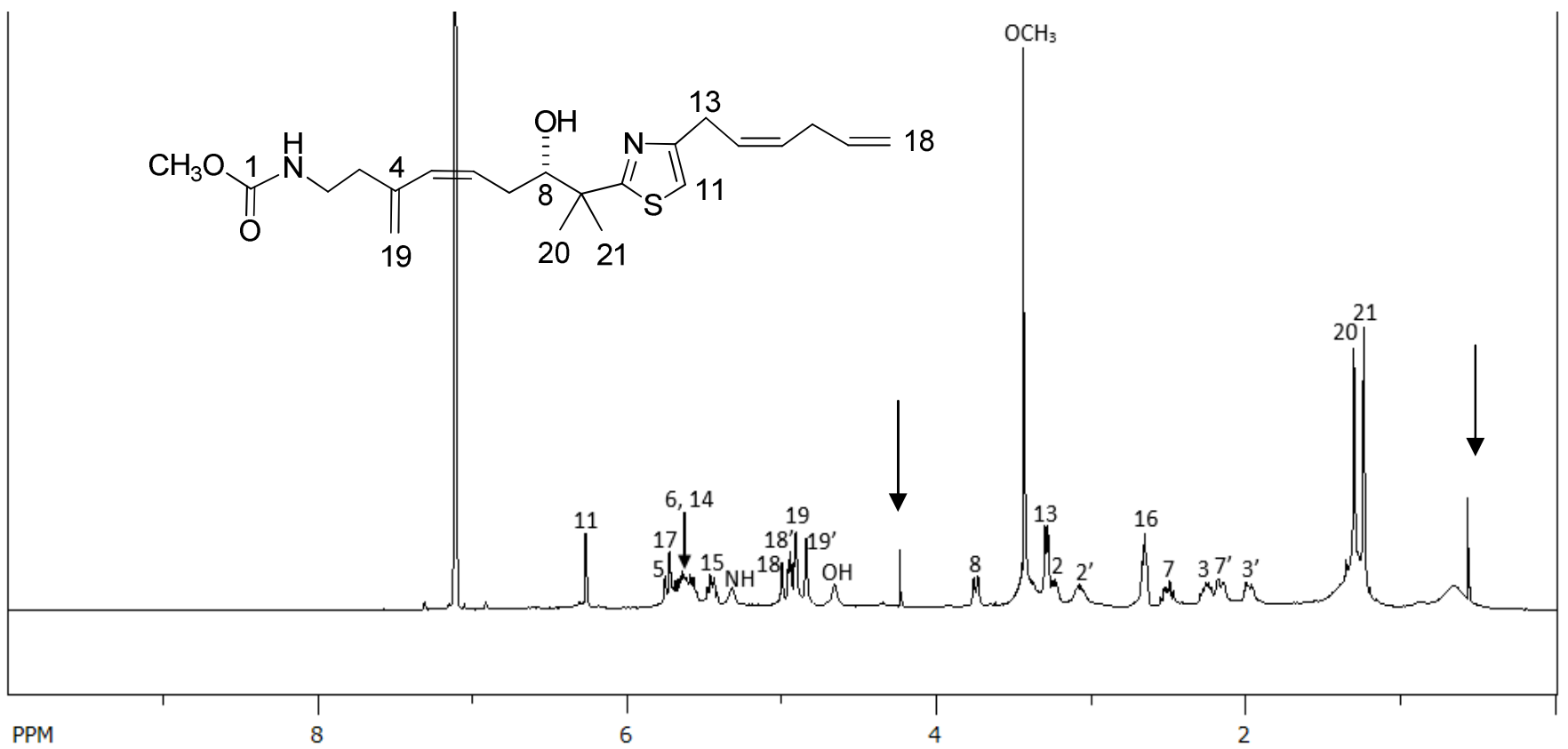

c) Reference standard. Sample of pure 1 in $\mathrm{CDCl}_{3}$ at $400 \mathrm{MHz}, 1$ week after purification. 
a)

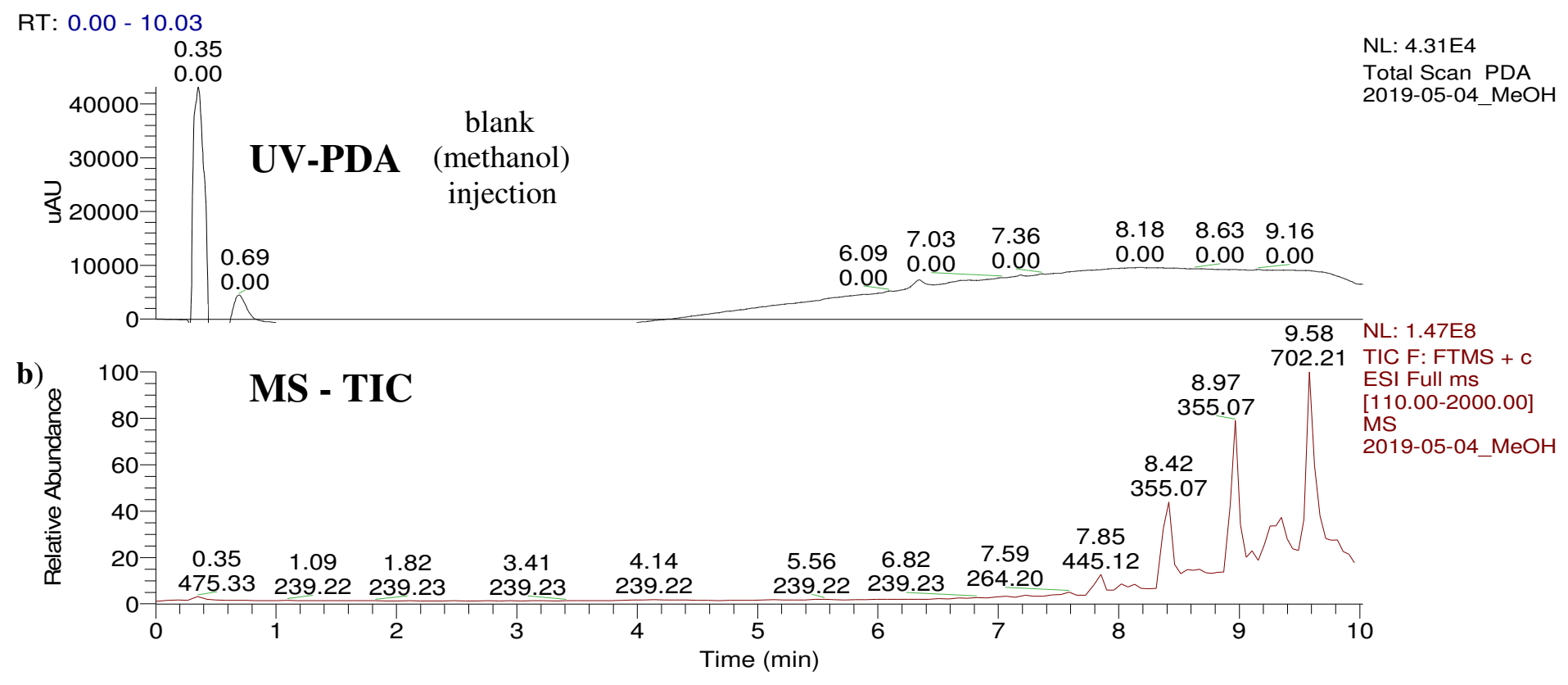

c)

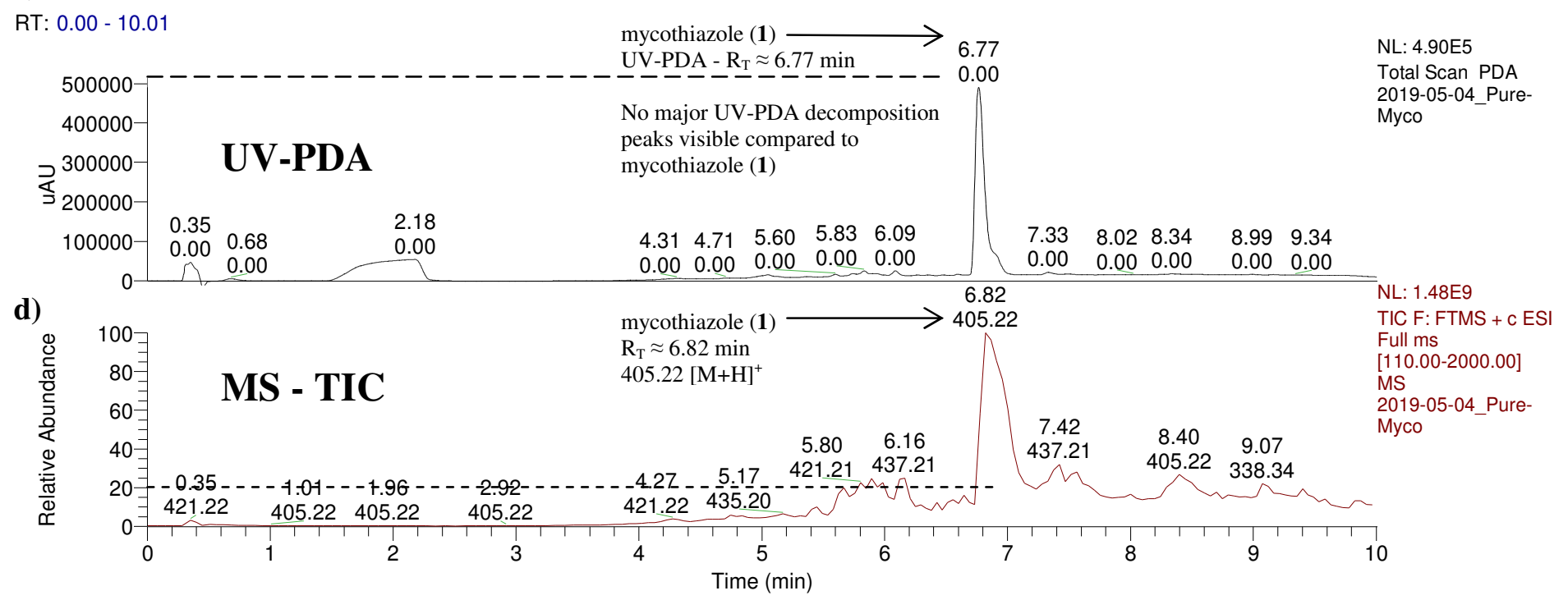

Figure S7. LCMS analysis of a) blank (methanol) sample injection showing ultraviolet-photo diode array (UV-PDA) detection trace and b) blank sample showing mass spectrometry - total ion current (MS-TIC) trace, c) mycothiazole (1) standard storage protocol (control) sample with large dashed line (---) indicating maximum absorbance units (uAU, yaxis) observed for reference compound mycothiazole $(\mathbf{1}, \approx 500000 \mathrm{uAU})$ from UV-PDA detection and $\mathbf{d})$ small dashed line (--) indicating relative abundance (y-axis) observed from MS-TIC minor component $\mathrm{m} / \mathrm{z}$ ion peaks detected $(\sim 20 \%)$. 
a)

RT: $0.00-10.03$

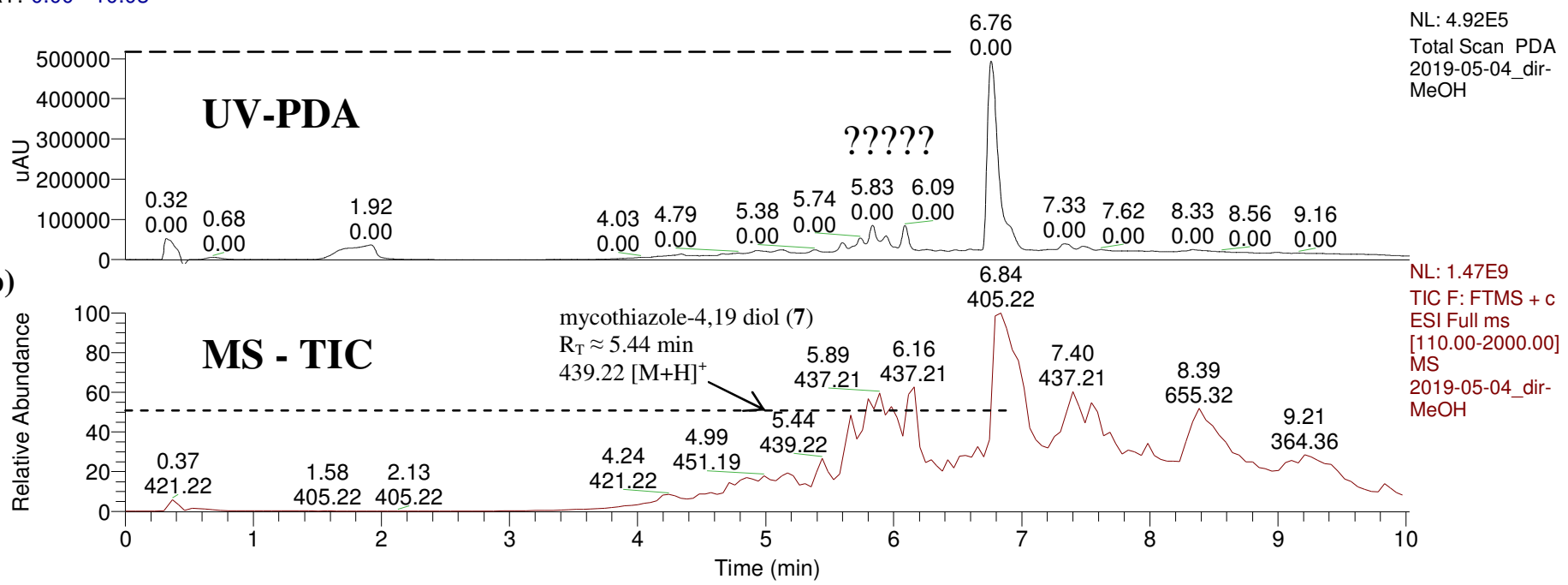

Figure S8. LCMS analysis of mycothiazole (1) amber vial sample immersed in methanol, dried using Air stream for 24 hours and observed with a) large dashed line (---) indicating maximum absorbance units (uAU, y-axis) observed for major metabolite reference compound mycothiazole $(\mathbf{1}, \approx 500000 \mathrm{uAU})$ from UV-PDA detection and b) small dashed line (--) indicating relative abundance (y-axis) observed from MS-TIC minor component $\mathrm{m} / \mathrm{z}$ ion peaks detected $(\sim \mathbf{4 5 \%})$. 
a)

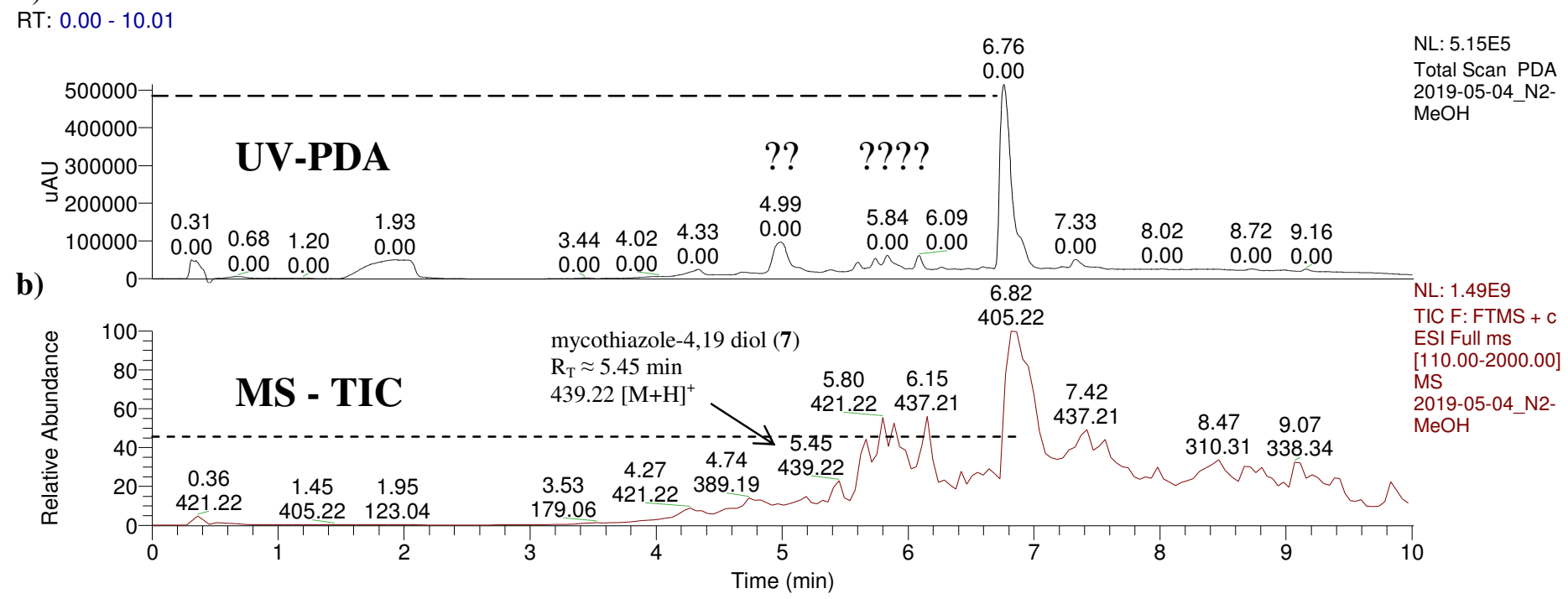

Figure S9. LCMS analysis of mycothiazole (1), amber vial sample immersed in methanol, dried using $\mathbf{N}_{\mathbf{2}}$ stream for 24 hours and observed with a) large dashed line (---) indicating maximum absorbance units (uAU, y-axis) observed for major metabolite reference compound mycothiazole $(\mathbf{1}, \approx 500000 \mathrm{uAU})$ from UV-PDA detection and b) small dashed line (--) indicating relative abundance (y-axis) observed from MS-TIC minor component $\mathrm{m} / \mathrm{z}$ ion peaks detected $(\sim \mathbf{4 5 \%})$. 
a)

RT: $0.00-10.03$

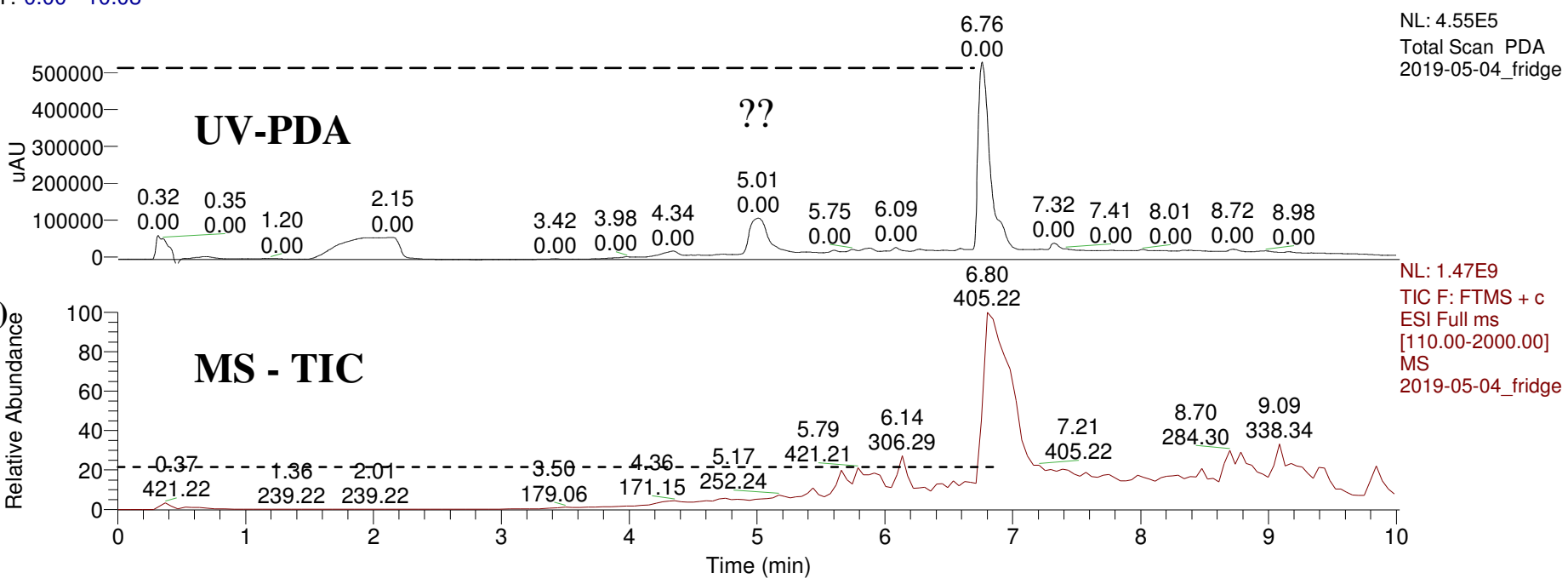

Figure S10. LCMS analysis of mycothiazole (1) amber vial sample, dried using $\mathrm{N}_{2}$ stream, purged with Argon, exposure to refrigeration $\left(4^{\circ} \mathrm{C}\right), 24$ hours and observed with a) large dashed line (---) indicating maximum absorbance units (uAU, y-axis) observed for major metabolite reference compound mycothiazole $(\mathbf{1}, \approx 500000 \mathrm{uAU})$ from UV-PDA detection and b) small dashed line (--) indicating relative abundance (y-axis) observed from MS-TIC minor component $\mathrm{m} / \mathrm{z}$ ion peaks detected $(\mathbf{2 0 \%})$. 
a)

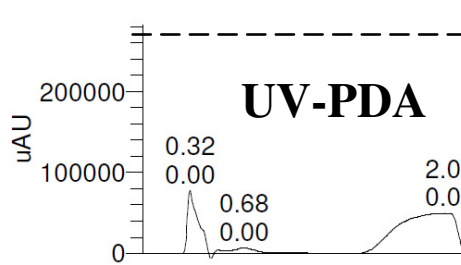

Total Scan PDA 2019-05-04 UV

b)

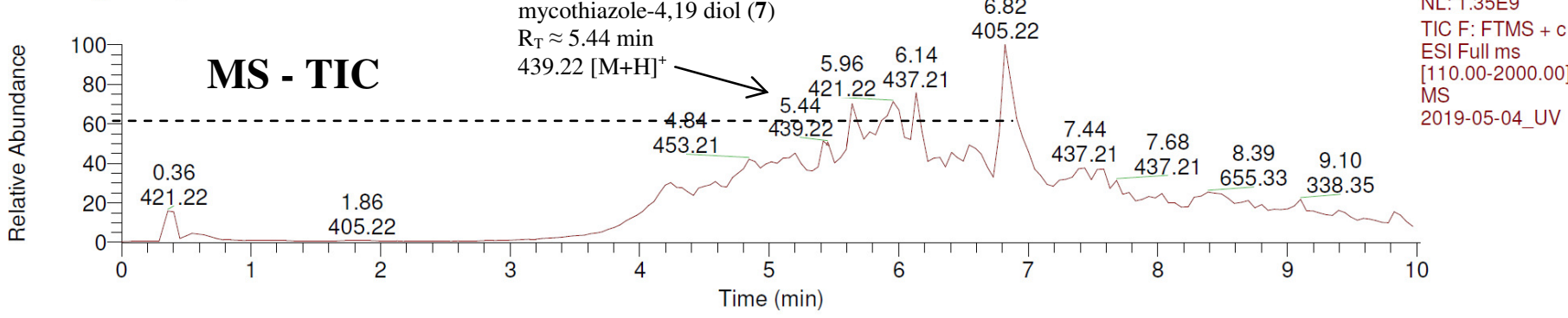

Figure S11. LCMS analysis of mycothiazole (1), clear vial, dried using $\mathrm{N}_{2}$ stream, exposure to direct light ( $h v$ ), 24 hours and observed with a) large dashed line (---) indicating maximum absorbance units (uAU, y-axis) observed for major metabolite reference compound mycothiazole $(\mathbf{1}, \approx 280000 \mathrm{uAU})$ from UV-PDA detection and b) small dashed line (--) indicating relative abundance (y-axis) observed from MS-TIC minor component $\mathrm{m} / \mathrm{z}$ ion peaks detected $(\sim \mathbf{6 0} \%)$. 
Figure S12.

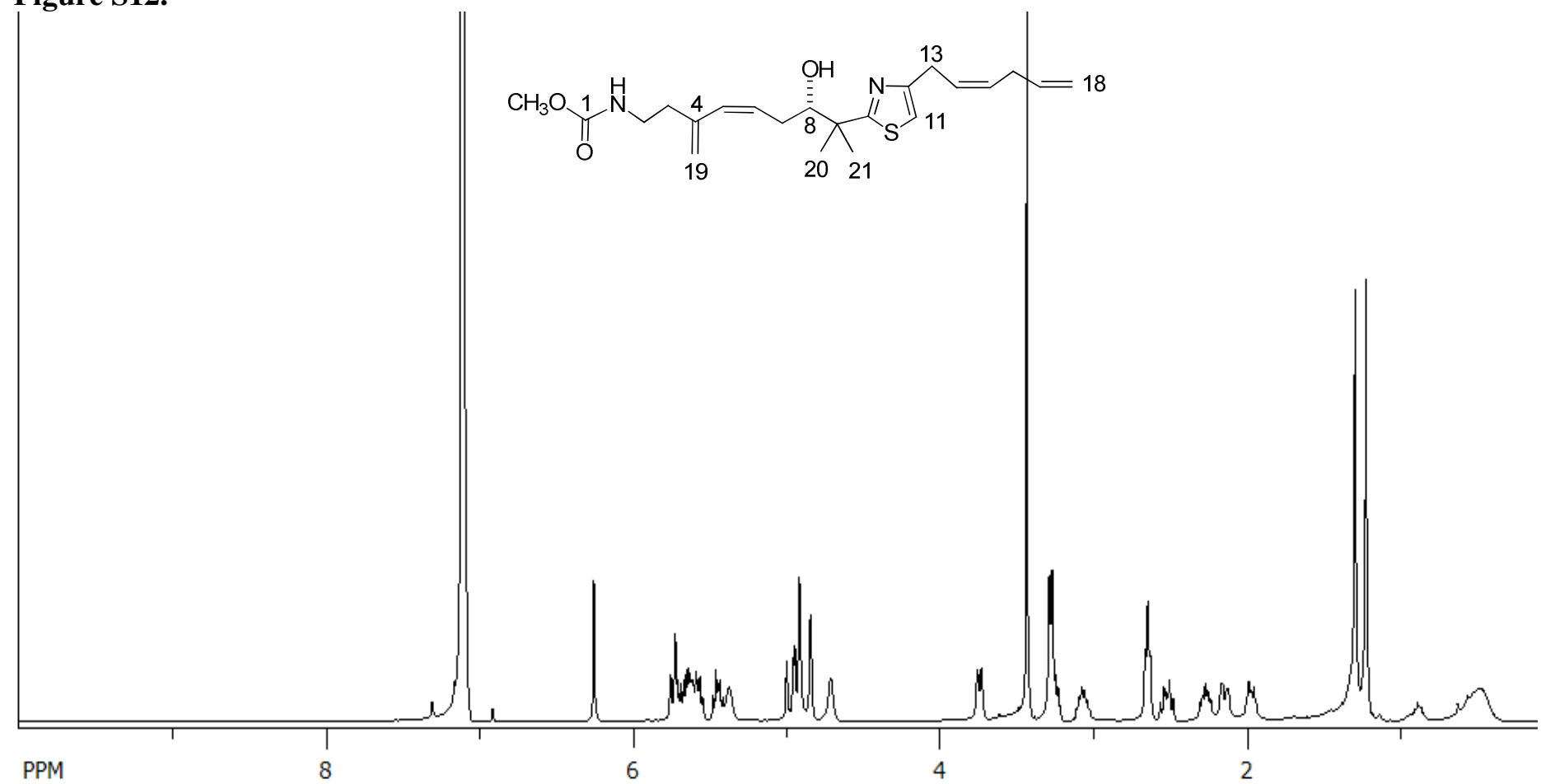

a) ${ }^{1} \mathrm{H}$ NMR of mycothiazole $(1,5 / 30 / 19)$ in Benzene- $d_{6}$. at $400 \mathrm{MHz}$ prior to taking ORD data.

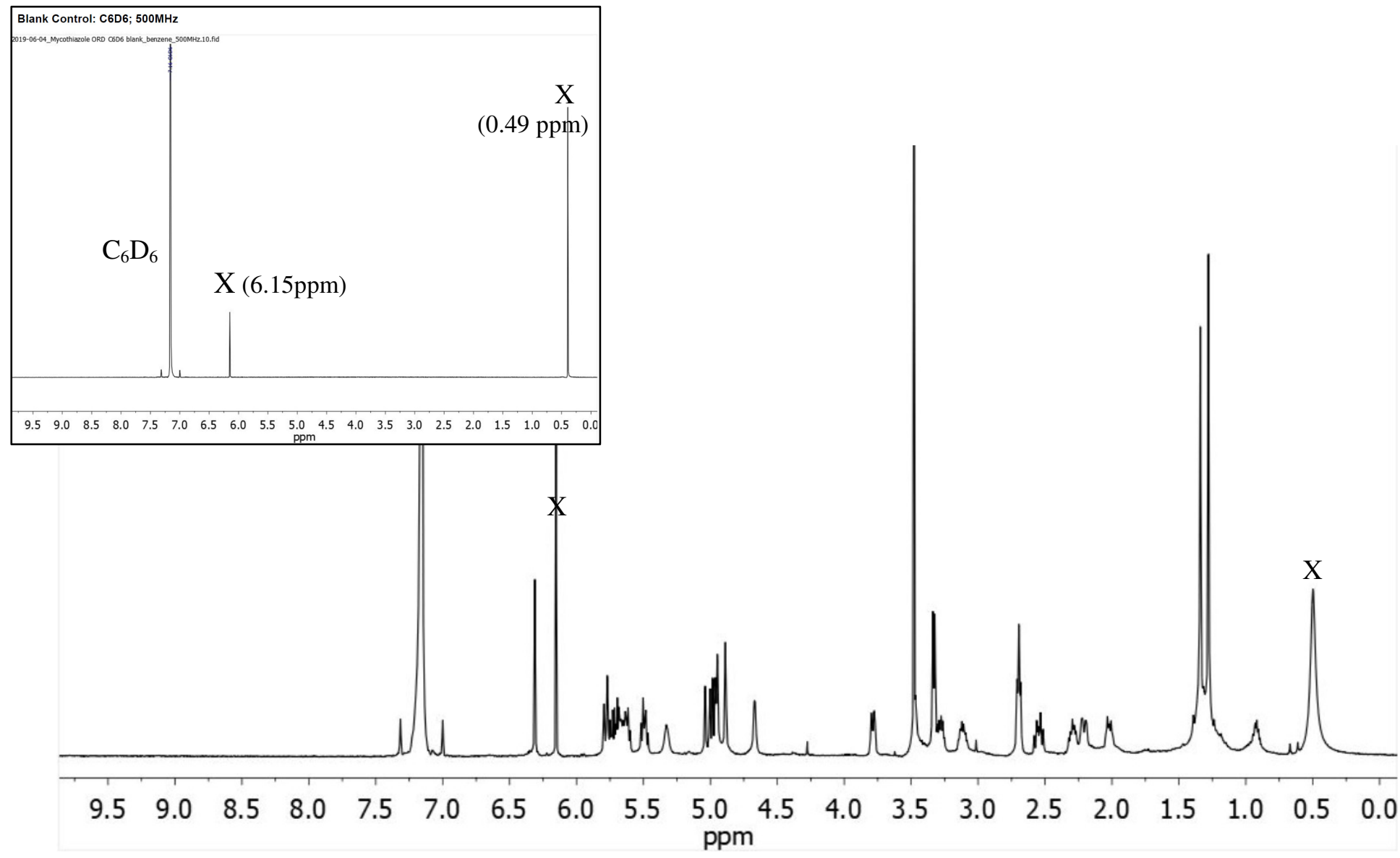

b) ${ }^{1} \mathrm{H}$ NMR of mycothiazole $(\mathbf{1}, 6 / 4 / 19)$ in Benzene- $d_{6}$. at $500 \mathrm{MHz}$ after taking ORD data.

NOTES: $\mathrm{X}=$ impurity peak in $\mathrm{C}_{6} \mathrm{D}_{6}$ solvent 
Figure S13.

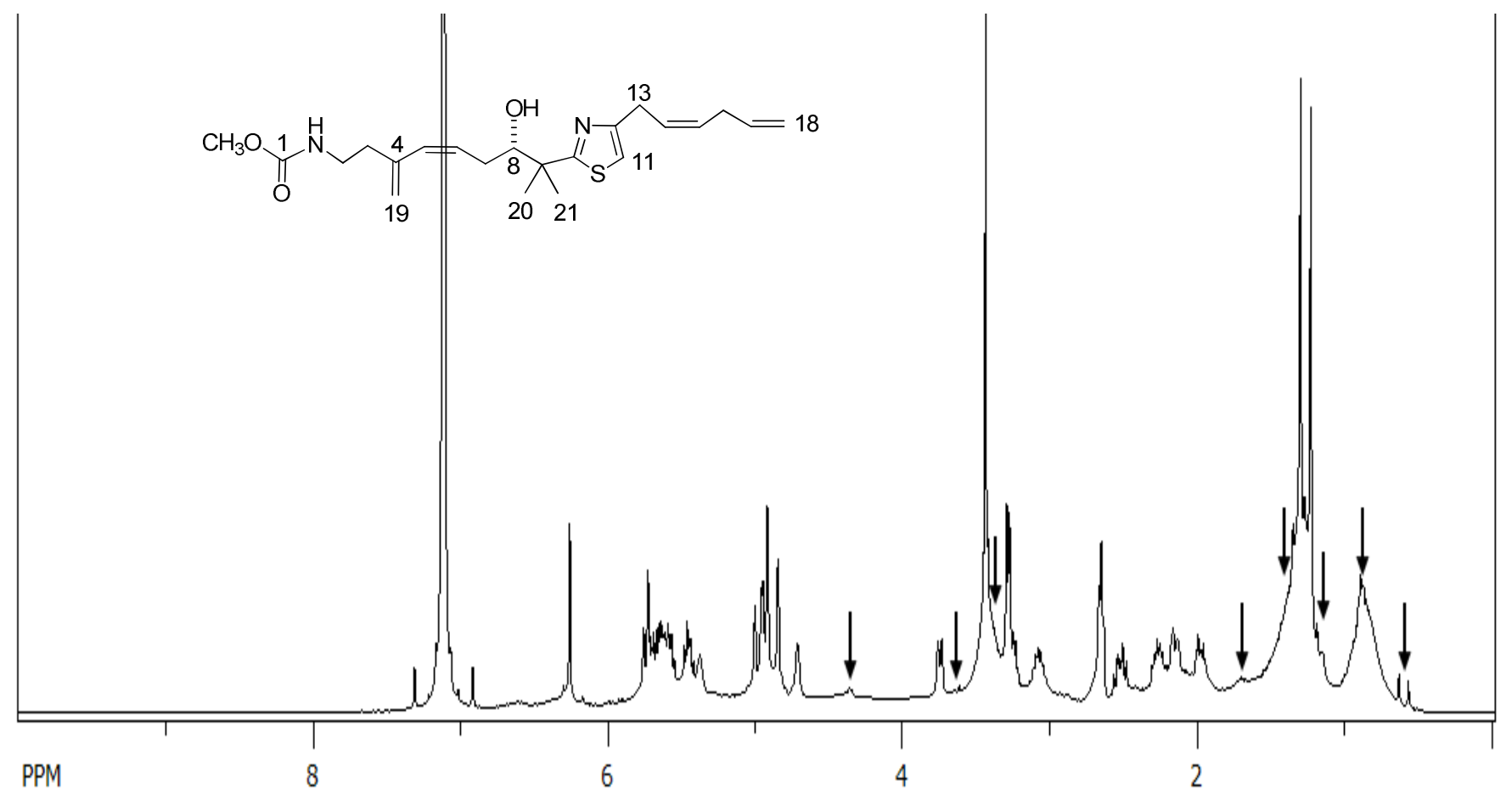

NOTE: Emerging impurities designated with arrows $\downarrow$ in above spectra.

a) ${ }^{1} \mathrm{H}$ NMR of semi-oxidized mycothiazole (1) in Benzene- $d_{6}$. at $400 \mathrm{MHz}$ prior to obtaining ORD data (5/31/19).

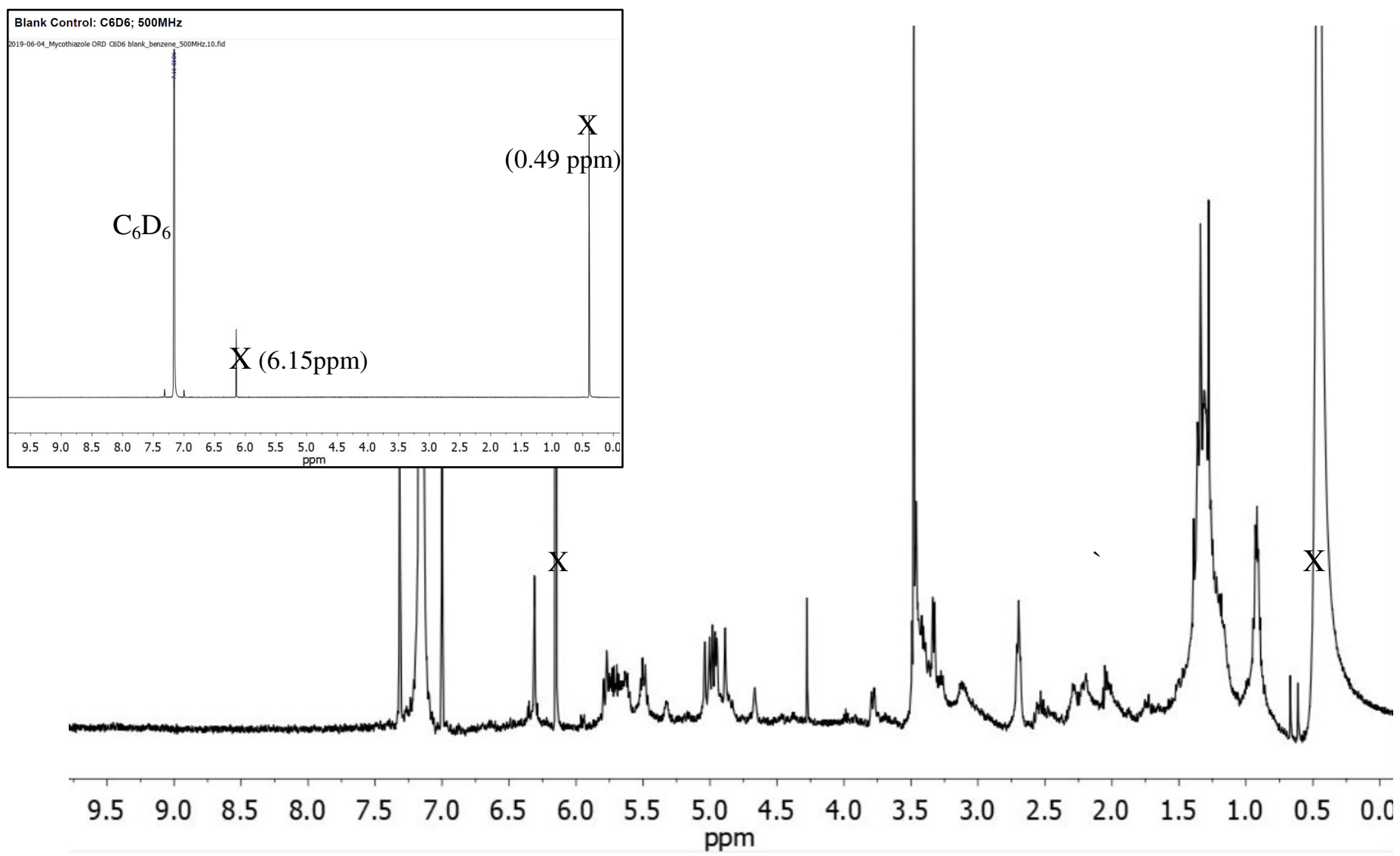

b) ${ }^{1} \mathrm{H}$ NMR of semi-oxidized mycothiazole (1) in Benzene- $d_{6}$. at $500 \mathrm{MHz}$ after obtaining ORD data (6/4/19). 
Figure S14. ${ }^{1} \mathrm{H}$ NMR spectrum of $8-O$-acetylmycothiazole (2) in Benzene- $d_{6}$ at $400 \mathrm{MHz}$.

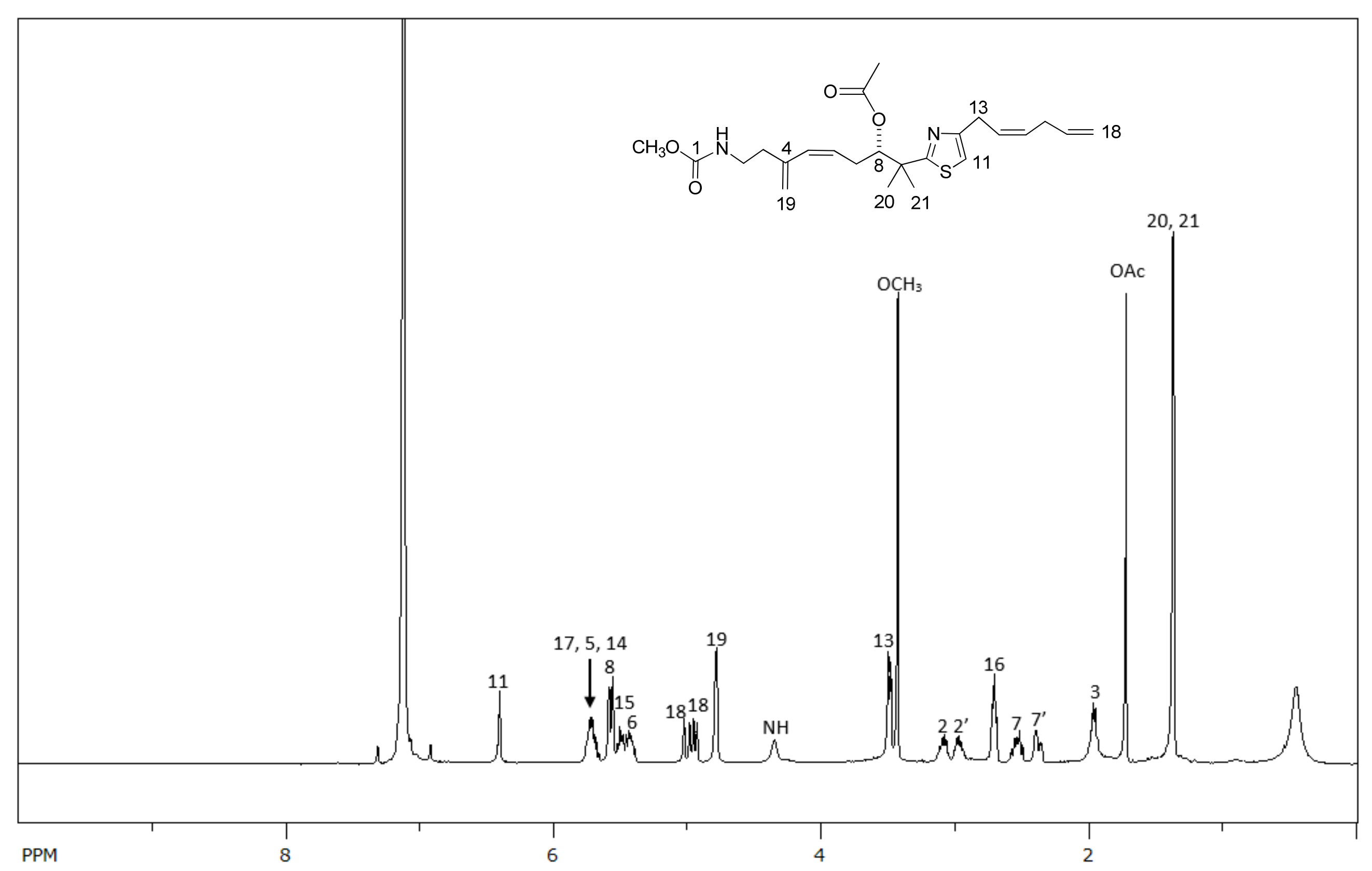


Figure S15. ${ }^{13} \mathrm{C}$ NMR spectrum of 8-O-acetylmycothiazole (2) in Benzene- $d_{6}$ at $100 \mathrm{MHz}$

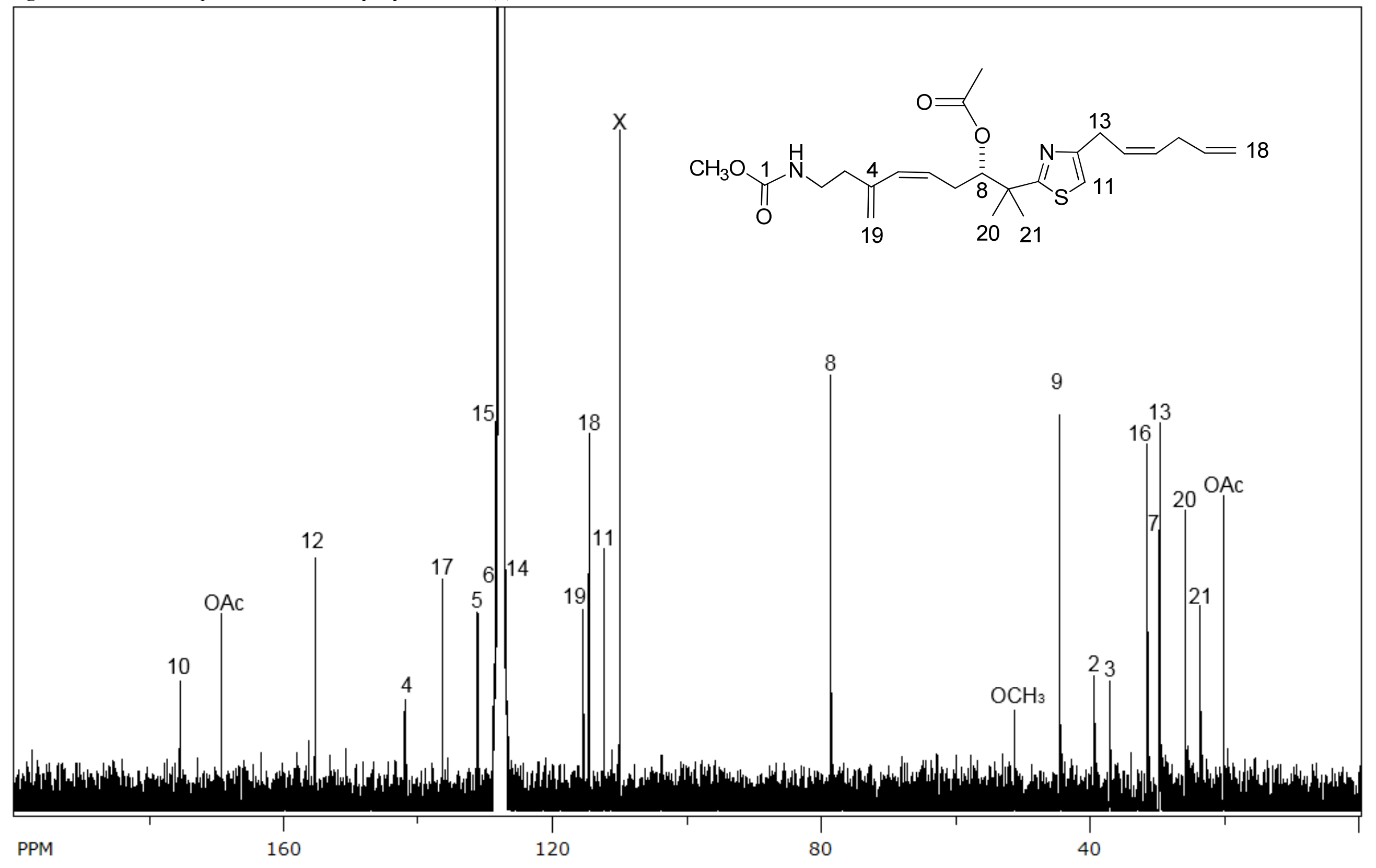


Figure S16.

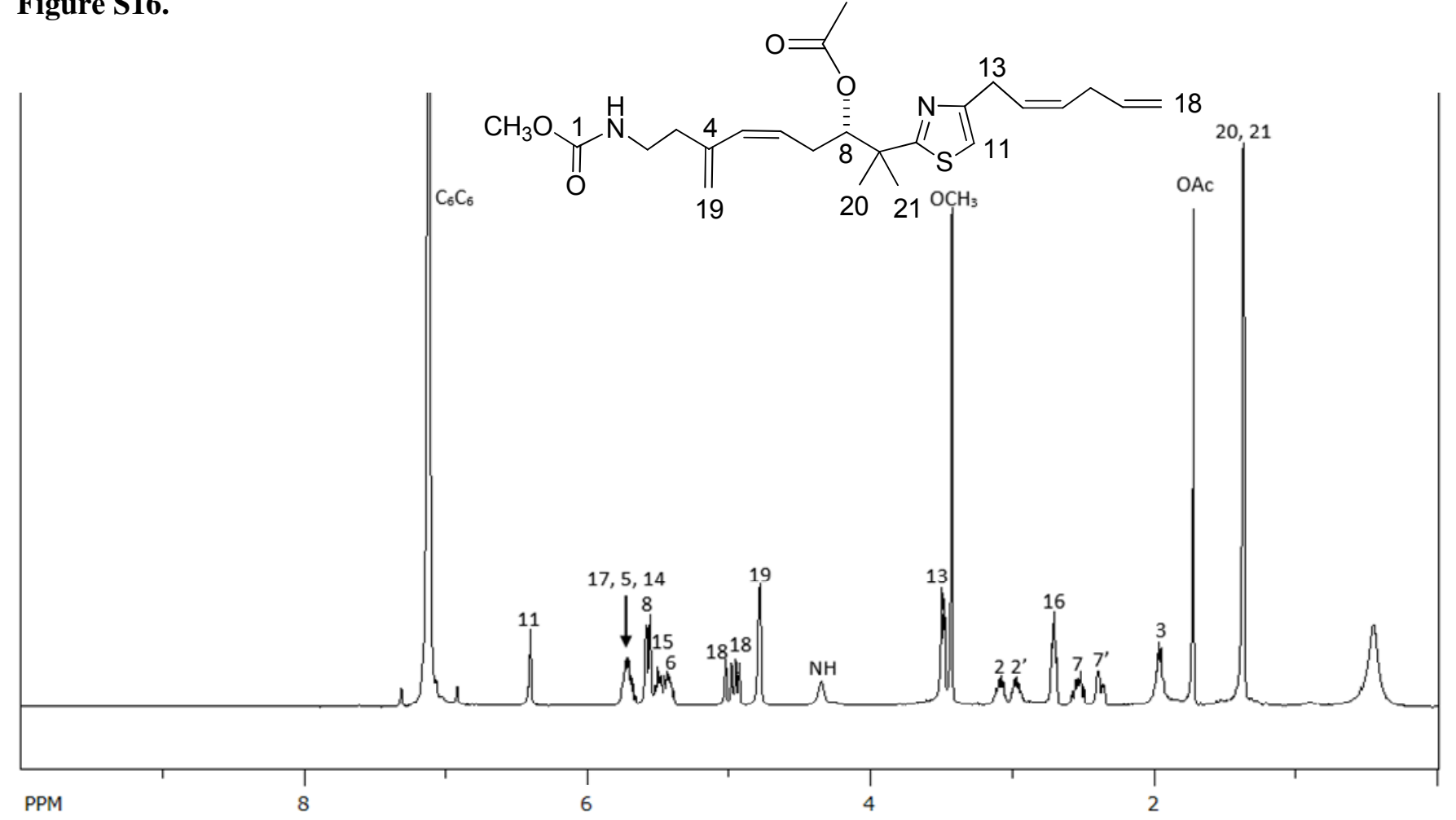

a) ${ }^{1} \mathrm{H}$ NMR spectrum of 8-O-acetyl-mycothiazole (2) in Benzene- $d_{6}$ at $400 \mathrm{MHz} 6$ days after purification.

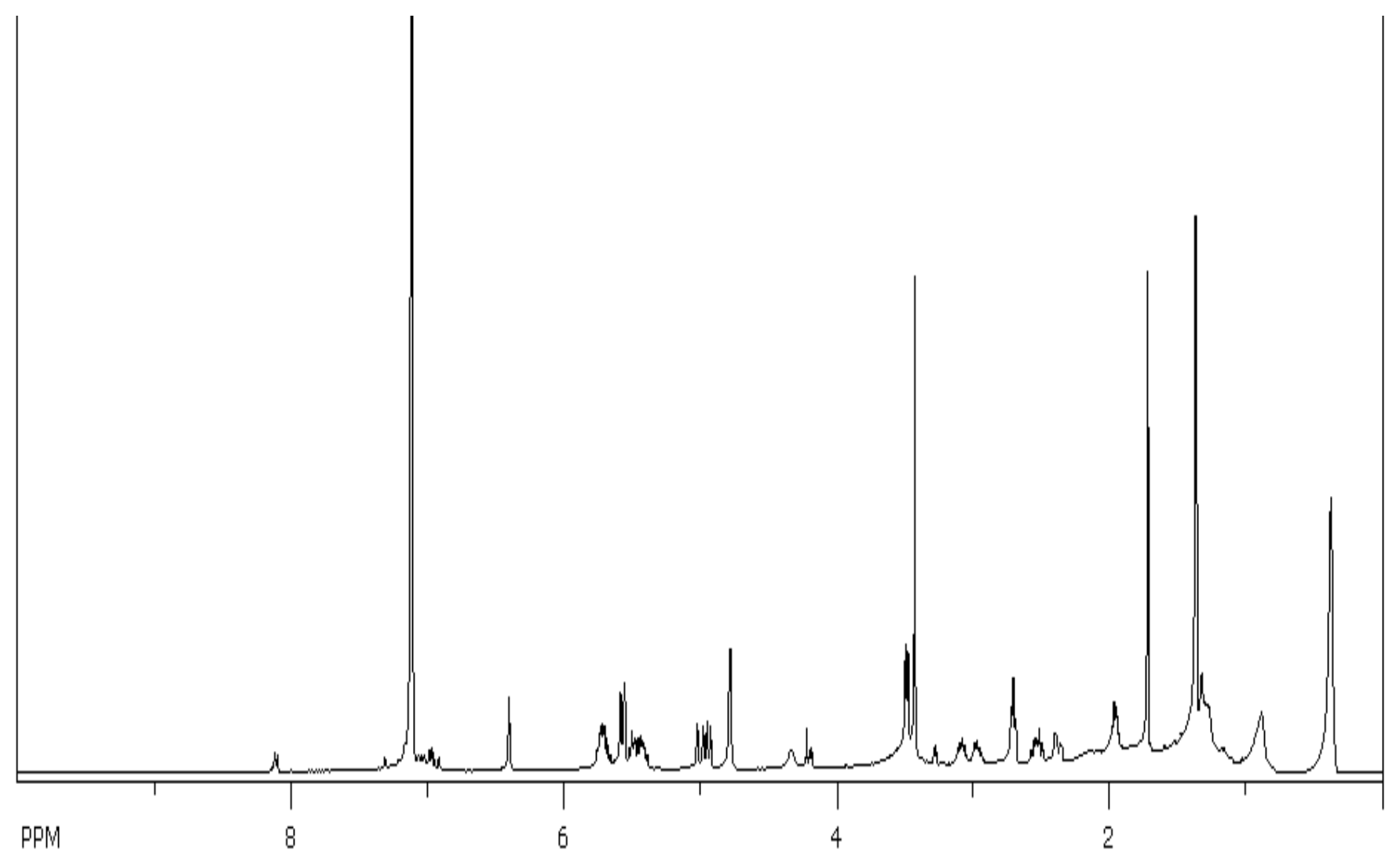

b) ${ }^{1} \mathrm{H}$ NMR spectrum of 8 - $O$-acetyl-mycothiazole (3) in Benzene- $d_{6}$ at $400 \mathrm{MHz} 6$ months after purification. 
Figure S17. ${ }^{1} \mathrm{H}$ NMR spectrum of 8 -Oxo-mycothiazole (8) in Benzene- $d_{6}$ at $400 \mathrm{MHz}$.

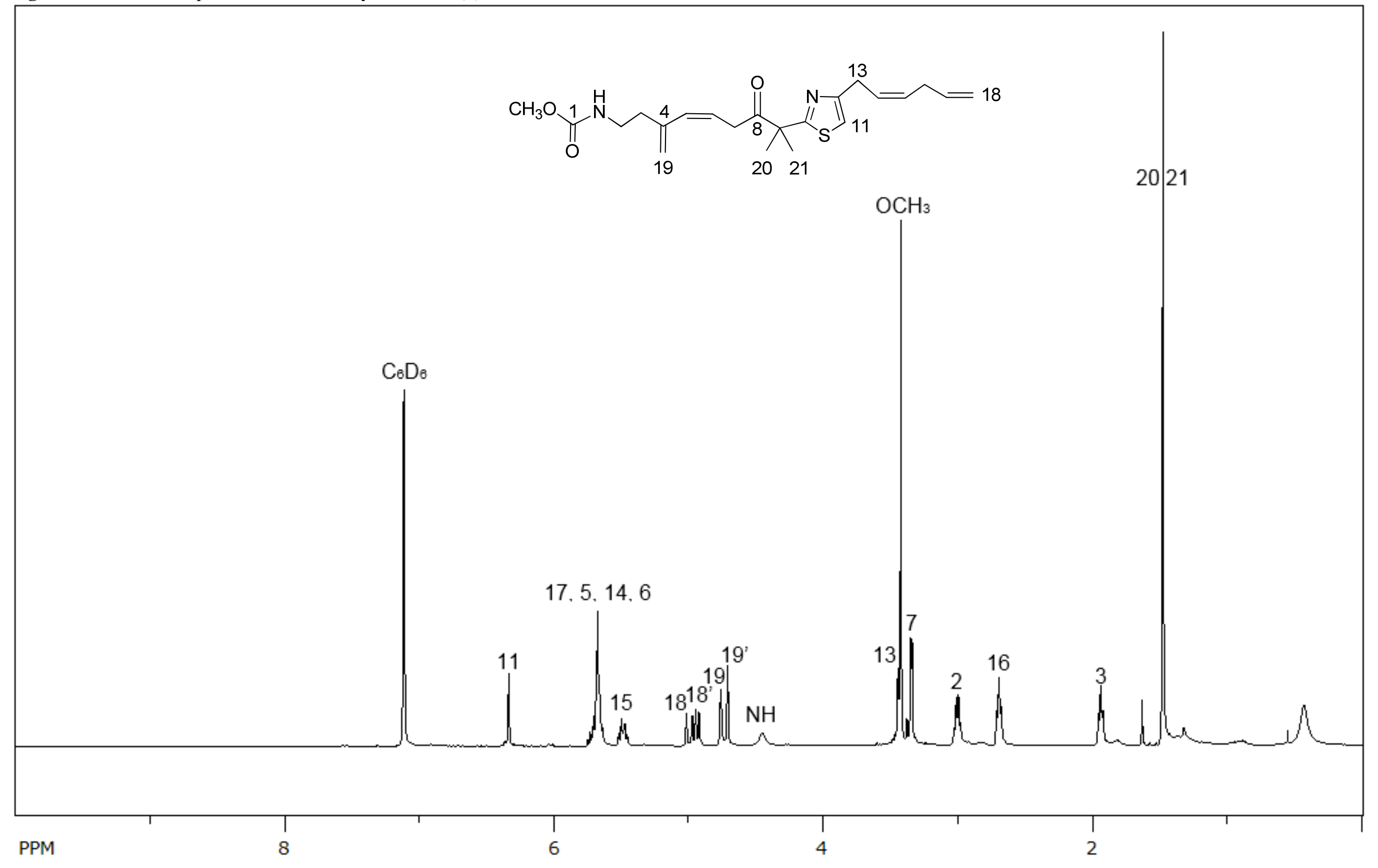


Figure S18. ${ }^{13} \mathrm{C}$ NMR spectrum of 8 -Oxo-mycothiazole (8) in Benzene- $d_{6}$ at $175 \mathrm{MHz}$.

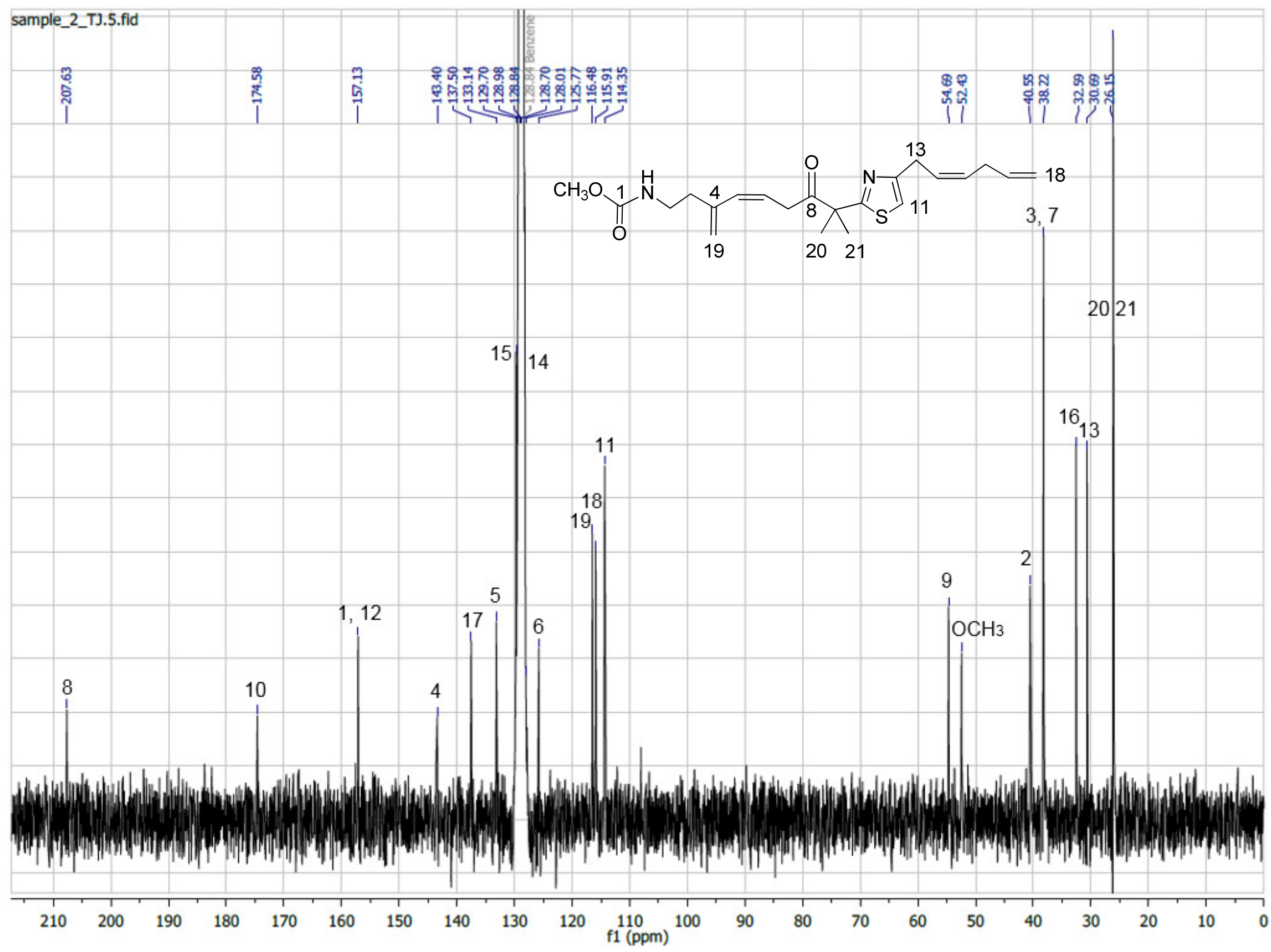


Figure S19. gCOSY spectrum of 8-Oxo-mycothiazole (8) in Benzene- $d_{6}$ at $700 \mathrm{MHz}$.

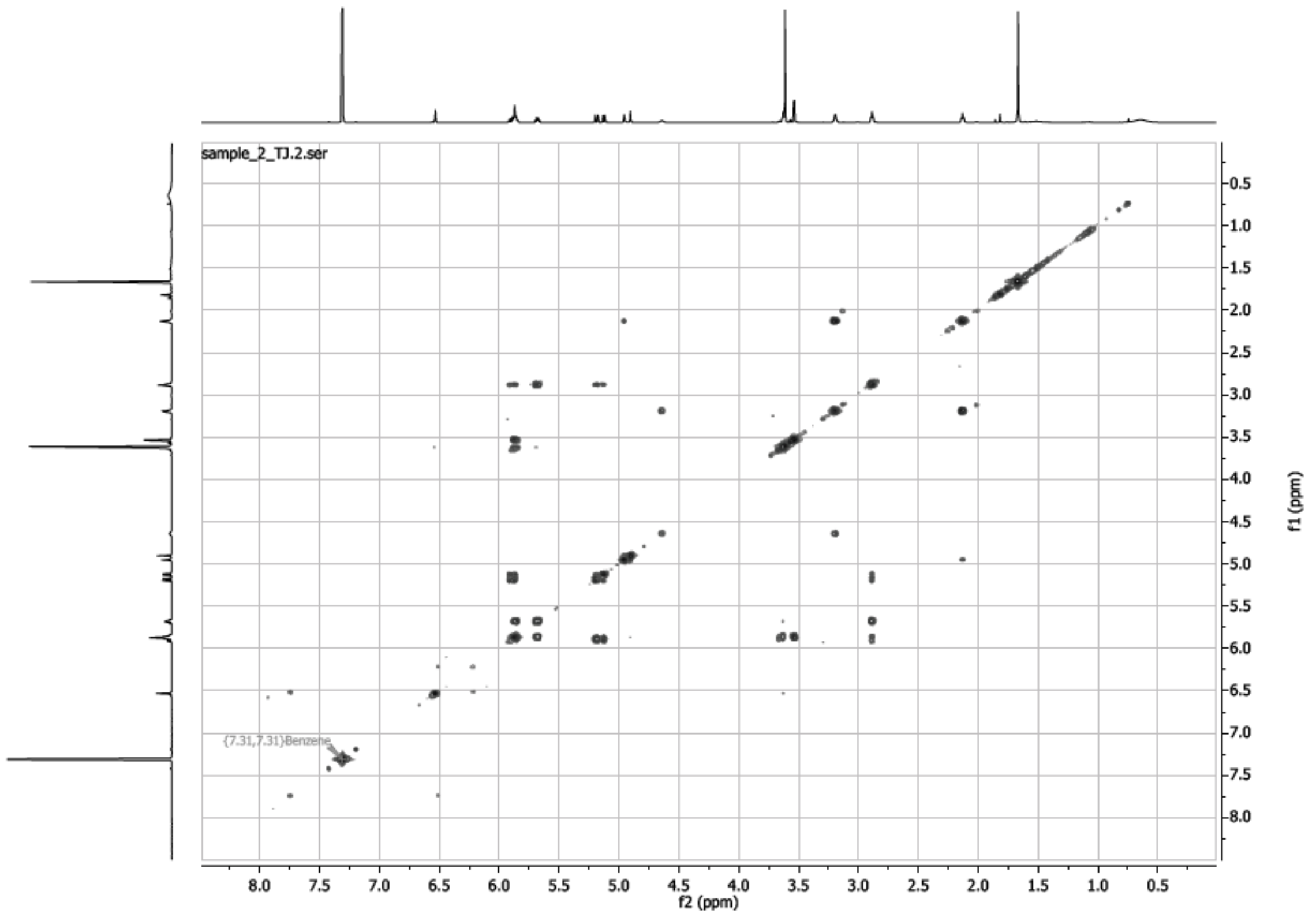


Figure S20. HSQC spectrum of 8-Oxo-mycothiazole (8) in Benzene- $d_{6}$ at $700 \mathrm{MHz}$.

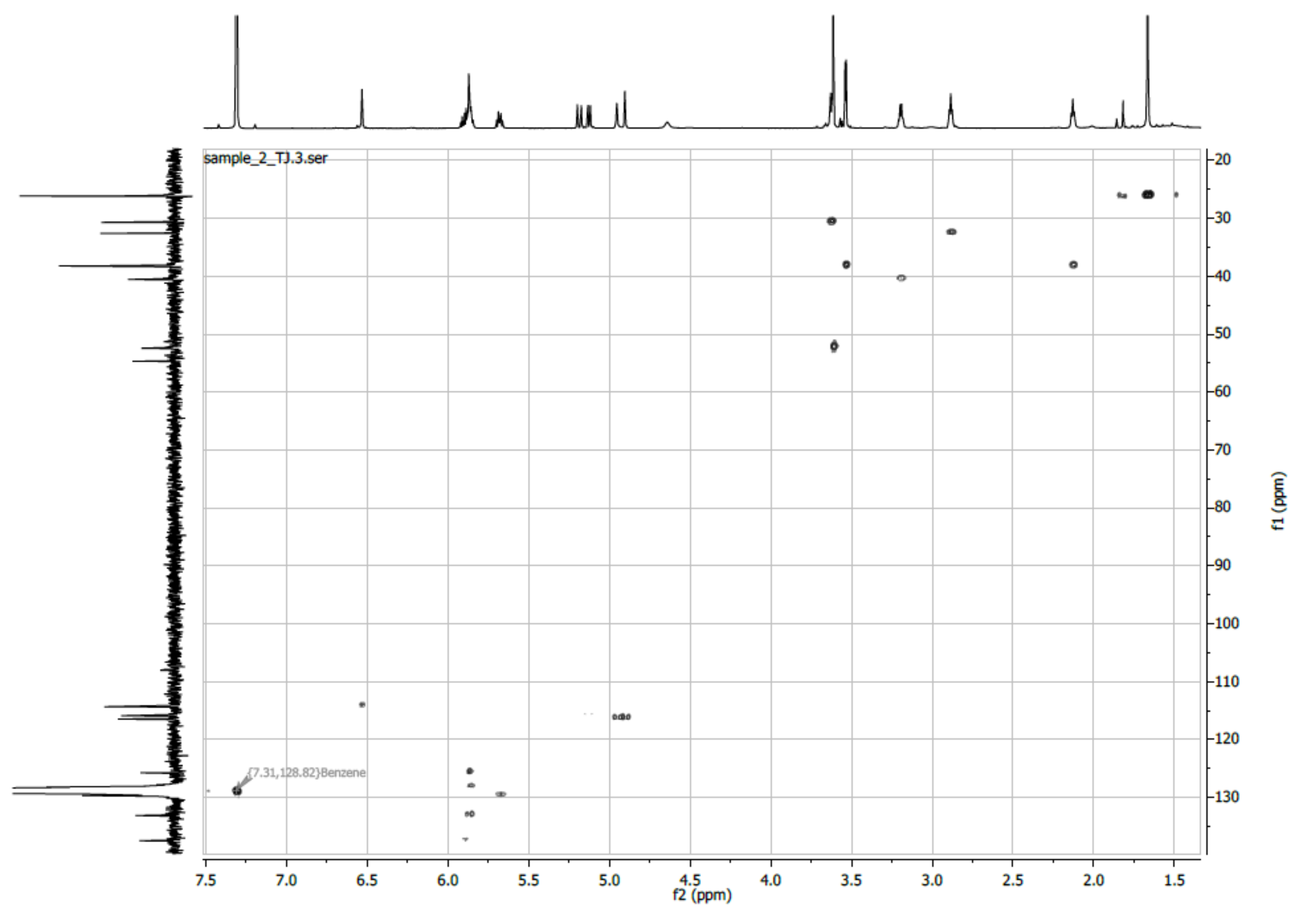


Figure S21. HMBC spectrum of 8-Oxo-mycothiazole (8) in Benzene- $d_{6}$ at $700 \mathrm{MHz}$.

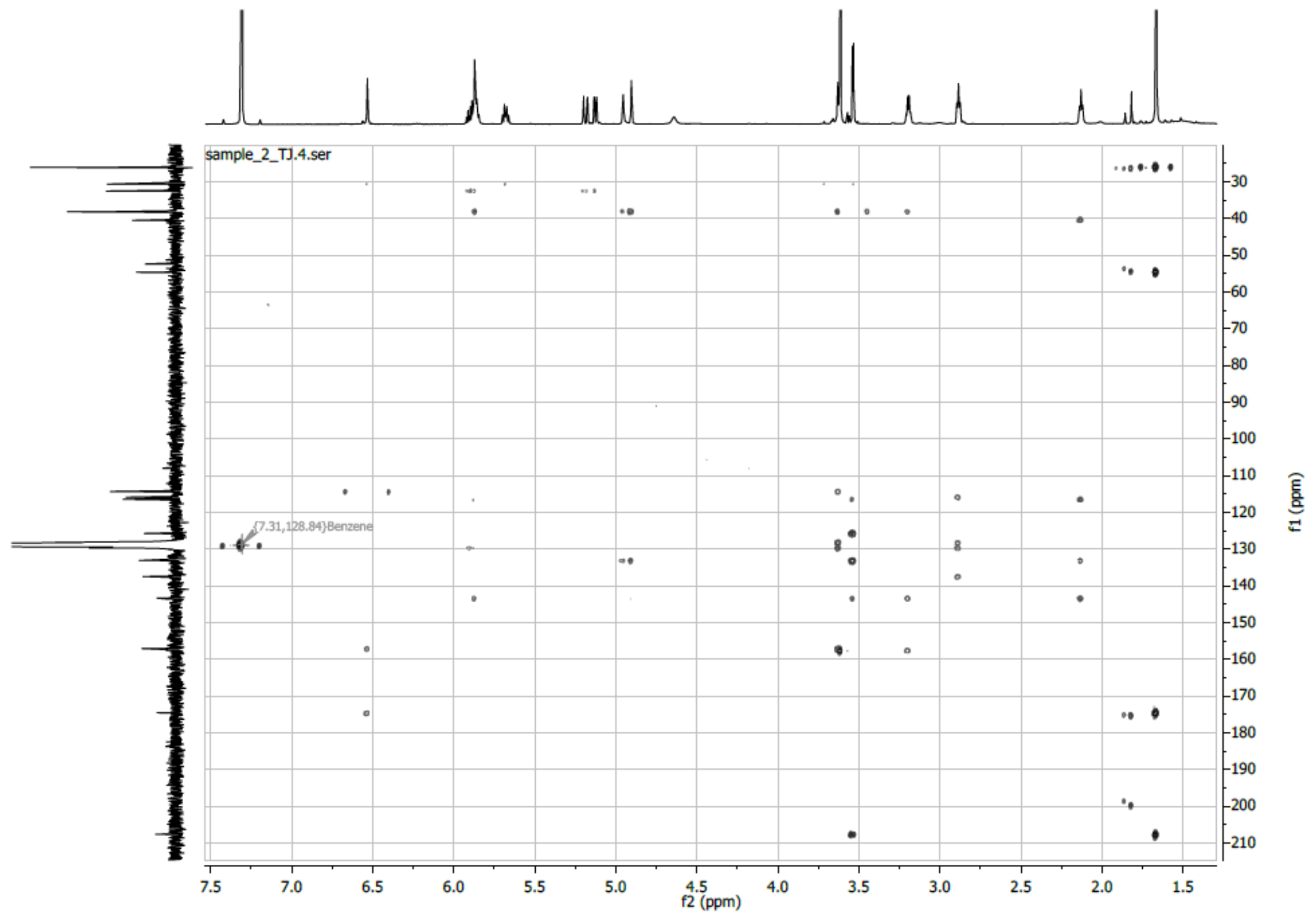


Figure S22. ${ }^{1} \mathrm{H}$ NMR spectrum of mycothiazole nitrosobenzene derivative 1 (MND1, 9a) in Benzene- $d_{6}$ at $500 \mathrm{MHz}$.

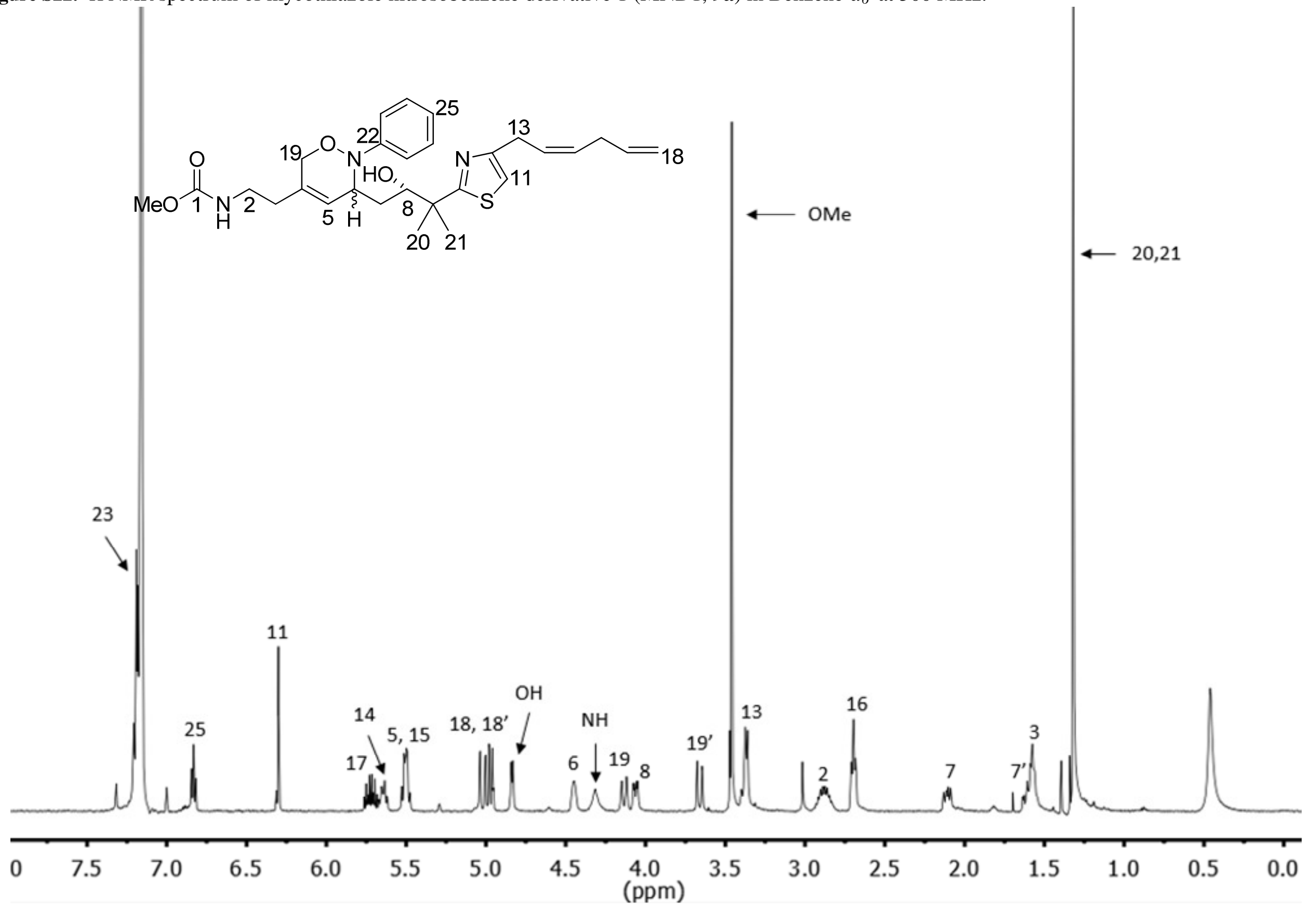


Figure S23. gCOSY spectrum of mycothiazole nitrosobenzene derivative 1 (MND1, 9a) in Benzene- $d_{6}$ at $500 \mathrm{MHz}$

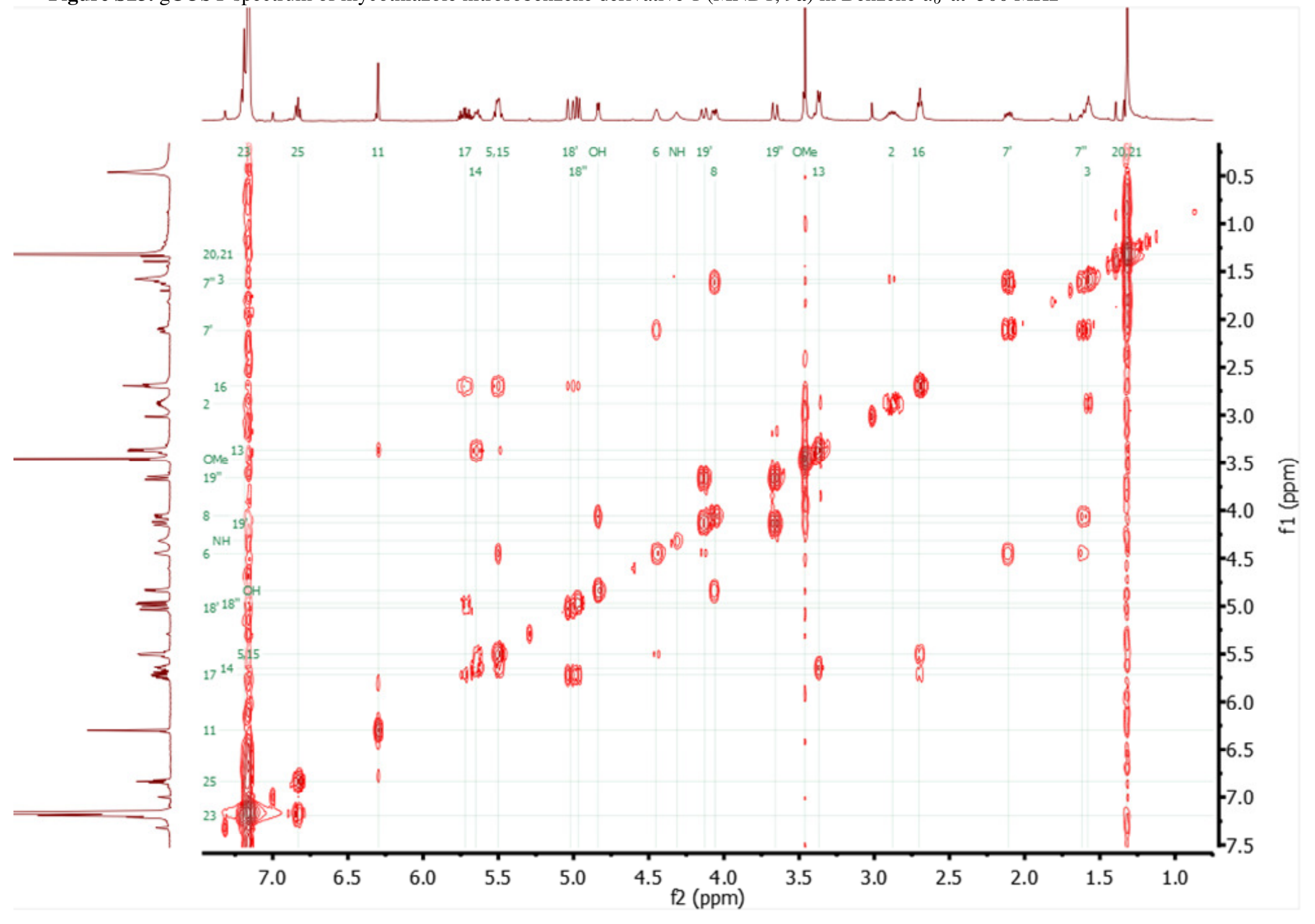


Figure S24. HSQC spectrum of mycothiazole nitrosobenzene derivative 1 (MND1, 9a) in Benzene- $d_{6}$ at $500 \mathrm{MHz}$.

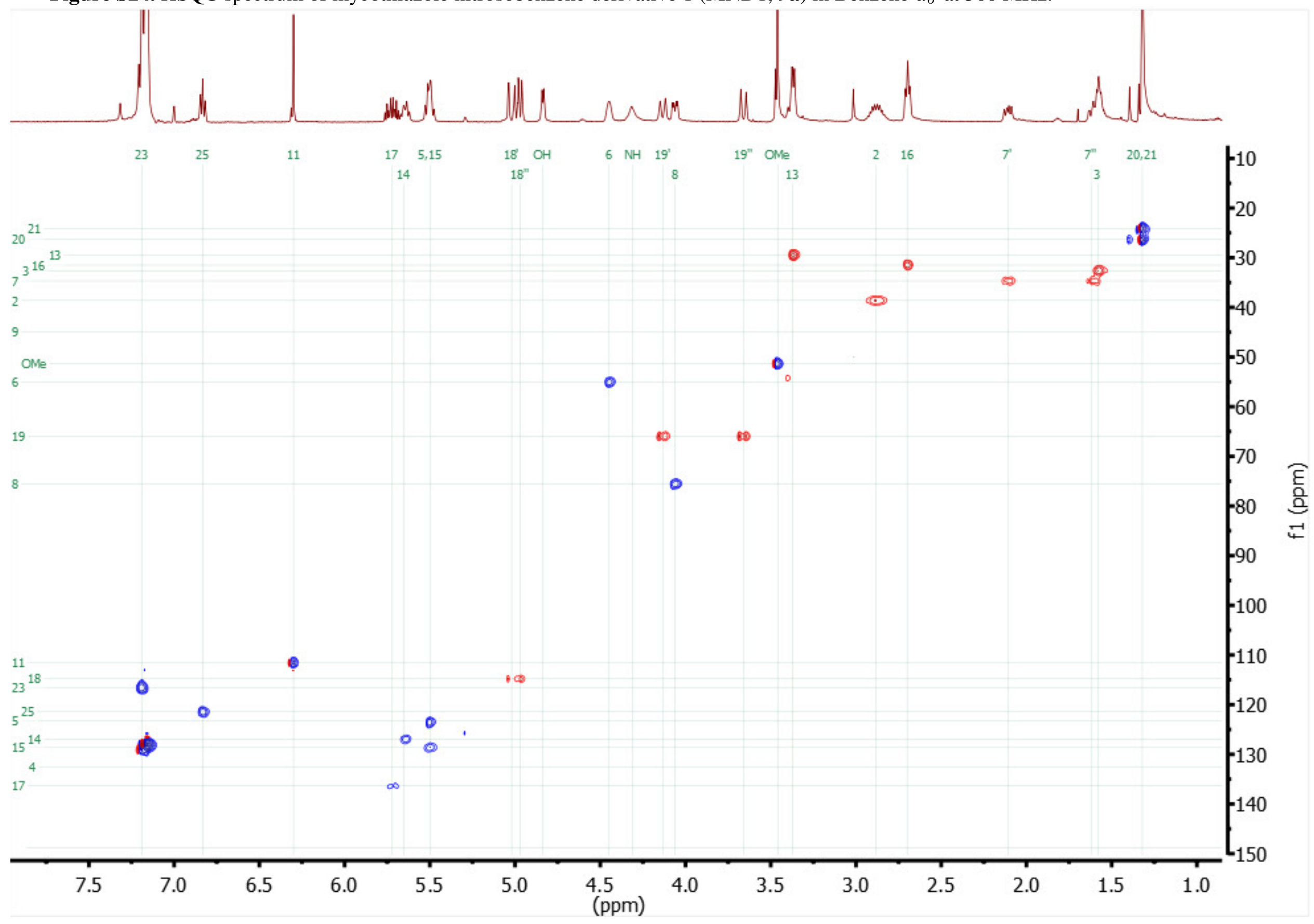


Figure S25. HMBC spectrum of mycothiazole nitrosobenzene derivative 1 (MND1, 9a) in Benzene- $d_{6}$ at $500 \mathrm{MHz}$. 2019-01-20_MND1_b_HMBC_500HMz.11.ser
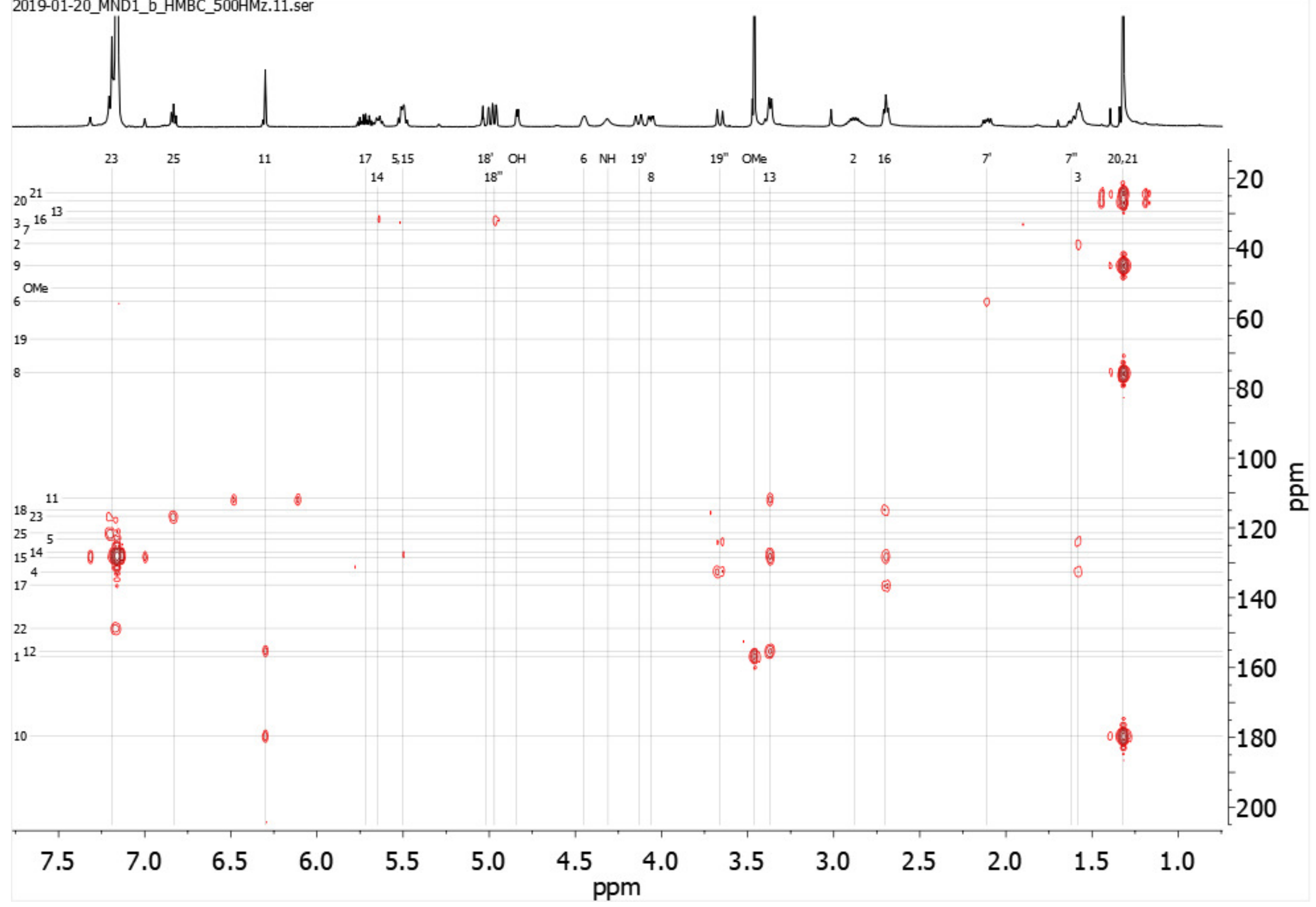
Figure S26. ${ }^{1} \mathrm{H}$ NMR spectrum of mycothiazole nitrosobenzene derivative $2(\mathrm{MND} 2,9 \mathrm{~b})$ in Benzene- $d_{6}$ at $500 \mathrm{MHz}$.
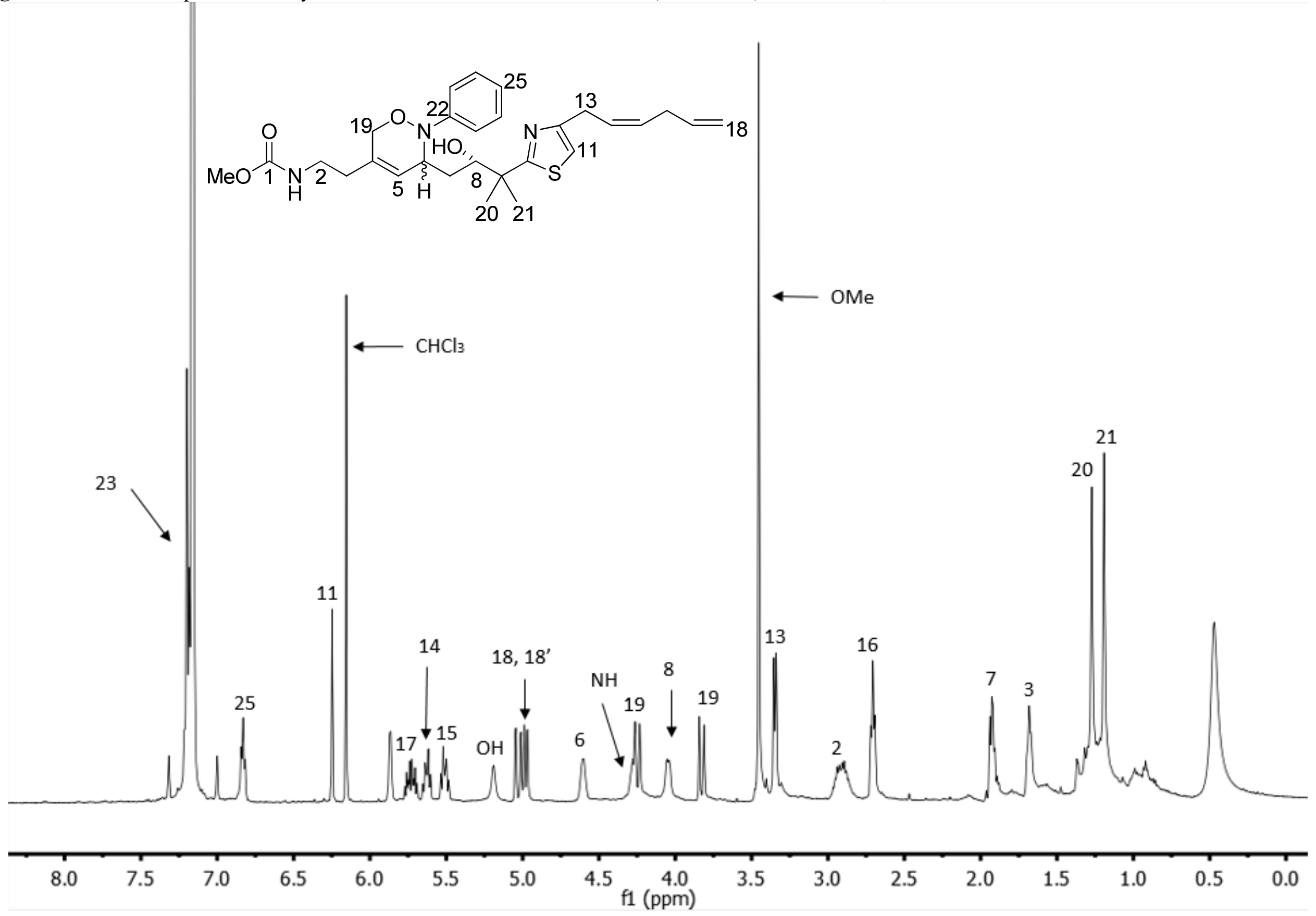
Figure S27. gCOSY spectrum of mycothiazole nitrosobenzene derivative 2 (MND2, 9b) in Benzene- $d_{6}$ at $500 \mathrm{MHz}$.

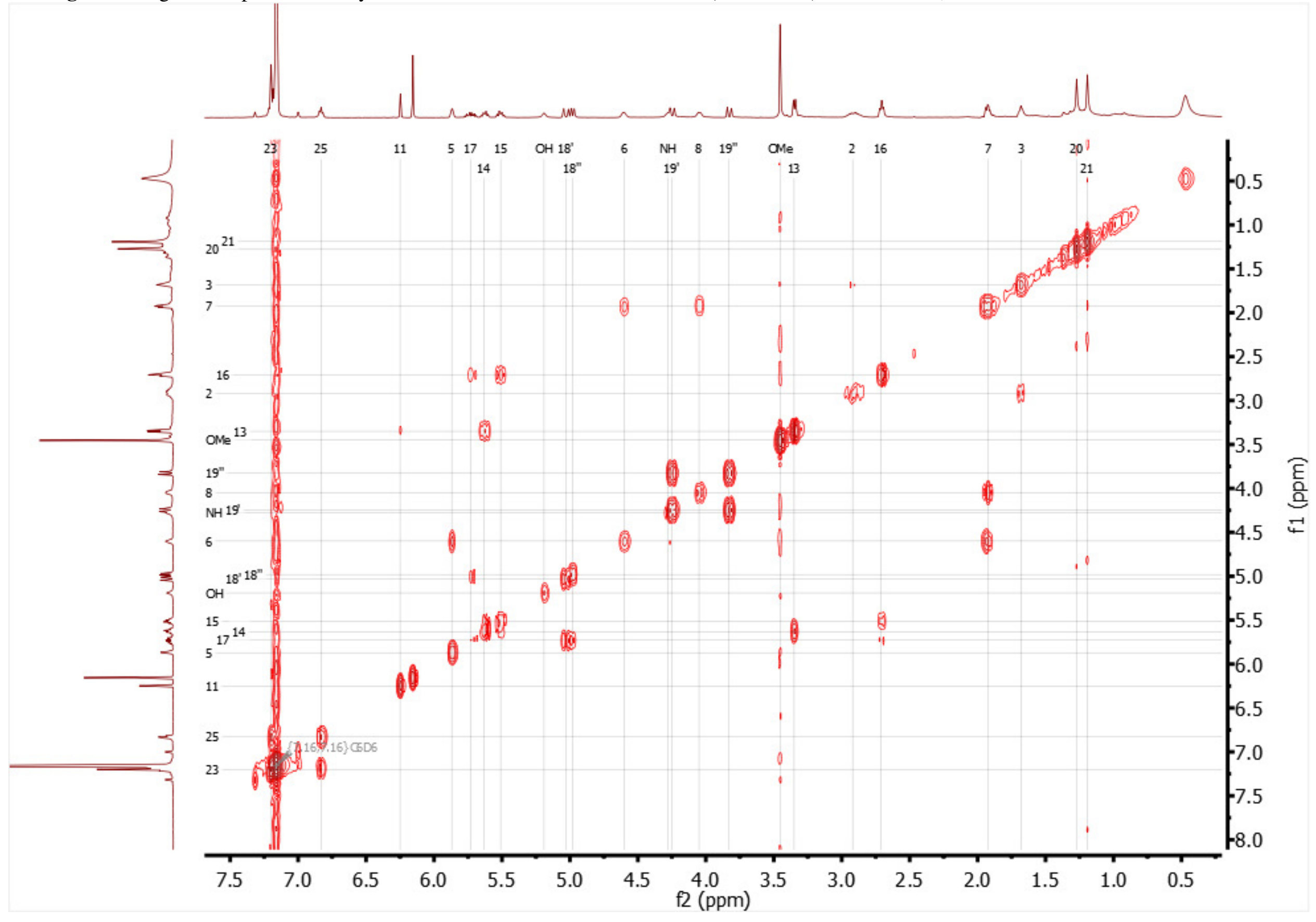


Figure S28. HSQC spectrum of mycothiazole nitrosobenzene derivative 2 (MND2, 9b) in Benzene- $d_{6}$ at $500 \mathrm{MHz}$.
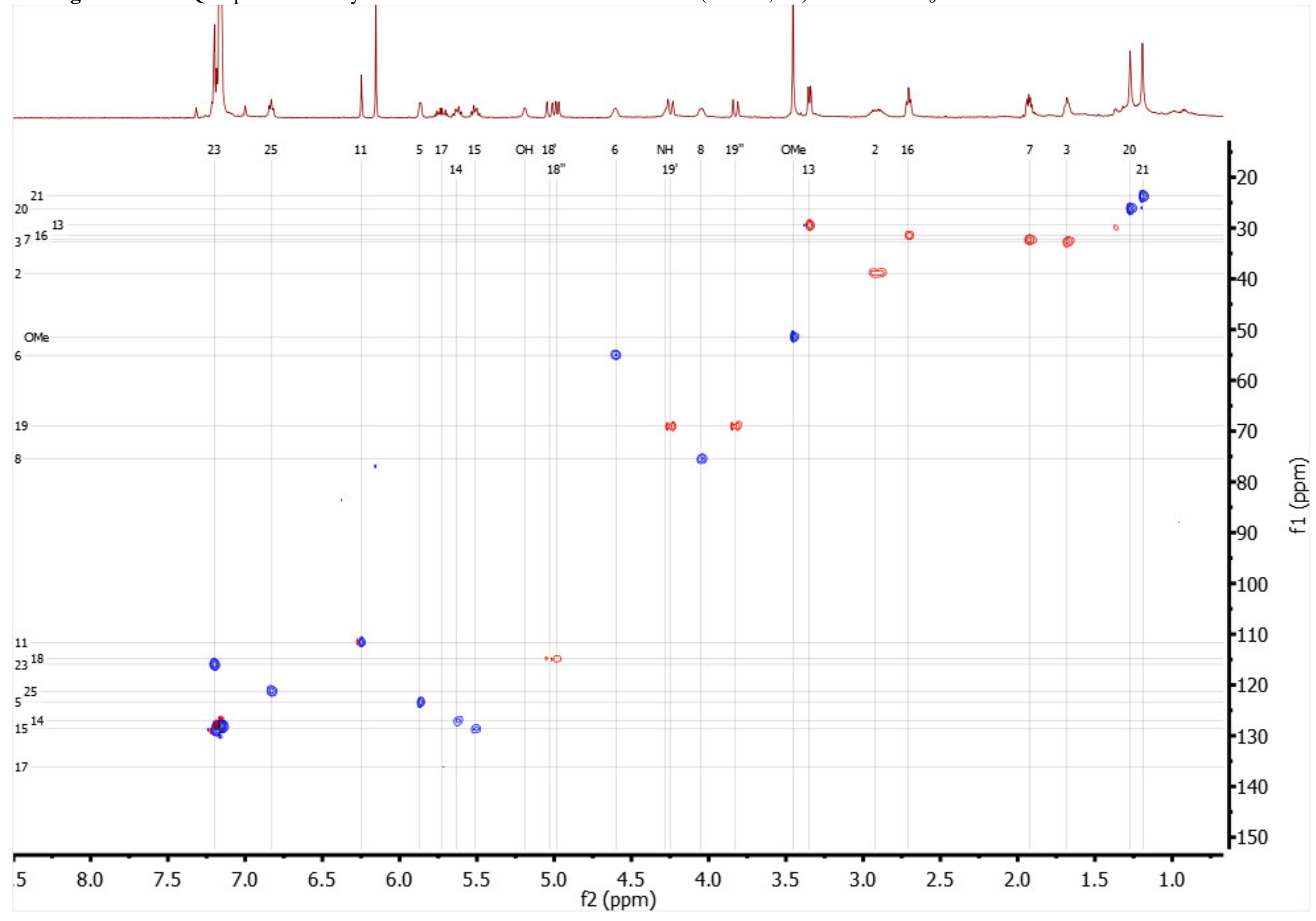
Figure S29. ${ }^{1} \mathrm{H}$ NMR spectrum of mycothiazole nitrosobenzene derivative 3 (MND3, 10) in Benzene- $d_{6}$ at $500 \mathrm{MHz}$.

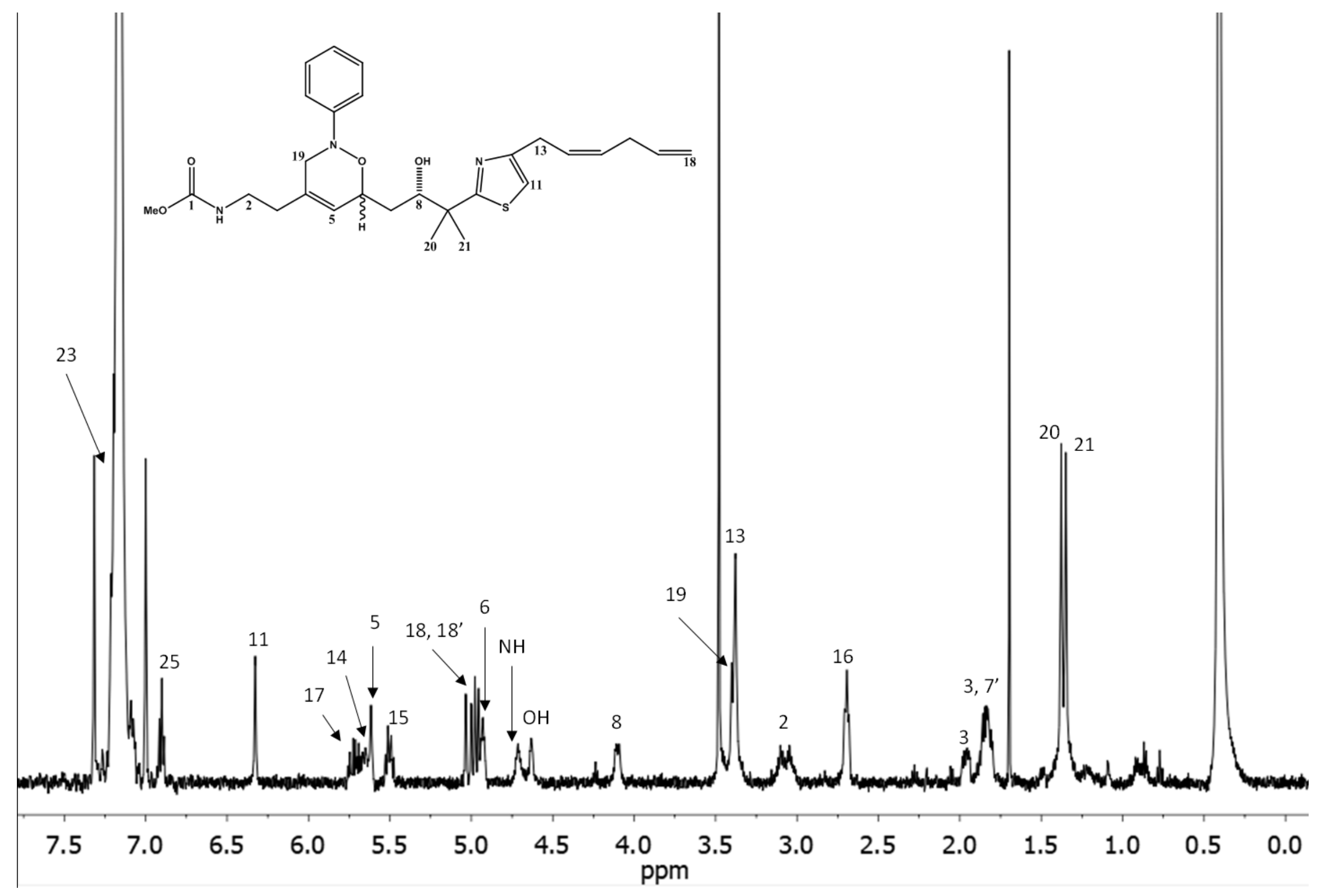


Figure S30. COSY NMR spectrum of mycothiazole nitrosobenzene derivative 3 (MND3, 10) in Benzene- $d_{6}$ at $500 \mathrm{MHz}$.

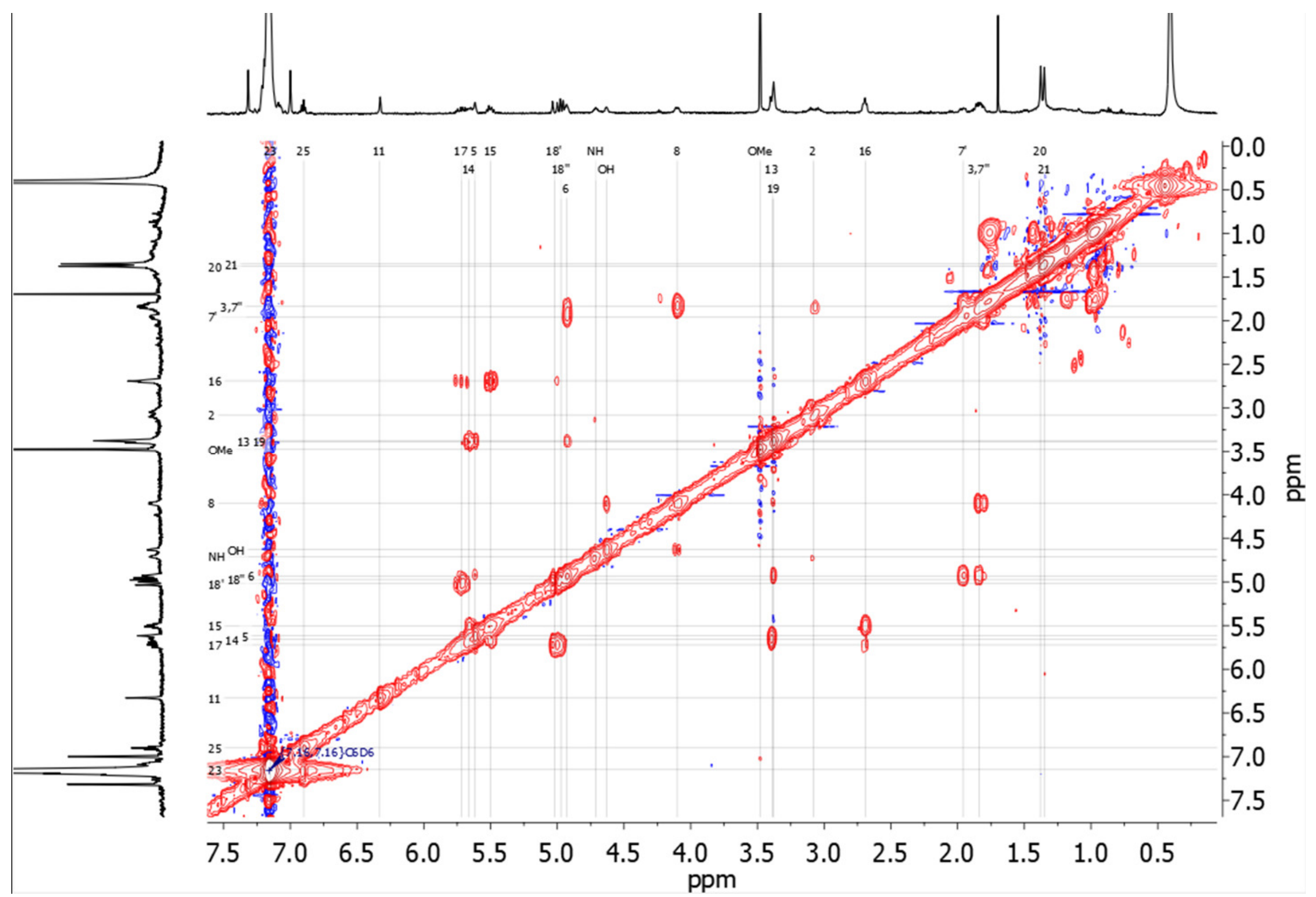


Figure S31. HSQC NMR spectrum of mycothiazole nitrosobenzene derivative 3 (MND3, 10) in Benzene- $d_{6}$ at $500 \mathrm{MHz}$.

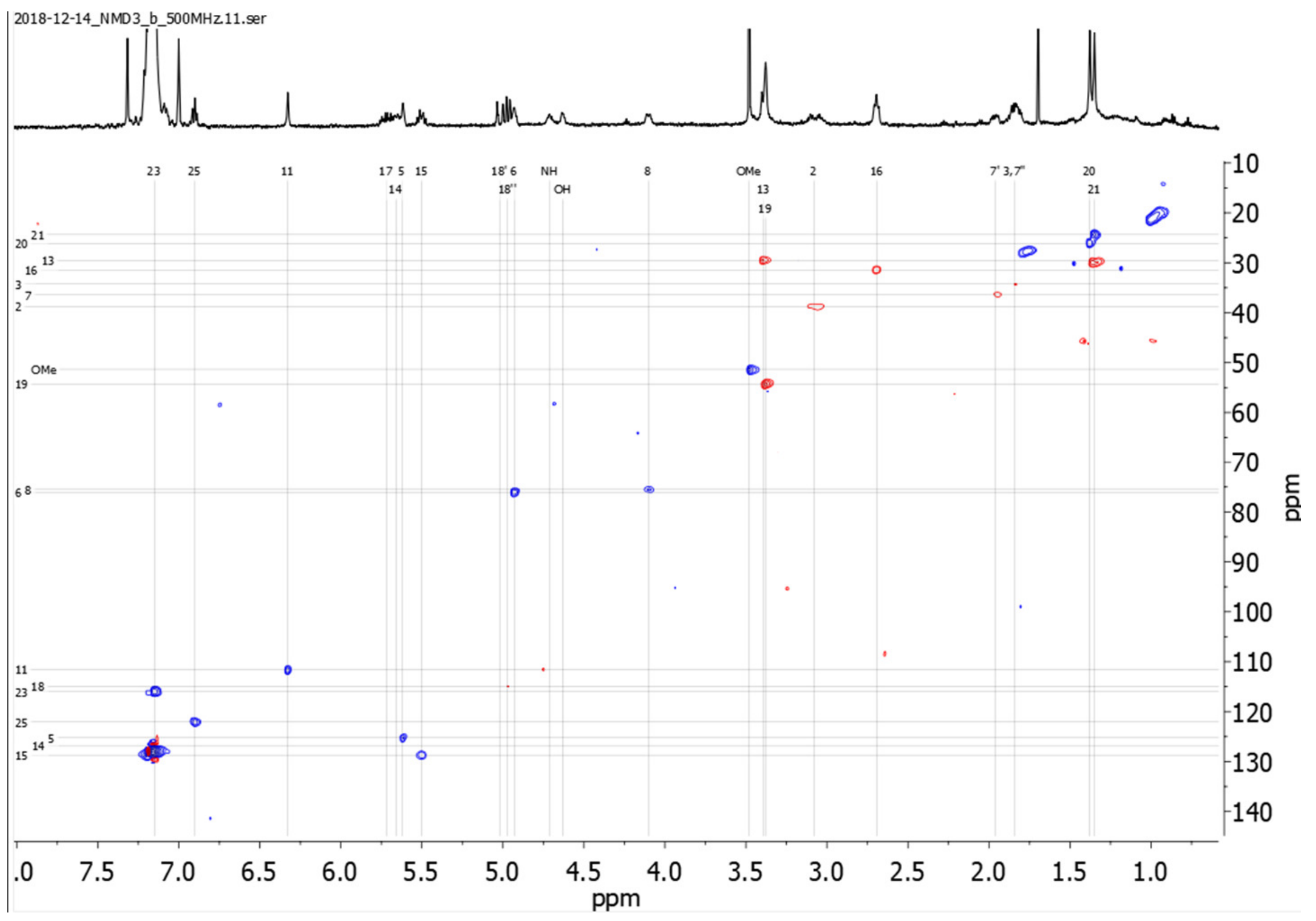


Figure S32. HAESIMS (LCMS) spectrum of 8-oxo mycothiazole (8)

RT: $0.00-10.02$

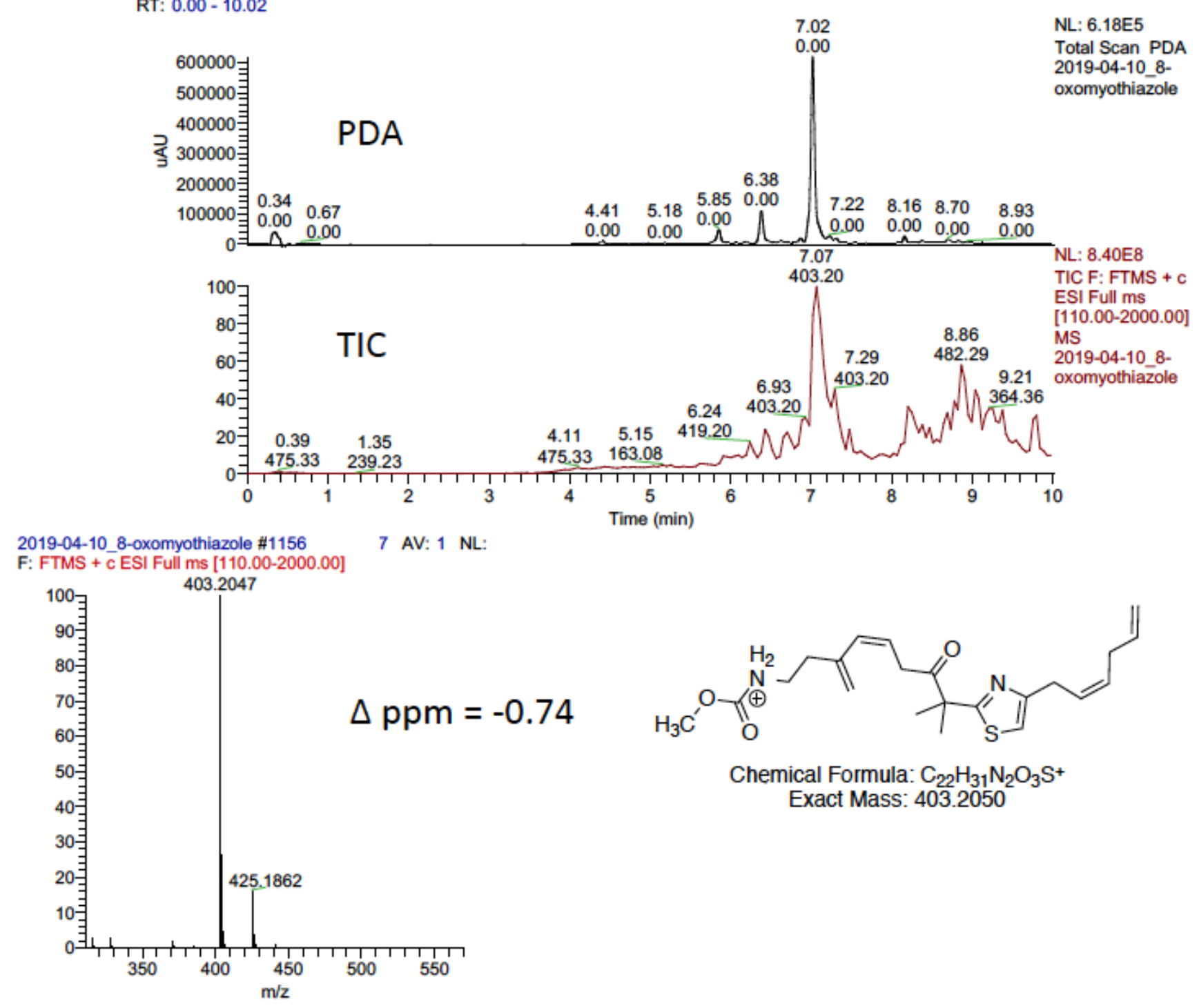


Figure S33. HAESIMS (LCMS) spectrum of mycothiazole nitrosobenzene derivative 1 (MND1, 9a)

RT: $0.00-10.05$

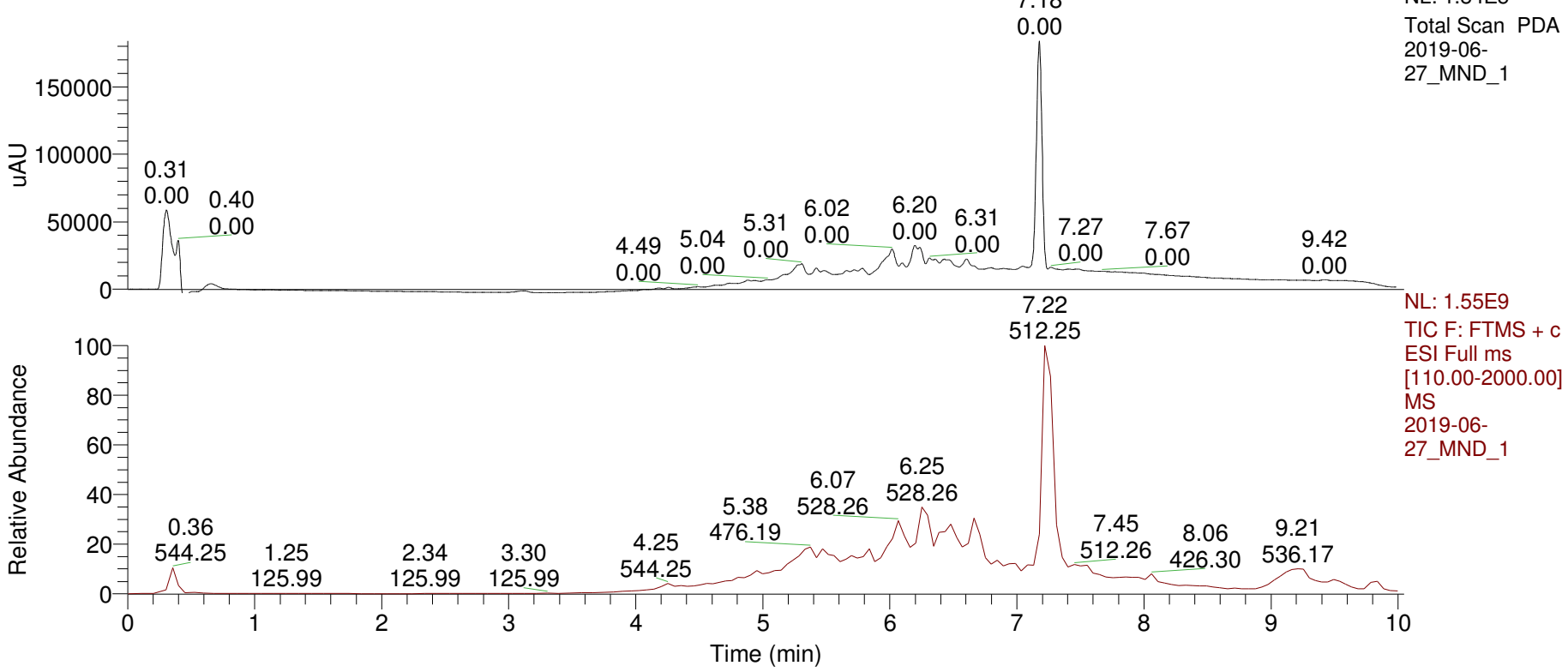

2019-06-27 MND 1 \#1233 RT: 7.22

F: FTMS + C ESI Full ms [110.00-200 ...

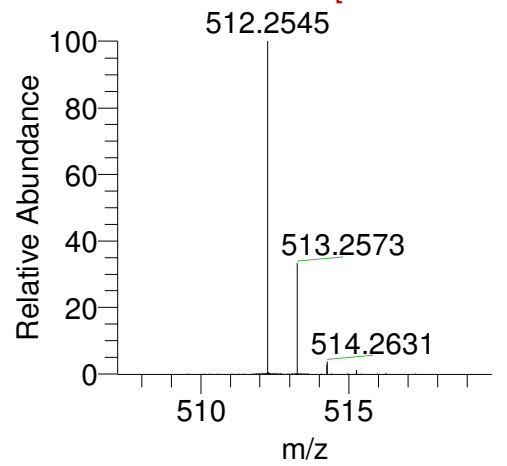


Figure S34. HAESIMS (LCMS) spectrum of mycothiazole nitrosobenzene derivative 2 (MND2, 9b)

RT: $0.00-10.05$

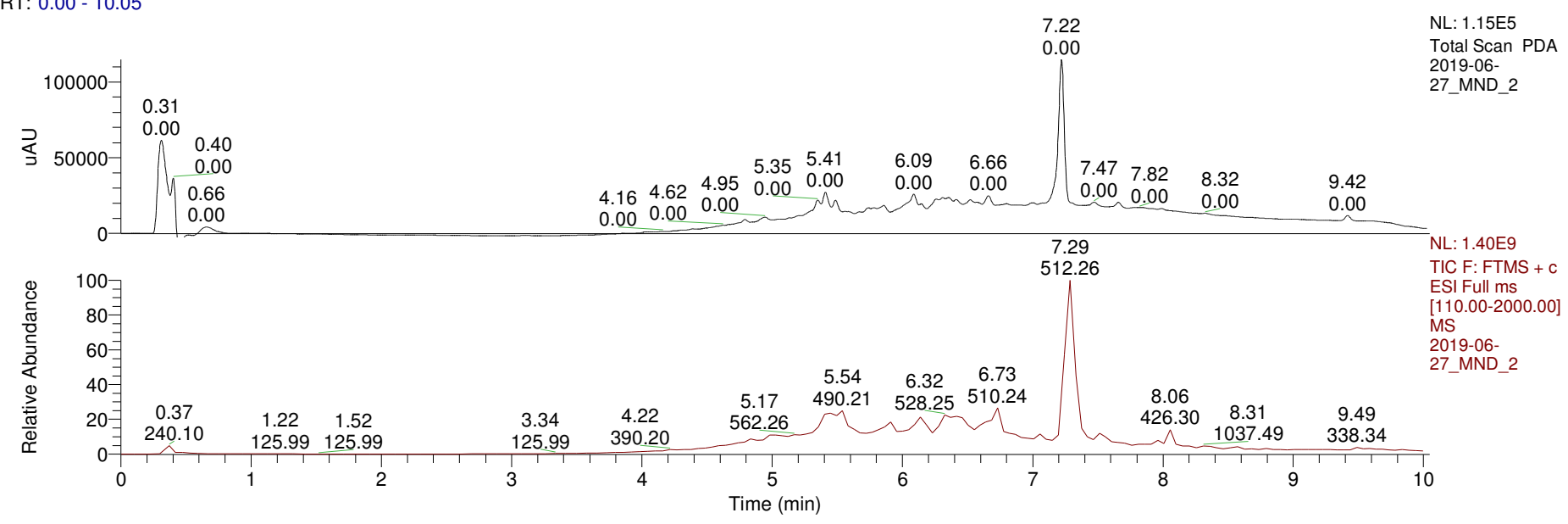

2019-06-27_MND_2 \#1249-1287 RT:

F: FTMS + c ESI Full ms [110.00-200 ...

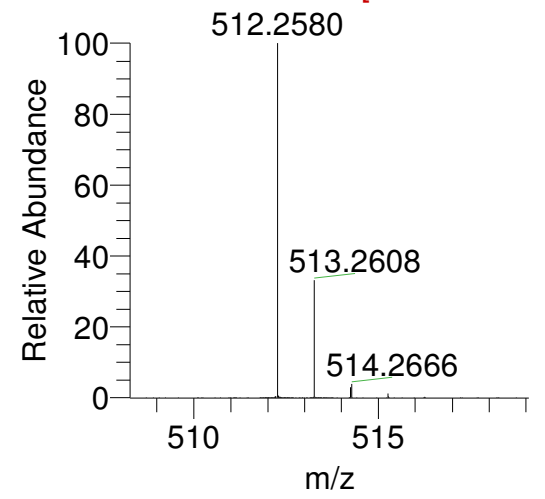


Figure S35. HAESIMS (LCMS) spectrum of mycothiazole nitrosobenzene derivative 3 (MND3, 10)

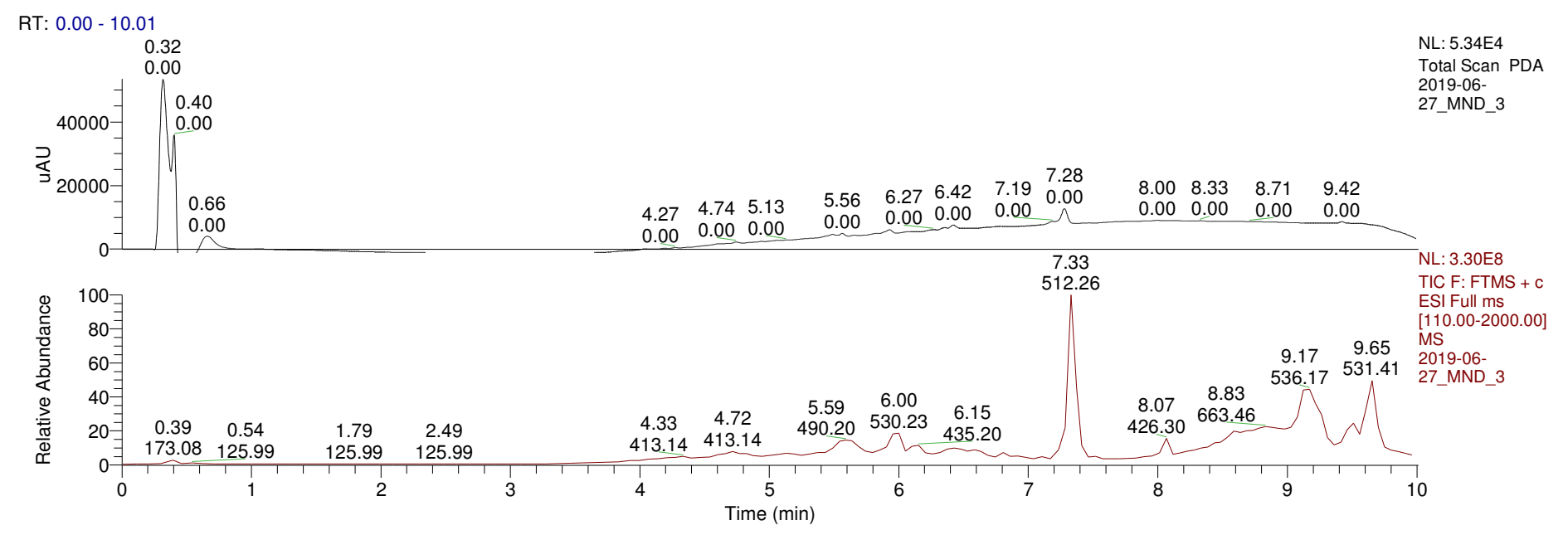

2019-06-27_MND_3 \#1101 RT: 7.33

F: FTMS + C ESI Full ms [110.00-200 ...

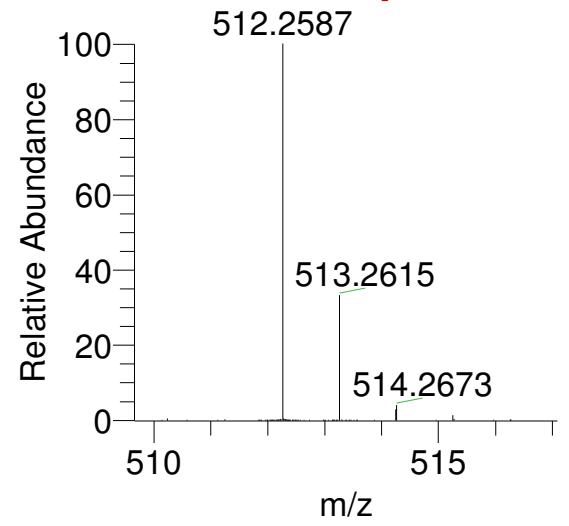


Figure 35. ${ }^{1} \mathrm{H}$ NMR of mycothiazole-4,19-diol (7) in d-DMSO at $600 \mathrm{MHz}$.

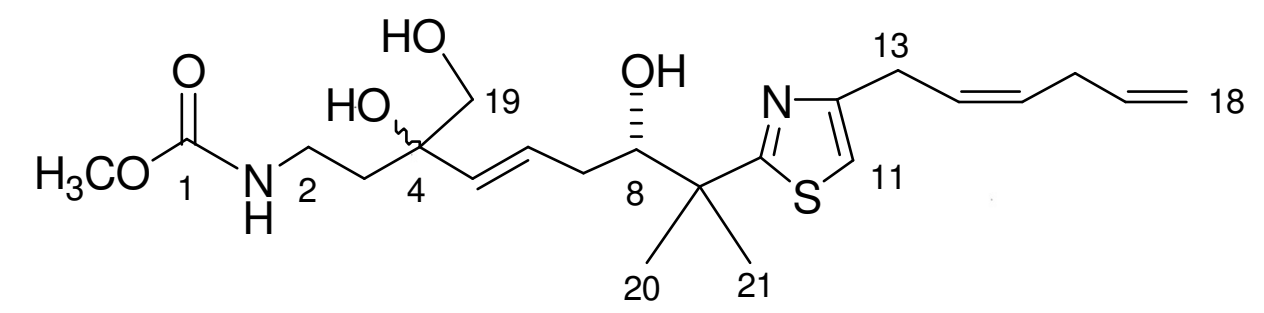

mycothiazole-4,19-diol (7)

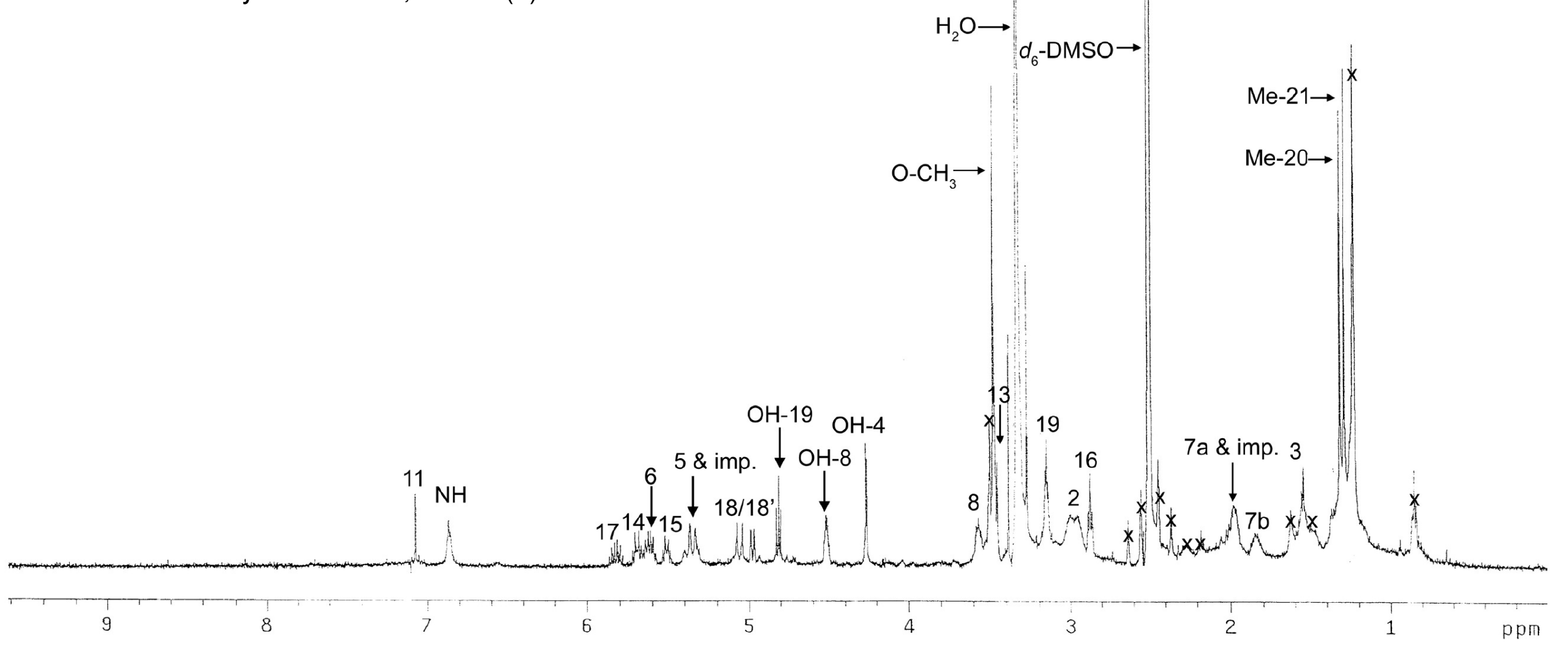

